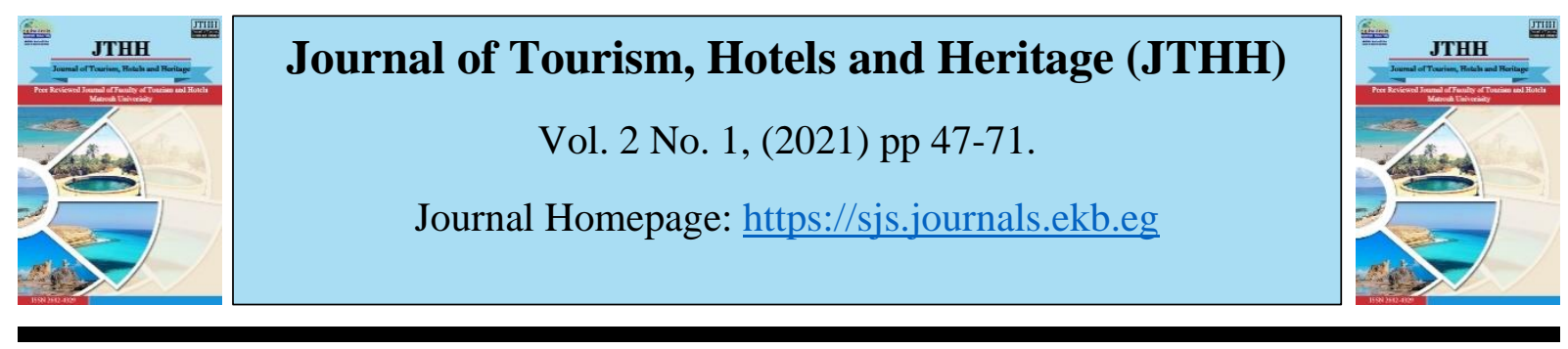

\title{
دور اختلاف الفئة العمرية في توجيه التفضيلات الذذائية \\ (دراسة تطبيقية على عملاء مطاعم الوجبات السريعة بمدينة الإسكندرية)
}

Mohamed Salah Ghanem ${ }^{1}$

Laila EI Zalaki

Mahmoud Ahmed Hamza ${ }^{3}$

${ }^{1}$ Higher Institute for Tourism, Hotels and Computer Sciences, Alexandria, Egypt.

${ }^{2}$ Higher Institute for Tourism, Hotels and Computer Sciences, Alexandria, Egypt.

${ }^{3}$ Faculty of Tourism and Hotels, Alexandria University.

\section{ARTICLE INFO}

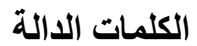

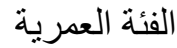

التفضيلات الغذائية

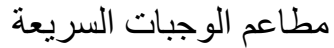

(JTHH)

Vol. 2 No. 1, (2021)

pp 47-71.
الملخص

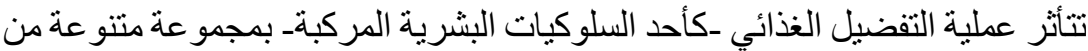

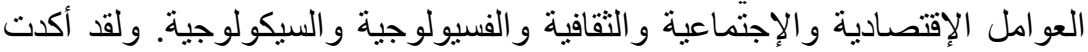

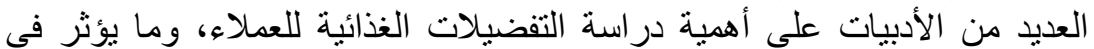

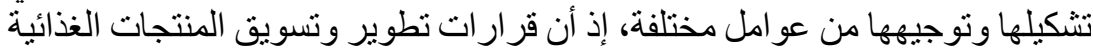

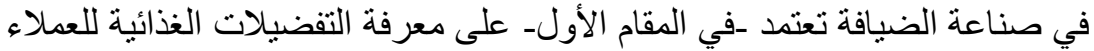

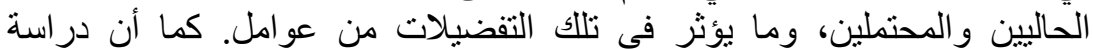

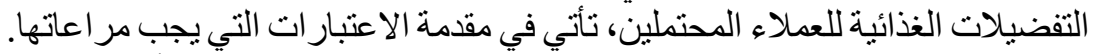

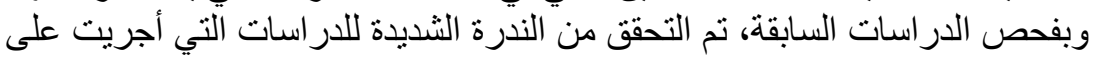

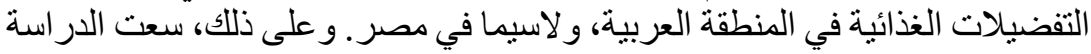

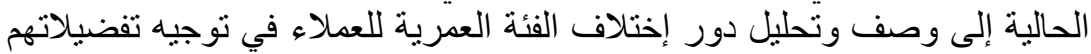
لمنتج الوجبات السريعة المقدم في المطاعم، وذللك بالتطبيق على مدينة العينة الإسكندرية،

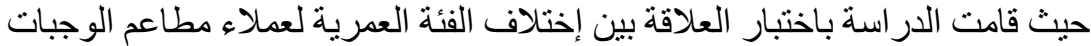

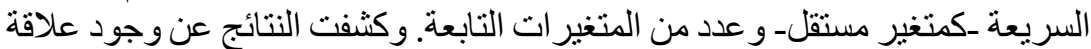

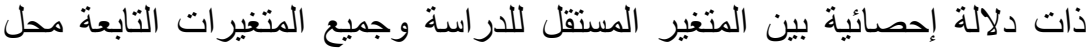
الدر اسة.

تتأثر عملية التفضـيل الغذائي ـكأحد السـلوكيات البثـرية المركبةــ بمجمو عة متنو عة من العو امل الإقتصـادية والإجتماعية

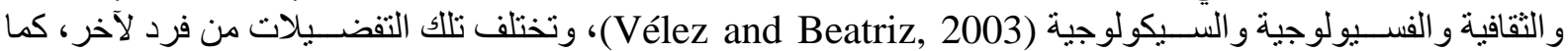

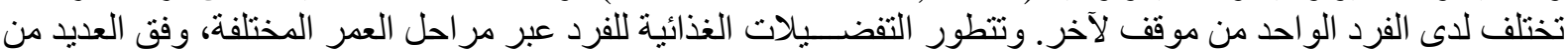

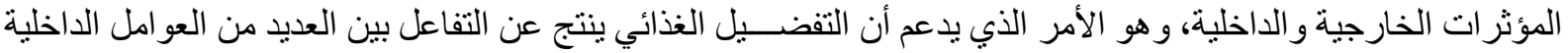
و الخارجية، المتعلقة بالفرد، وبالمنتج الغذائي، وبالبيئة المحيطة (Van Loo et al., 2019).

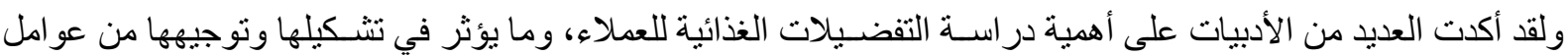

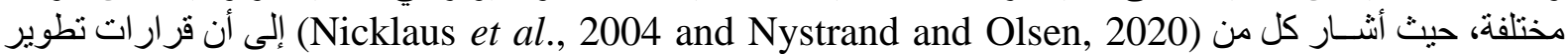

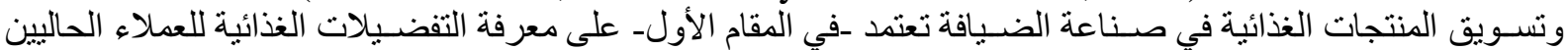

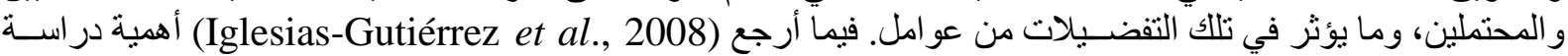

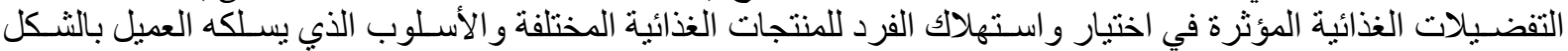

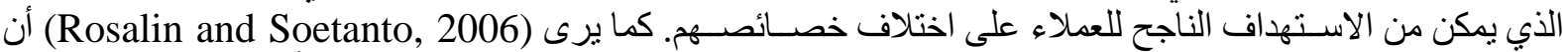

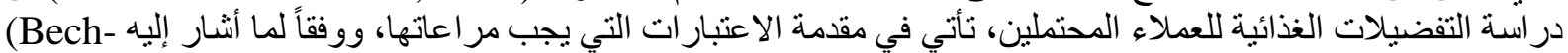

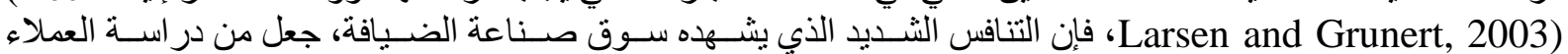
وتفضيلاتهم الغذائية أمر اً حاسماً في التطوير و استمر ارية النجاح.

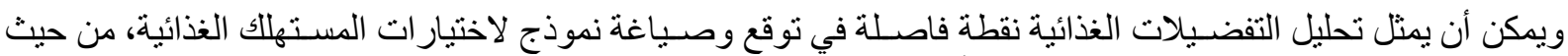

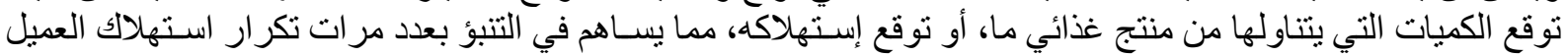
لمختلف المنتجات الغذائية (Robertet al., 2020). 


\section{r - خلفية نظرية

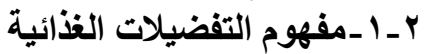

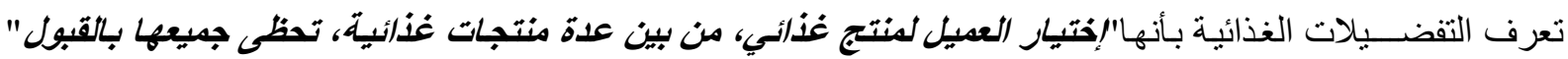

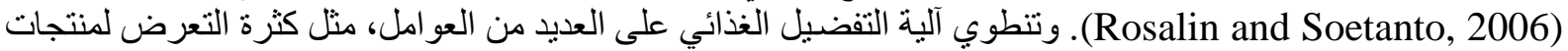

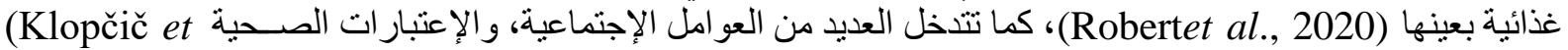

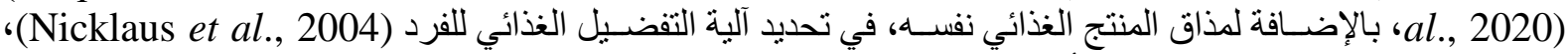

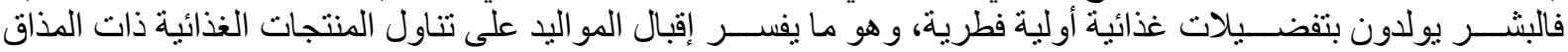

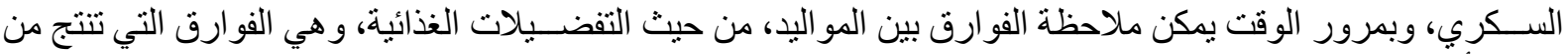

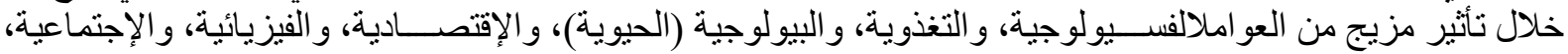
و الثقافية، والسيكولوجية، والبيئية (Raynor et al., 2004; Bellisle, 2005 and Reid, 2005).

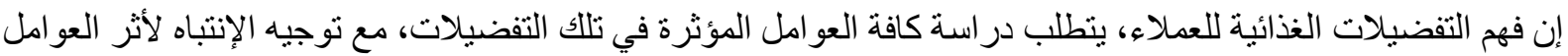

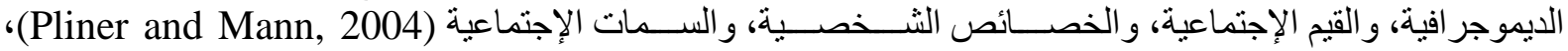

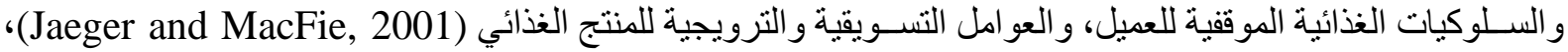

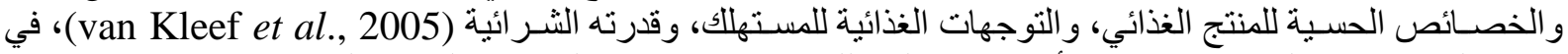

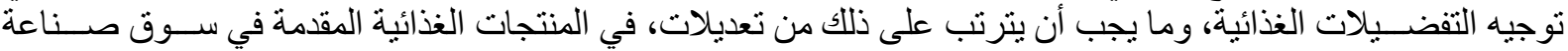

الضيافة . توحاه

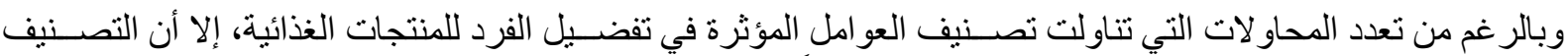

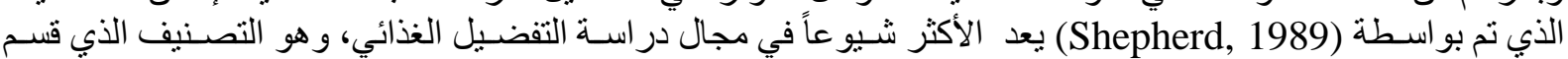
عو أمل إختيار وتفضيل المنتجات الغذائية إلى ثلاث مجمو عاتِّ رئيسية:

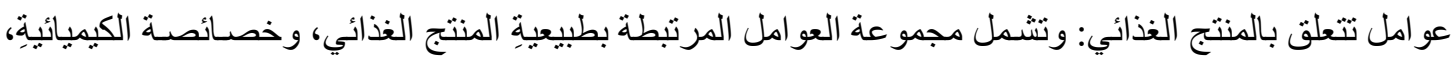

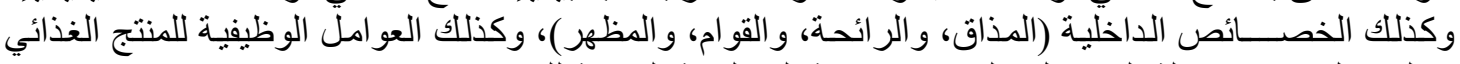
(تغليف المنتج، وسهولة الحصول عليه)، بالإضافة إلى القية القيمة الغذائية للمنتج.

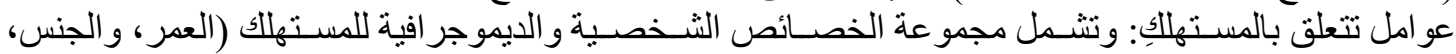

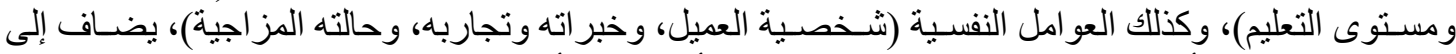

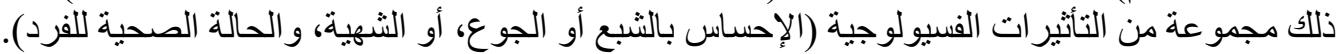

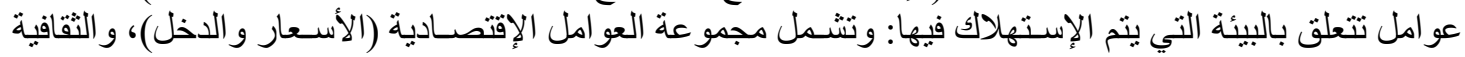

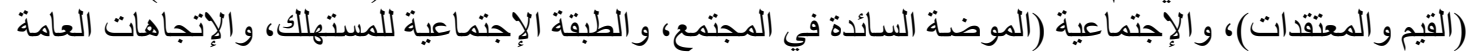

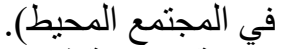

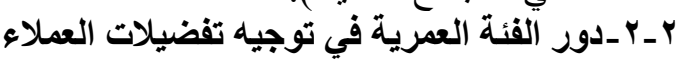

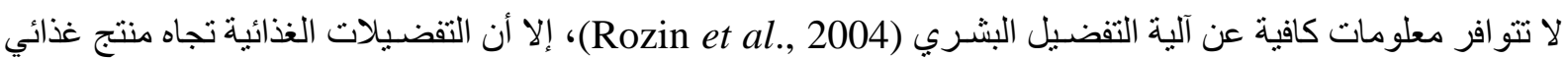

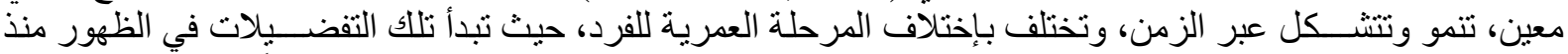

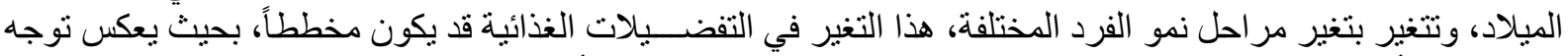

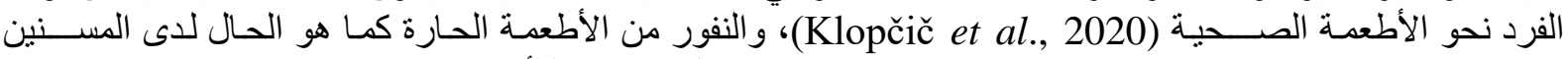

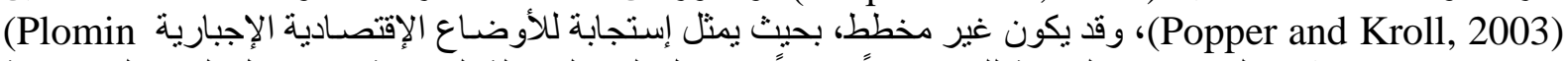
عائ (et al, 2001)

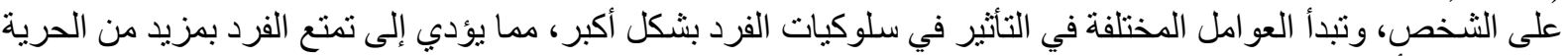

في إختيار الأغذية والمشروبات التي يفضلها (USDA, 2006).

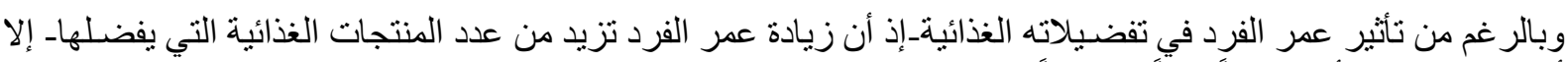

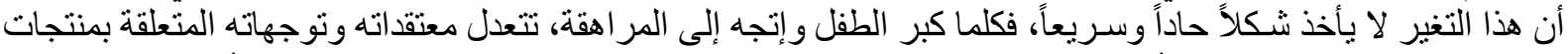

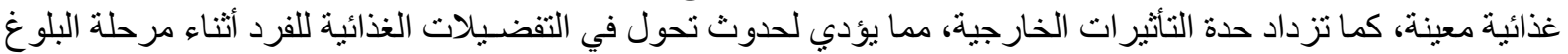

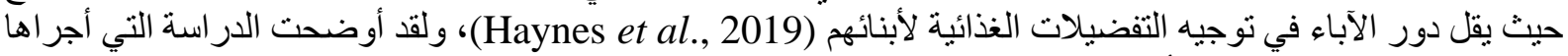
(Gilmour et al., 2004)

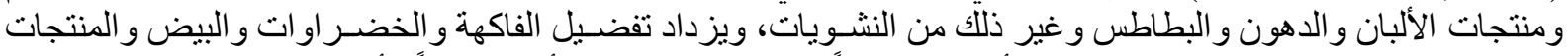

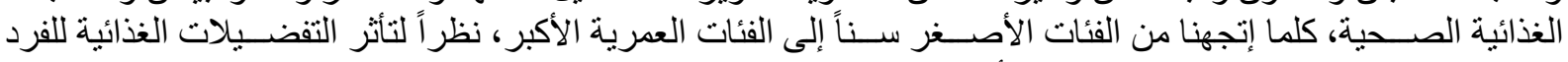

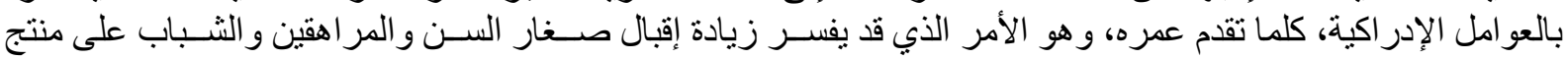
الوجبات السريعة (Bin et al., 2006; Lair, 2007 and Simon et al., 2008). 


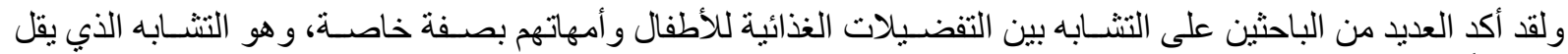

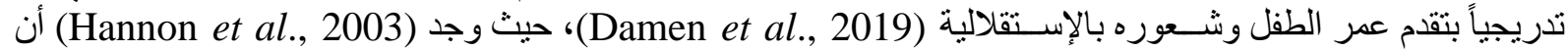
العلاقة بين التفضيلات الغذائية للبالغين و آبائهم، أقوى من العلاقة بين التفضيلات الغذائية للأطفال غير البالغين وآبائهم، في

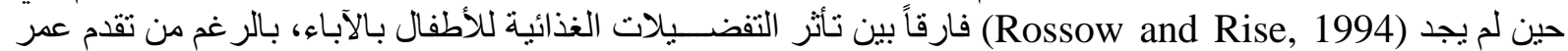

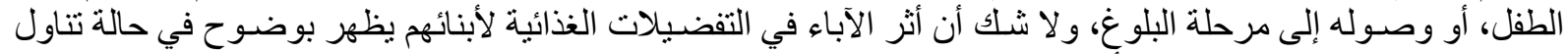

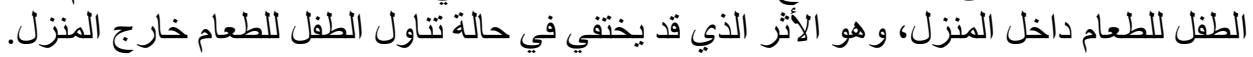

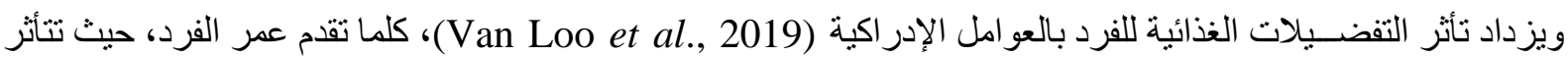

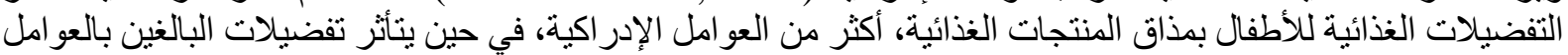

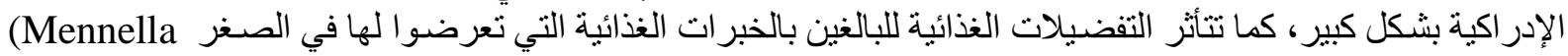
.et al., 2008 and Muñoz-Vilches et al., 2020)

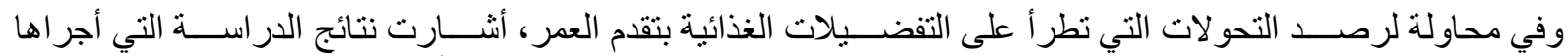

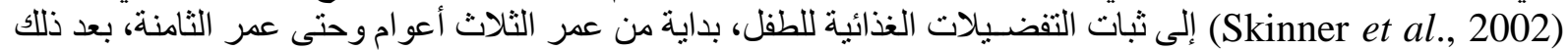

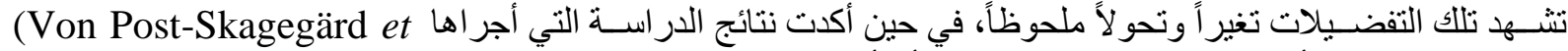

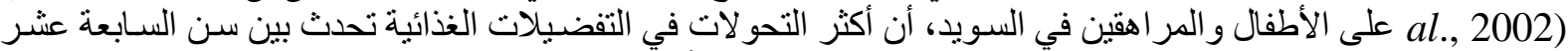

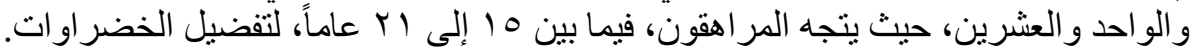

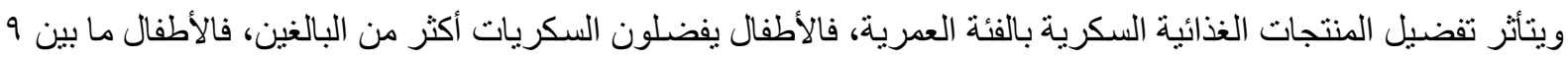

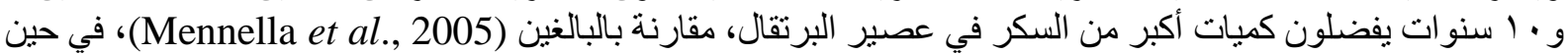

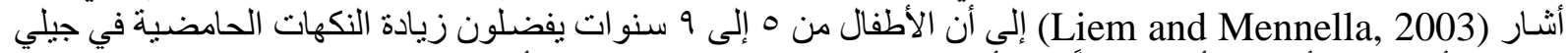

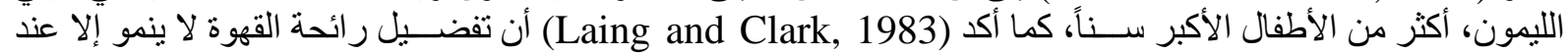

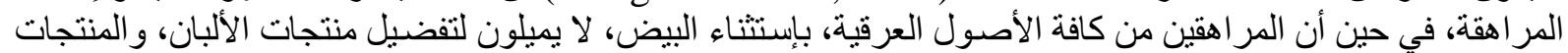

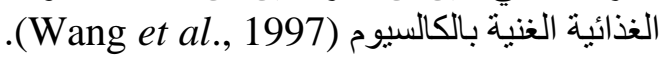

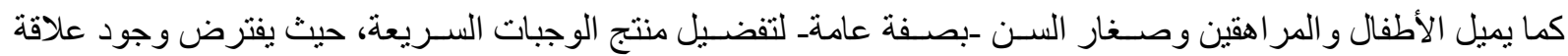

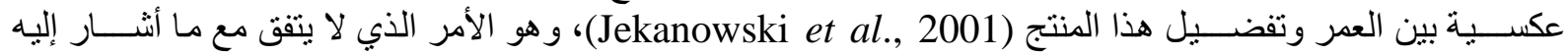

(Mihalpoulos and Demoussis, 2001)

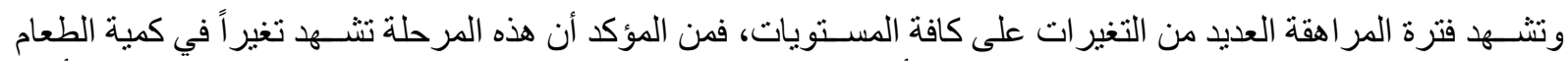

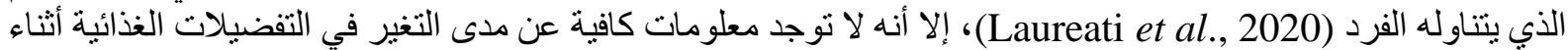

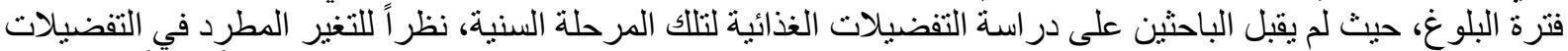

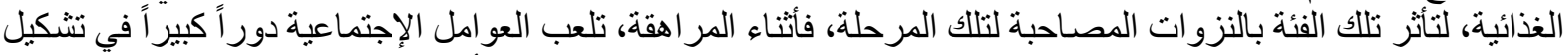

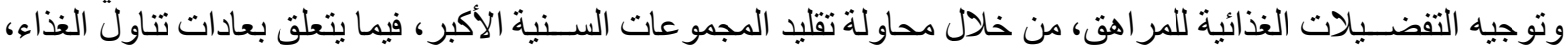

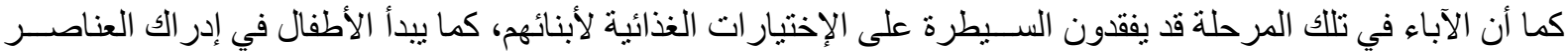

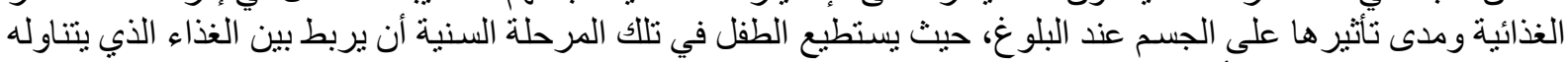

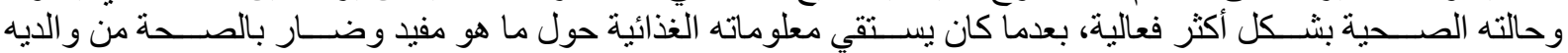

.(Ballcoet al., 2019)

وتبرز أهمية العو امل الإجتماعية في توجيه تفضــيلات المر اهقين، حيث يقبلوا على تفضــيل عدد من المنتجات الغذائية التي

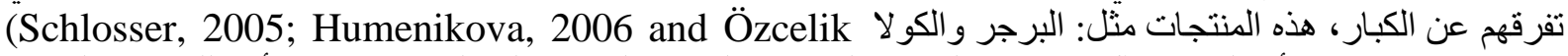
(Det al., 2007)

مصاف الكبار، هذه المنتجات مثل: المشروبات الكحولية والقهوة والتو ابل (Damenet al., 2019).

ولقد وجد (Özgen and ve Sanlier, 2002) أن المذاق هو العامل الأكثر أهمية في تفضـيل المسـتهلكين لمنتج الوجبات

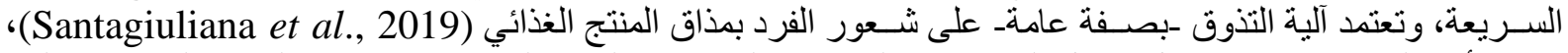

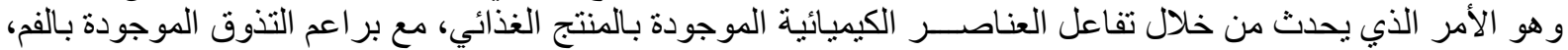

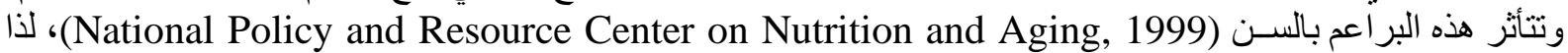

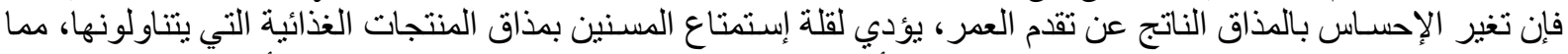

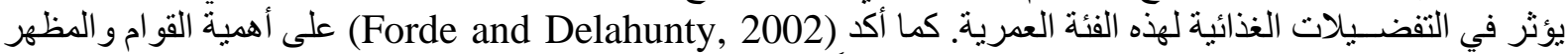

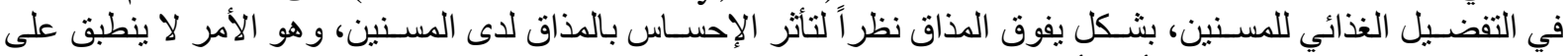
صغار السن، حيث يكون المذاق أكثر أهمبة من القو ام والمظهر في توجيه التفضيلات الغذائية (Laureati et al., 2020).

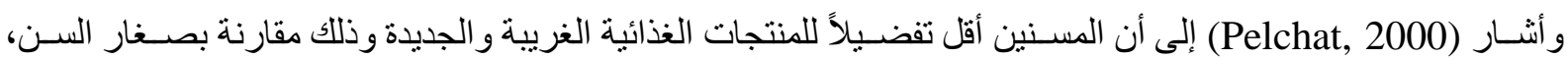

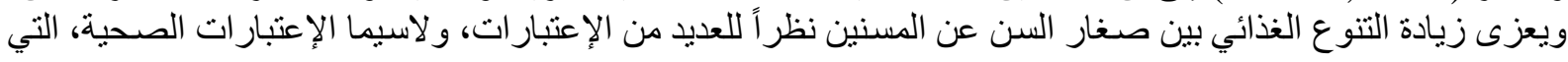


قد لا تجيز للمسـنين تناول العديد من المنتجات الغذائية، مما يؤثر بالضـرورة في التفضـيلات الغذائية للمسـنين، وهو الأمر

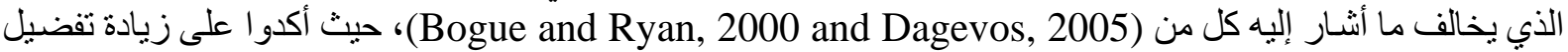

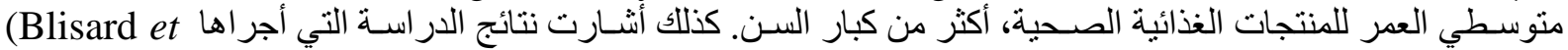

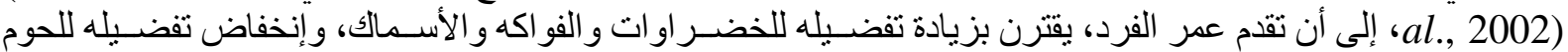

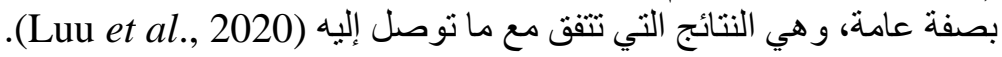

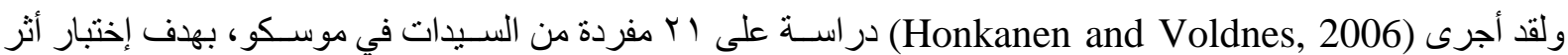

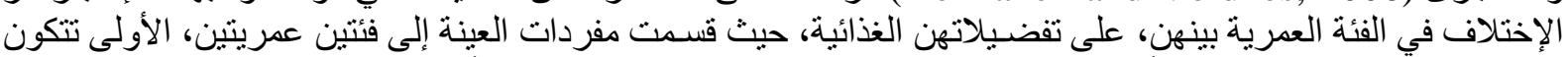

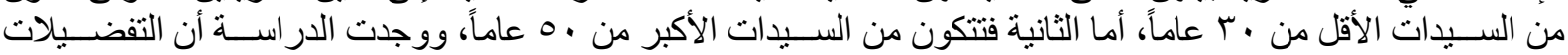

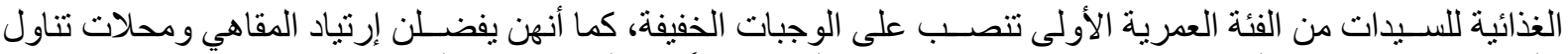

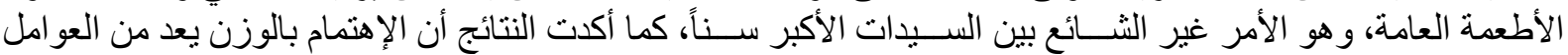

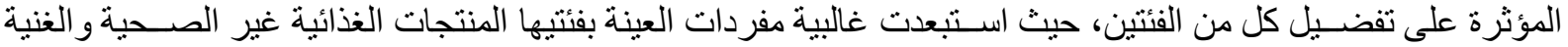

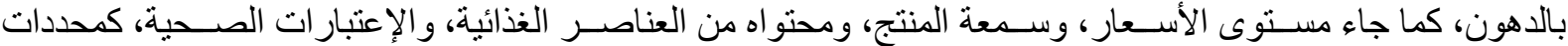
رئيسية، تؤثر في إختيار وتفضيل مختلف المنتجات الغذائية، بين غالبية مفردات العينة بفئتيها العمرية.

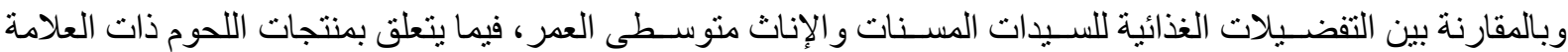

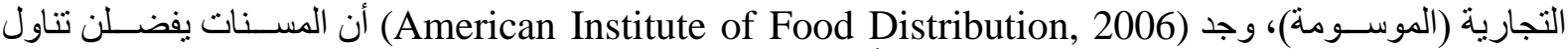
منتجات اللحوم الموسومة، مقارنة بالإناث الأصغر سناً.

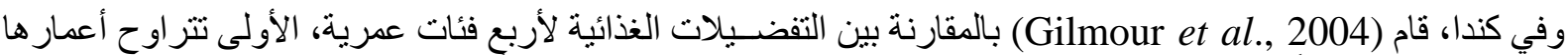

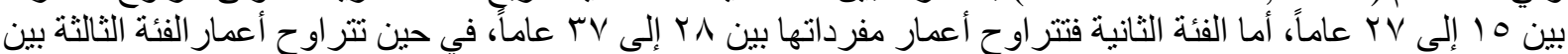

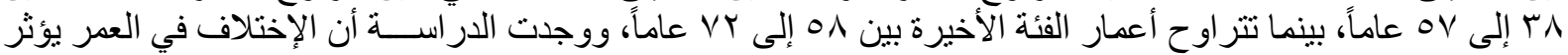

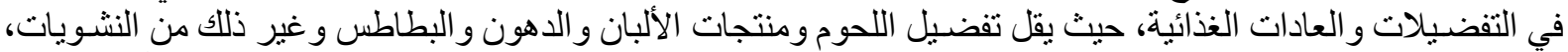

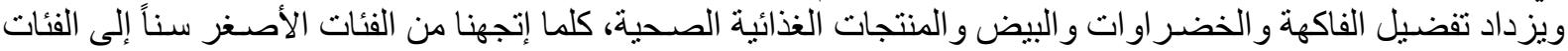

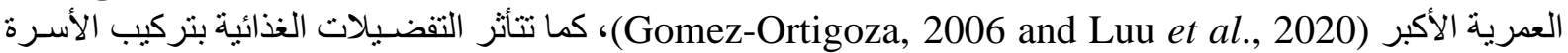

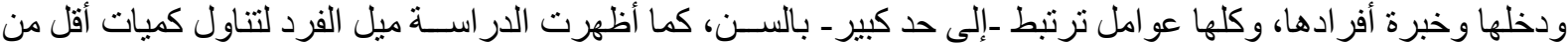

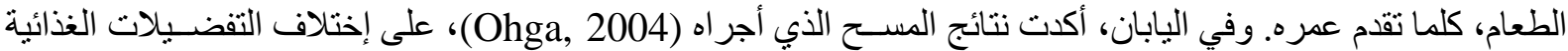

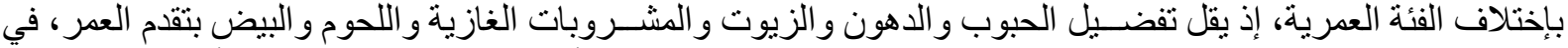

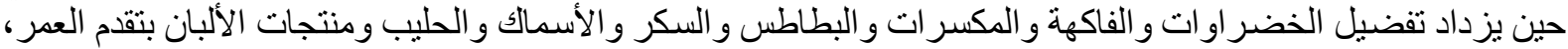
بينما يحظى الأرز بتفضيل كافة الفئات العمرية.

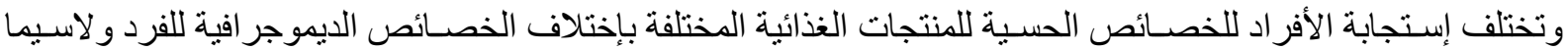

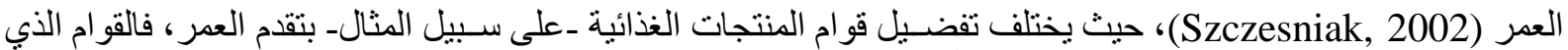

يفضله الرضع، يختلف عن الأطفال الأكبر عمر اً، يختلف عما يفضله البالغون و المسنون (Laureati et al., 2020).

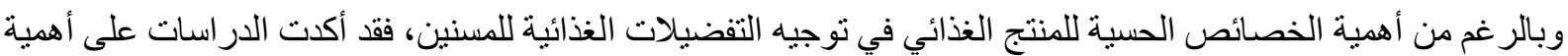

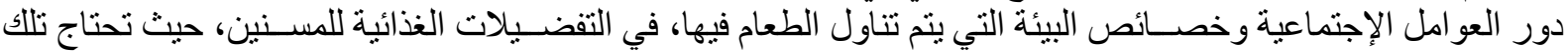

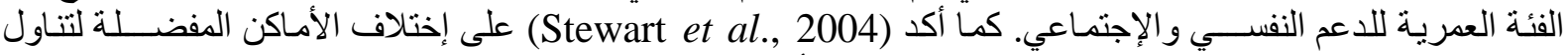

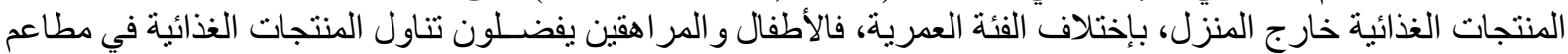
الوجبات السريعة، في حين يفضل كبار السن و المسنين تناول المنتجات الغذائية في المطاعم التقليدية.

r- هدف الدراسة

تسعى الدراسة الحالية إلى وصف وتحليل دور إختلاف الفئة العمرية للعملاء في توجيه تفضيلاتهم لمنتج الوجبات السريعة المقدم في المطاعم وذللك بالتطبيق على مدينة الإسكندرية.

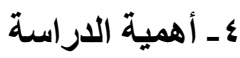

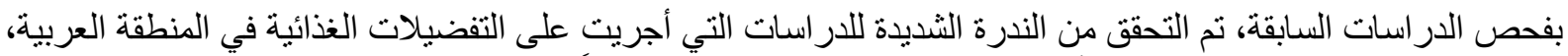

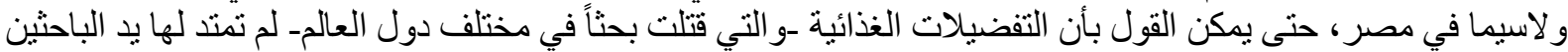
العرب و المصريين بالدر اسة و التحليل بالقدر الذي يتناسب مع أهميتها، وهو ما يدلل على أهمية الدراسة الحالية.

هـ فرضيات الار اسة ومتغيراتها

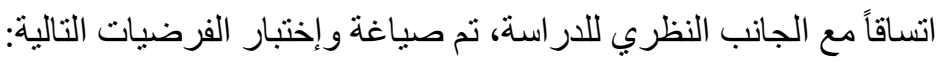


H:

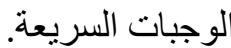

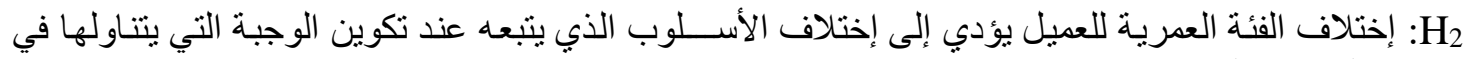
مطاعم الوجبات السريعة.

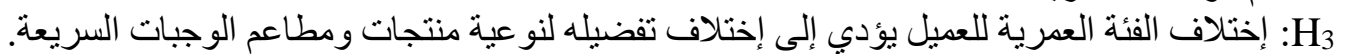

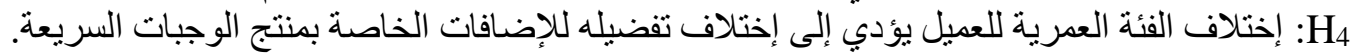

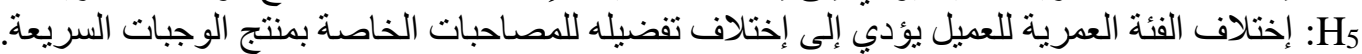

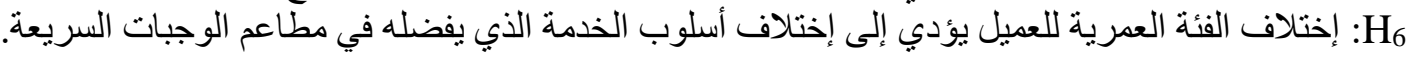

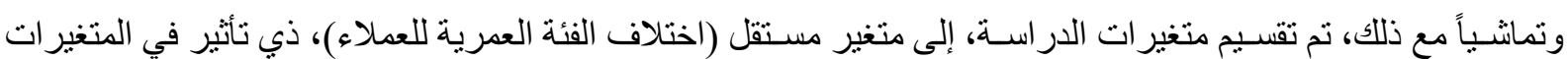

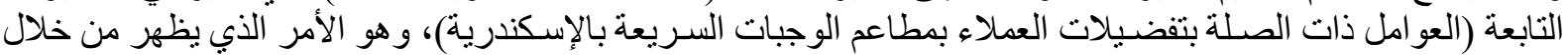

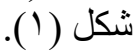

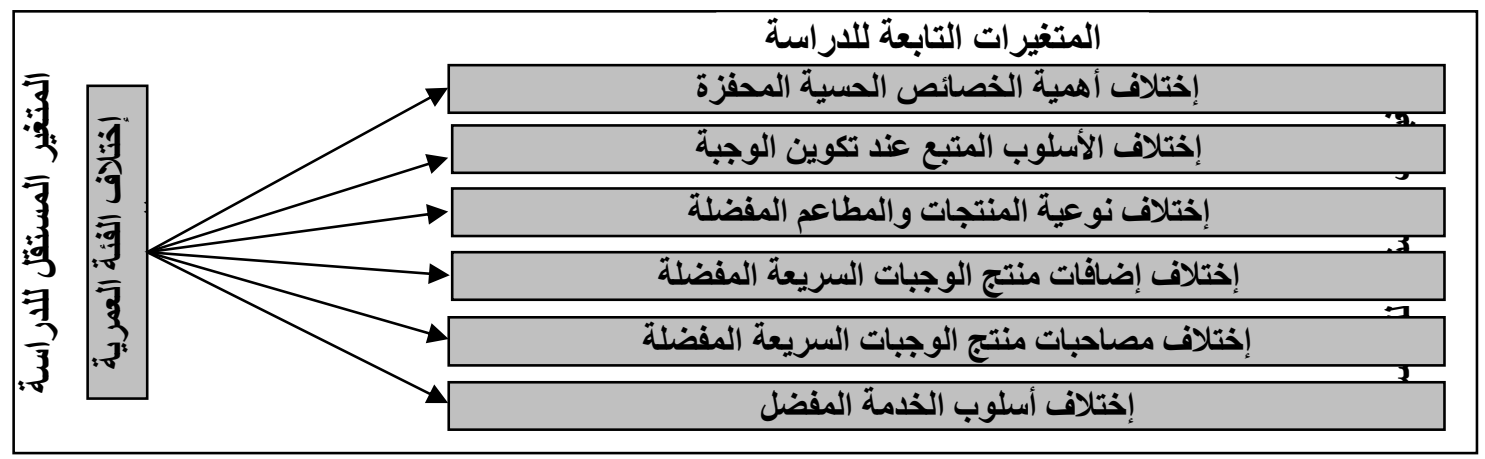

شكل (1 ) العلاقة بين مختلف المتغيرات محل الاراسة

\section{1 - منهجية الاراسة}

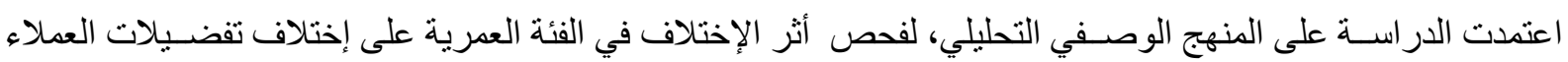

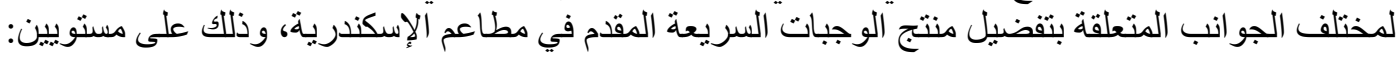
- وصف الاختلاف الو اقع على مختلف جو انب تفضيل العملاء لمنتج الوجبات السريعة المقدم في الإسكندرية، تبعاً لاختلاف الفئة العمرية لعينة الدراسة.

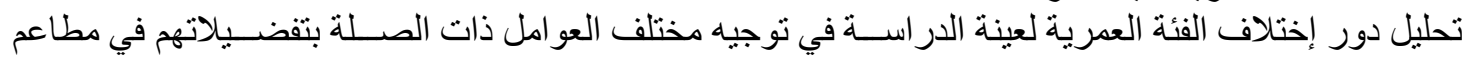
الوجبات السريعة.

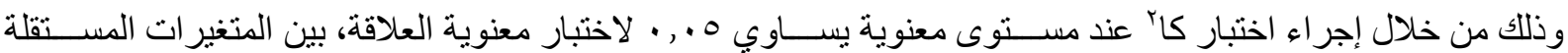

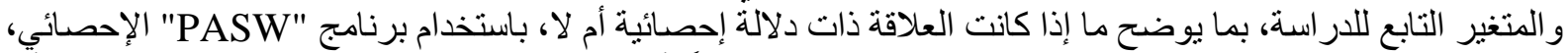

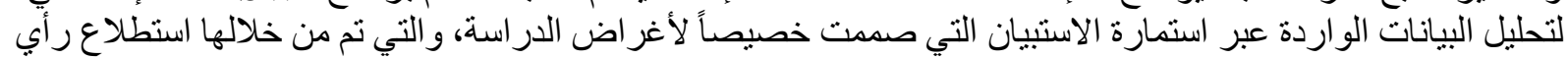

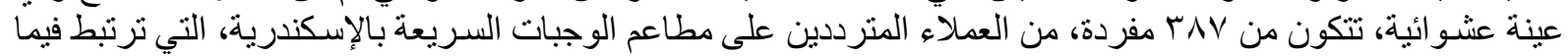

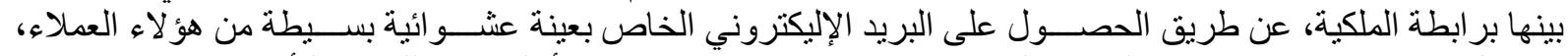

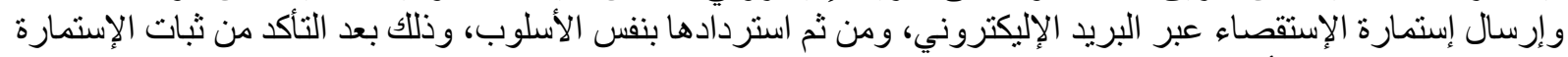

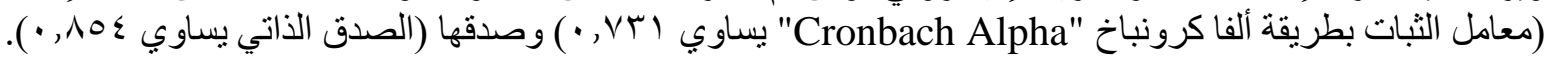

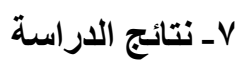

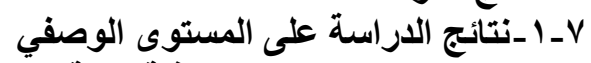

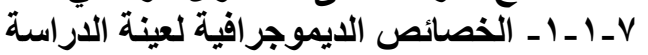

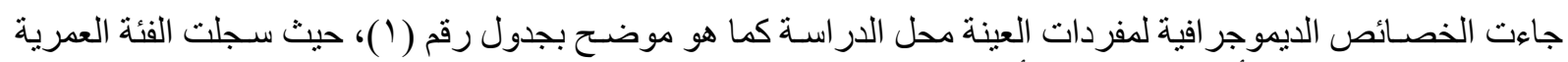

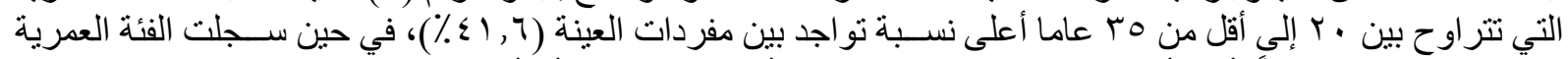

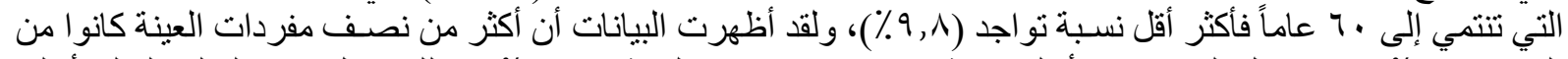

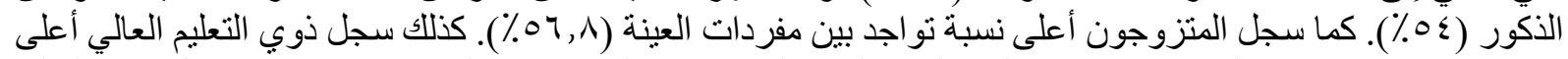

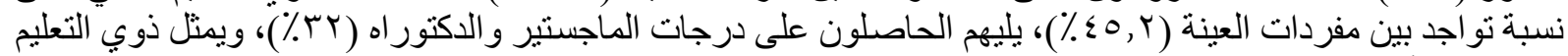

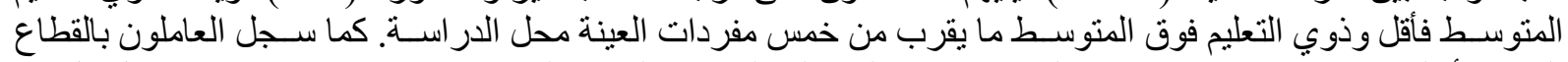

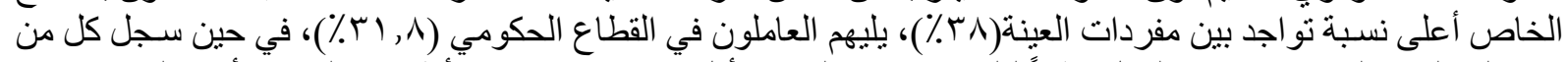

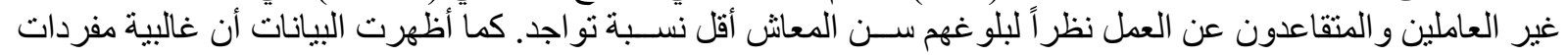




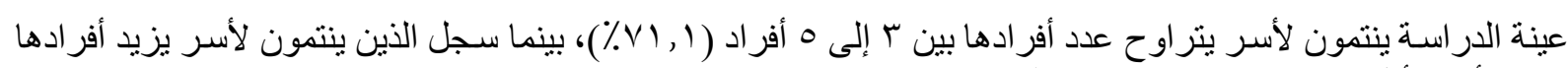

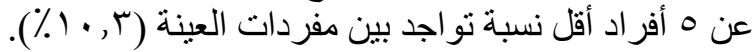

جدول (1 ) الخصائص الديموجرافية لمفردات العينة محل الدراسة (1/انة

\begin{tabular}{|c|c|c|c|c|c|}
\hline الاتحراف المعياري & الوسط الحسابي & $1 \ldots \%$ & 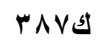 & \multicolumn{2}{|c|}{ الخصائص الديموجرافية } \\
\hline \multirow{5}{*}{$1,1 \vee \wedge$} & \multirow{5}{*}{$r, 04$} & 17,0 & $7 \varepsilon$ & أقلّ من · r عاماً & \multirow{5}{*}{ الفئة العمرية } \\
\hline & & $\leq 1,7$ & 171 & من · r عاماً إلى أقل من هب عامـا & \\
\hline & & $r 1, r$ & Ar & من هـ عاماً إلى أقل من هـ عامـا & \\
\hline & & $1 \cdot, 9$ & $\varepsilon r$ & من ه ؛ عاماً إلى أقل من ج عاماً & \\
\hline & & 9,1 & $\mathrm{r \Lambda}$ & . . . عاما فأكثر & \\
\hline \multirow{2}{*}{$\cdot, \leqslant 99$} & \multirow{2}{*}{$1,0 \leq$} & $\leqslant 7$ & $1 V \wedge$ & أنثى & \multirow{2}{*}{ الجنس } \\
\hline & & $0 \leqslant$ & $r \cdot q$ & ذكر & \\
\hline \multirow{2}{*}{$\cdot, \leqslant 97$} & \multirow{2}{*}{$1, \varepsilon r$} & $\Delta 7, \Lambda$ & rre & متزوج & \multirow{2}{*}{ الاجتماعية } \\
\hline & & $\varepsilon r, r$ & 178 & غير متزوج (أعزب/ مطلق/ أرمل) & \\
\hline \multirow{4}{*}{ •, 904} & \multirow{4}{*}{ r, qV } & $\mid r, 1$ & $\leqslant V$ & تعليم متوسط فأقلّ & \multirow{4}{*}{ مستوى التعليم } \\
\hline & & $1 \cdot, 7$ & $\leqslant 1$ & تعليم فوق متوسط & \\
\hline & & $\leq 0, r$ & ivo & تعليم عالي & \\
\hline & & rr & $1 Y \varepsilon$ & ماجستير/ دكتوراه & \\
\hline \multirow{5}{*}{$1,1 \pi \mathrm{N}$} & \multirow{5}{*}{$r, 1 \wedge$} & $1 r, \varepsilon$ & or & 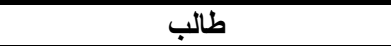 & \multirow{5}{*}{ الوظيفية } \\
\hline & & $\Lambda, \Lambda$ & $r \leq$ & ل لا يعمل & \\
\hline & & $r 1, \Lambda$ & irr & يعمل بالقطاع الحكومي & \\
\hline & & rN & $1 \leqslant V$ & يعمل بالقطاع الخاص & \\
\hline & & $\wedge$ & r & بالمعاش & \\
\hline \multirow{3}{*}{ •, OMr } & \multirow{3}{*}{$1,9 r$} & 11,7 & VY & أقلّ من ب أفراد & \multirow{3}{*}{ عدأسد أفراد } \\
\hline & & $v 1,1$ & rvo & من r أفراد إلى • أفراد & \\
\hline & & $1 \cdot, r$ & $\varepsilon$. & ج أفراد فأكثر & \\
\hline
\end{tabular}

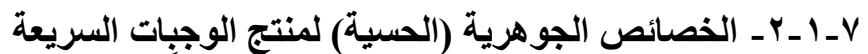

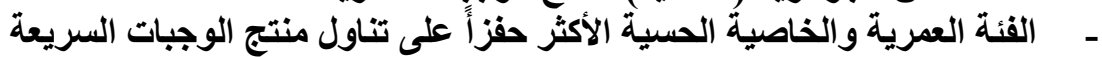

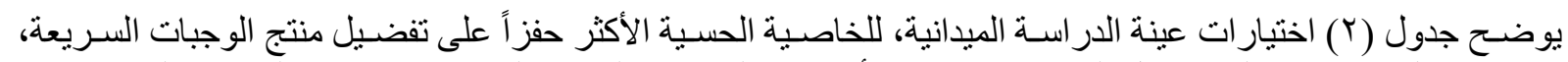

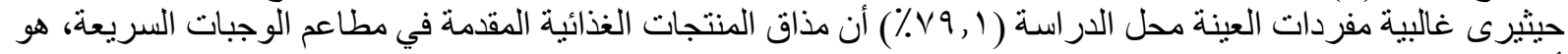

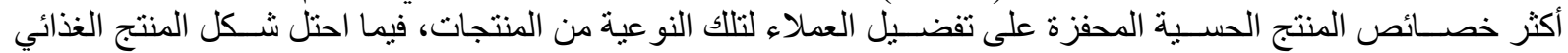

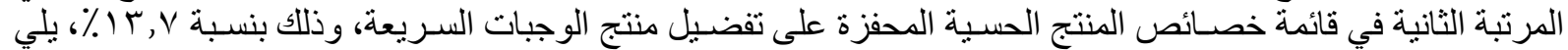

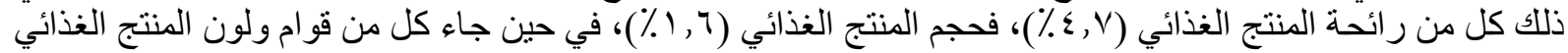

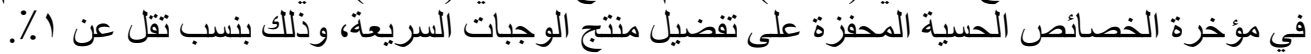
جدول (r) الخصائص الحسية المحفزة على تفضيل منتج الوجبات السريعة.

\begin{tabular}{|c|c|c|c|c|}
\hline 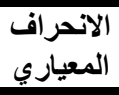 & الحسابي & $\%$ & ك5 & 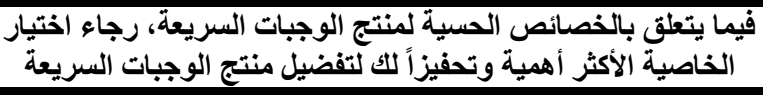 \\
\hline \multirow{7}{*}{$1, v \vee$} & \multirow{7}{*}{$1, \wedge r$} & $v 9,1$ & 5.7 & مذاق المنتج \\
\hline & & $\varepsilon, V$ & 11 & رائحة المنتج \\
\hline & & $\cdot, r$ & 1 & لون المنتج \\
\hline & & $\cdot, \Lambda$ & $r$ & قوام المنتج \\
\hline & & 1,7 & 7 & حجم المنتج \\
\hline & & $1 T, V$ & or & شكل المنتج \\
\hline & & $1 \ldots$ & rAv & الإجمالي \\
\hline
\end{tabular}

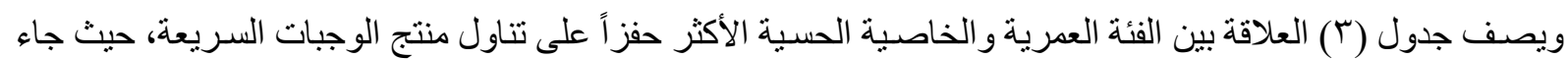

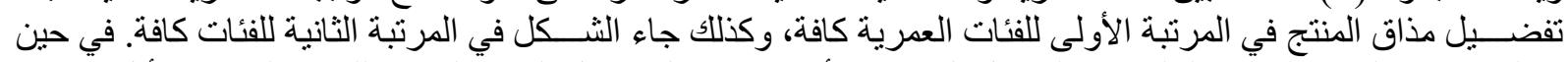

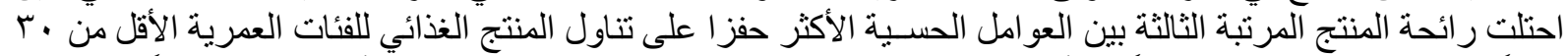

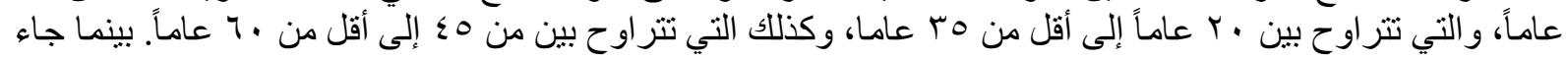


لون المنتج في المرتبة الثانية لكل من الفئة العمرية التي تتر اوح بين هب عاماً إلى أقل من 0؛ عاما، و التي تتنمي إلى . عاما فأكثر.

جدول (ب) علاقة الفئة العمرية لمفردات العينة محل الدراسة بالخاصية الحسية الأكثر حفزاً على تناول المنتج.

\begin{tabular}{|c|c|c|c|c|c|c|}
\hline \multicolumn{6}{|c|}{ الخاصية الحسية الأكثر حفزاً على تناول منتج الوجبات السريعة } & \multirow[b]{2}{*}{ الفئة العمرية } \\
\hline 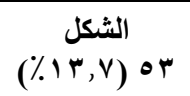 & 7 (الحجم & 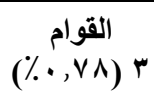 & ا (اللون, • •\%) & 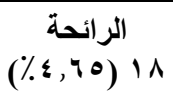 & 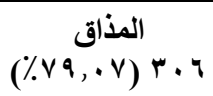 & \\
\hline$(\% r r, \varepsilon \varepsilon) 10$ & ------ & ------- & ------- & $(\%, 1 r) r$ & $(\% \vee r, \varepsilon \varepsilon) \leq V$ & أقلّ من · عاماً \\
\hline$(\%, r, \cdot \varepsilon) r_{1}$ & $(\%, r r) 1$ & $(\%, \wedge \nsucc)^{\mu}$ & ------- & $(\%,, Y 1) 1$. & $(\% \vee \wedge, r q) \backslash r^{\prime}$ & من • • ب إلى أقلّل \\
\hline$(\%, r r)\urcorner$ & $(\%, r 7)^{r}$ & 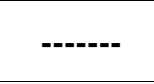 & 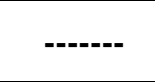 & $(\%, r, \varepsilon) r$ & $(\% \wedge \neg, \diamond 9) \vee 1$ & من ه ه إلى أقلّل \\
\hline$(\% 11,9) \bullet$ & $(\% \varepsilon, \vee\urcorner) r$ & ------ & ------ & $\left(\% q, r^{\circ}\right) \leq$ & ו & 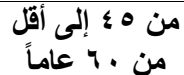 \\
\hline$(\% 10, \vee 9)^{7}$ & - & -------. & $(\% r, 7 r) 1$ & ------ & $(\% \wedge 1,0 \wedge) \mu_{1}$ & • \\
\hline
\end{tabular}

- الفئة العمرية وتفضيل مذاق منتج الوجبات السريعة

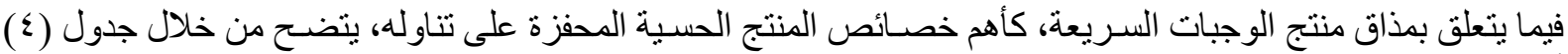

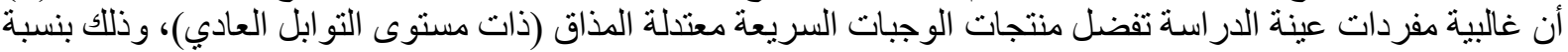

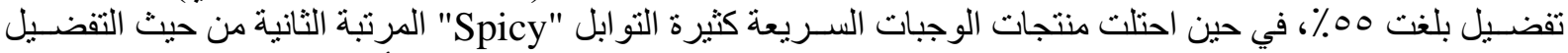

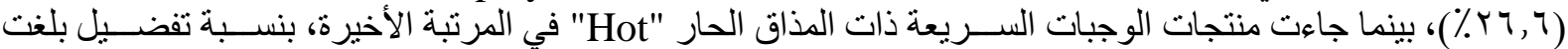

جدول (ع ) تفضيل مفردات عينة الاراسة لمذاق منتج الوجبات السريعة.

\begin{tabular}{|c|c|c|c|c|}
\hline الاتحراف المعياري & الوسط الحسابي & $\%$ & ك5 & عند تناول منتج الوجبات السريعة أفضل المنتجات \\
\hline \multirow{4}{*}{$\cdot, \wedge \bullet q$} & \multirow{4}{*}{ r, Y^ } & $r q, 7$ & $1 \cdot r$ & كثيرة التوابل كpicy" \\
\hline & & $1 \Lambda, r$ & vi & "Hot" الحارة \\
\hline & & 00 & YIr & معتدلة المذاق (ذات مستوى التوابل العادي) \\
\hline & & $1 \ldots$ & rAv & الإجمالي \\
\hline
\end{tabular}

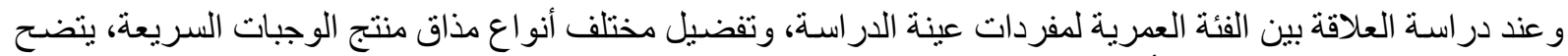

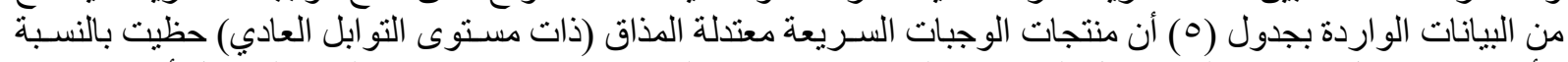

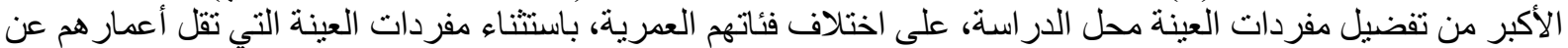

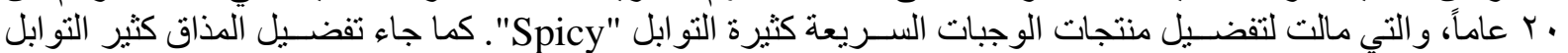

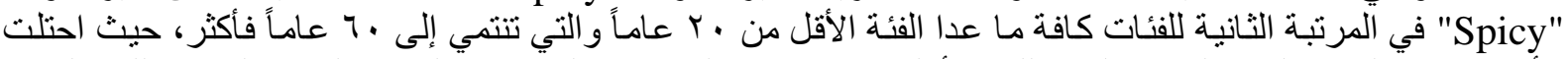

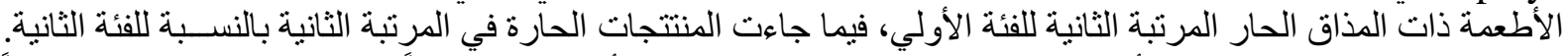

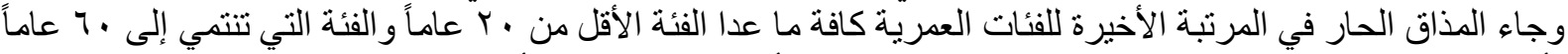

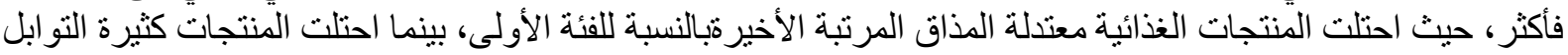
المرتبة الأخيرة بالنسبة للفئة الثانية. 
جدول (•) علاقة الفئة العمرية لمفردات العينة محل الدراسة بتفضيل مختلف أنواع مذاق المنتج.

\begin{tabular}{|c|c|c|c|}
\hline \multicolumn{3}{|c|}{ تفضيل المذاق } & \multirow[b]{2}{*}{ الفئة العمرية } \\
\hline 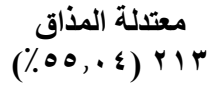 & 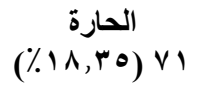 & كثيرة التوابل (1) & \\
\hline$(\%, 1, \wedge \wedge) 1 \leq$ & $(\% r V, 0) Y \varepsilon$ & $(\% \varepsilon \cdot, 7 r) Y q$ & أقل من · r عاماً \\
\hline$(\% \nabla V, V 7) q r$ & $(\% 17, V V) r v$ & $(\% Y \bullet, \leqslant V) \leqslant 1$ & من · r إلى أقل من هr عامLا \\
\hline$(\% .07,1) \leq 7$ & $(\% 10, \wedge \theta) \backslash \mu$ & $(\%, \wedge, \cdot \theta) r r$ & من هr إلى أقل من ه ؛ عامـا \\
\hline$(\% 71,9) \times 4$ & $(\%, 9,0 Y) \leq$ & $(\% r \Lambda, \otimes V) \backslash r$ & من 0 ؛ إلى أقل من · \ عاماً \\
\hline$(\% \wedge q, \varepsilon V) r \varepsilon$ & $(\%, \wedge ৭)^{r}$ & $(Y, 7 Y) 1$ & 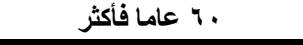 \\
\hline
\end{tabular}

- - الفئة العمرية وتفضيل قوام منتج الوجبات السريعة

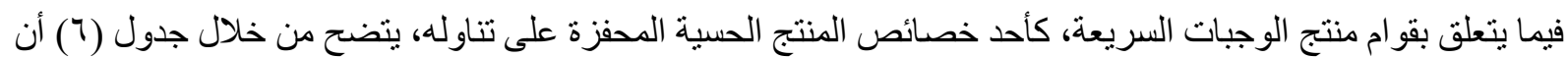

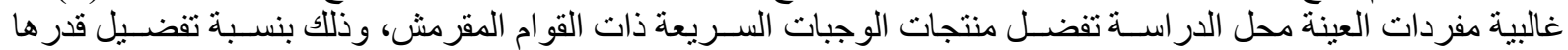

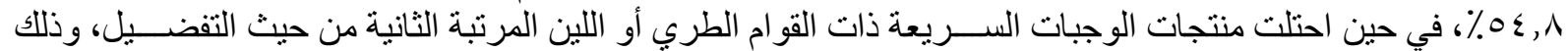

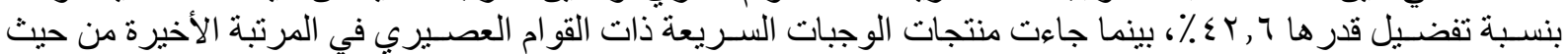

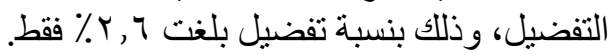

جدول (†) تفضيل مفردات عينة الدراسة لقوام منتج الوجبات السريعة.

\begin{tabular}{|c|c|c|c|c|}
\hline الانحراف المعياري & الوسط الحسابي & $\%$ & ك & عند تناول منتج الوجبات السريعة أفضل المنتجات ذات القوام: \\
\hline \multirow{4}{*}{$\cdot, 00$} & \multirow{4}{*}{$1, \leqslant \wedge$} & $0 \leqslant, \Lambda$ & YIr & المقرمش \\
\hline & & $\leqslant Y, Y$ & 170 & الطري أو اللين \\
\hline & & $r, Y$ & 1. & العصيري \\
\hline & & $1 \ldots$ & rAv & الإجمالى \\
\hline
\end{tabular}

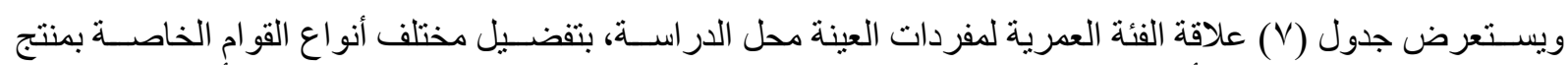

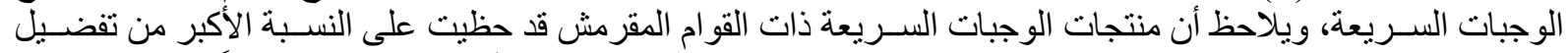

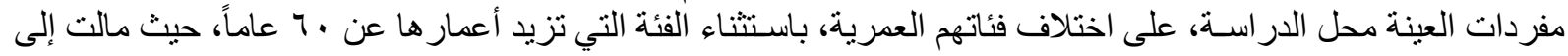
تفضيل منتجات الوجبات السريعة ذات القو القة الطرة الطري (اللين).

جدول (V) علاقة الفئة العمرية لمفردات عينة الدراسة بتفضيل مختلف أنواع قوام منتج الوجبات السريعة.

\begin{tabular}{|c|c|c|c|}
\hline \multicolumn{3}{|c|}{ تفضيل القوام } & \multirow[b]{2}{*}{ الفئة العمرية } \\
\hline 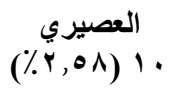 & 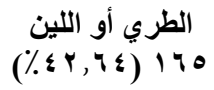 & 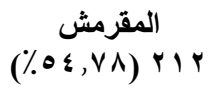 & \\
\hline ------- & $(\% 1 \varepsilon, .7)^{9}$ & $(\% \wedge 0,9 \leq) \bullet 0$ & أقّل من · r عاماً \\
\hline$(\% r, V \Psi)^{\top}$ & $(\% \leq 1,71) 7 v$ & $(\% \circ \leq, 77) \wedge \wedge$ & من · r إلى أقلّل من ه ب عاما \\
\hline$(\%, 74)^{r}$ & $(\% \leq 1, \leqslant 7) \Psi \leq$ & $(\% \Delta \leq, \wedge \wedge) \leq 0$ & من ه广 إلى أقلّ من ه ؛ عاما \\
\hline$(\%, r \wedge) \backslash$ & $(\% \varepsilon \cdot, \leqslant \Lambda) \backslash V$ & $(\% \circ V, 1 \leq) Y \leq$ & من 0 ؛ إلى أقلّل من · ج عاماً \\
\hline ------- & $(\% 1 \cdots) \Gamma \wedge$ & ------- & . 7 . عاما فأكثر \\
\hline
\end{tabular}

- الفئة العمرية وتفضيل حجم منتج الوجبات السريعة

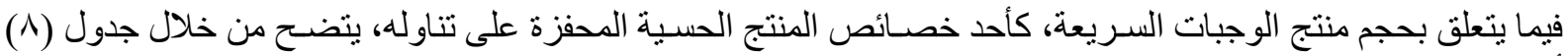

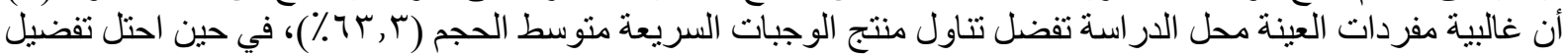

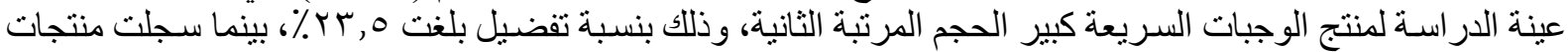

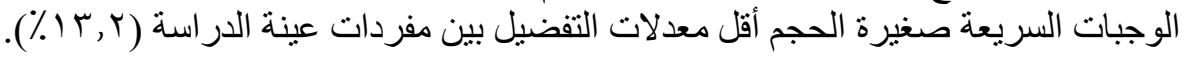

جدول (^) تفضيل مفردات عينة الاراسة لحجم منتج الوجبات السريعة.

\begin{tabular}{|c|c|c|c|c|}
\hline الانحراف المعياري & الوسط الحسابي & $\%$ & ك & عند تناول منتج الوجبات السريعة أفضل: \\
\hline \multirow{4}{*}{$\cdot, 09 \wedge$} & \multirow{4}{*}{$r, 1}$. & $1 r, Y$ & 01 & الحجم الأصغر \\
\hline & & $7 \mu, r$ & $r \leqslant 0$ & الحجم المتوسط \\
\hline & & $r r, 0$ & 91 & الحجم الأكبر \\
\hline & & $1 \ldots$ & rAv & الإجمالى \\
\hline
\end{tabular}




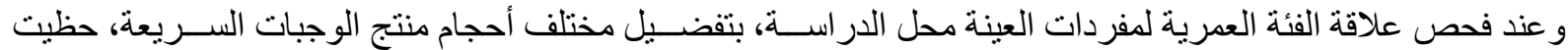

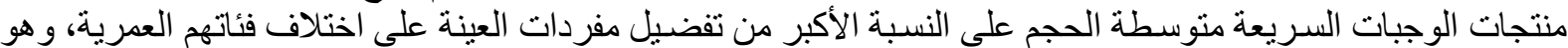

الأمر الذي يظهر من خلال جدول (9).

جدول (9) علاقة الفئة العمرية لمفردات العينة محل الدراسة بتفضيل مختلف أحجام منتج الوجبات السريعة.

\begin{tabular}{|c|c|c|c|}
\hline \multicolumn{3}{|c|}{ تفضيل الحجم } & \multirow[b]{2}{*}{ الفئة العمرية } \\
\hline 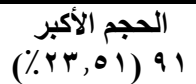 & 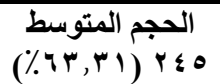 & 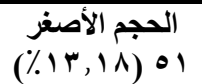 & \\
\hline$(\% \varepsilon r, 1 q) r V$ & $(\% \Delta q, Y 0) r q$ & $(\% 1,07) 1$ & أقلّ من · r عاماً \\
\hline$(\% Y 0, \leqslant V) \leqslant 1$ & $(\% \neg \vee, \wedge) 1 \cdot \Lambda$ & $(\% V, \leqslant 0) \backslash Y$ & من · ץ إلى أقل من ه ب عامـا \\
\hline$(\% r r, I V) 19$ & $(\% \curlyvee \bullet, \wedge \bullet) \bullet \leq$ & $(\% 1 \cdot, 9 \wedge)^{9}$ & من هب إلى أقل من ه ؛ عامـا \\
\hline$(\%, 9,0 Y) \leq$ & $(\% \Delta q, \Delta r) Y \Delta$ & $(\% r \cdot, 90) \backslash r$ & من 0 ؛ إلى أقل من ¥ عاماً \\
\hline ------- & $(\% \bullet V, \wedge ৭) Y r$ & $(\%\{Y, 11) 17$ & عاما فأكثر \\
\hline
\end{tabular}

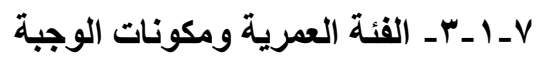

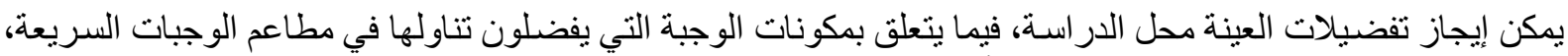

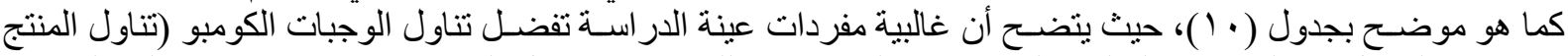

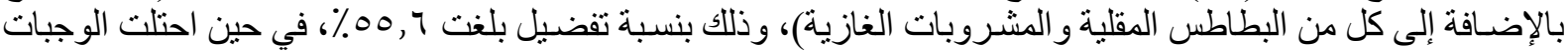

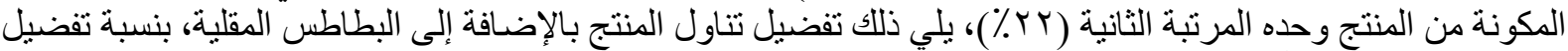

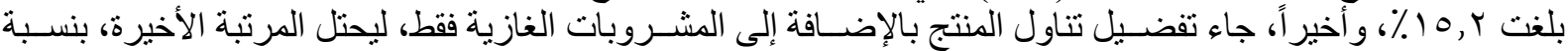

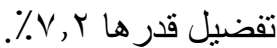

جدول ( • 1) تفضيل مفردات عينة الاراسة لمكونات الوجبة في مطاعم الوجبات السريعة.

\begin{tabular}{|c|c|c|c|c|}
\hline الانحراف المعياري & الوسط الحسابي & $\%$ & ك & عند تناول منتج الوجبات السريعة أفضل: \\
\hline \multirow{5}{*}{$1,1,1$} & \multirow{5}{*}{$r, 97$} & rr & 10 & تناول المنتج فقط \\
\hline & & $10, r$ & 09 & تناول المنتج بالإضافة إلى البطاطس المقلية فقط \\
\hline & & $V, r$ & rA & تناول المنتج بالإضافة إلى المشروبات الغازية فقط \\
\hline & & 00,7 & Y 10 & تناول المنتج بالإضافة إلى كلية من البطاطس المقلية \\
\hline & & $1 \ldots$ & $r \wedge V$ & الإِ \\
\hline
\end{tabular}

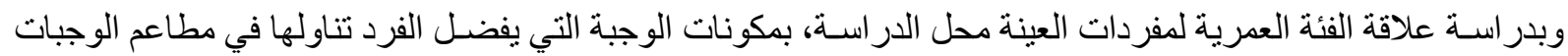

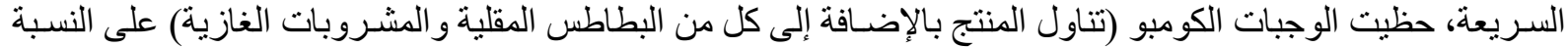

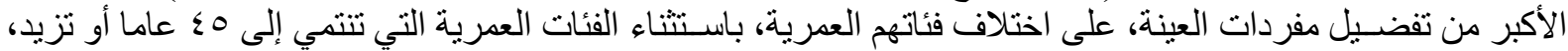
حيث مالو التفضـــيل تناول المنتج فقط، بدون البطاطس المقلية أو المشــروبات الغازية، وهو الأمر الذي يظهر من خلال

جدول (1).

جدول ( 11 ) علاقة الفئة العمرية لعينة الدراسة بمكونات الوجبة المفضلة في مطاعم الوجبات السريعة.

\begin{tabular}{|c|c|c|c|c|}
\hline \multicolumn{4}{|c|}{ مكونات الوجبة } & \multirow[b]{2}{*}{ الفئة العمرية } \\
\hline المنتج مع البطاطس المقلية & 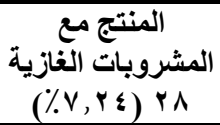 & 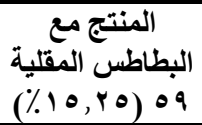 & 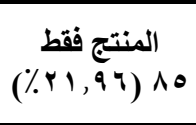 & \\
\hline$(\% \vee r, \varepsilon \varepsilon) \leq V$ & ------ & $(\%, Y \bullet) \leq$ & $(\%, r, r) \mid r$ & أقل من · r عاماً \\
\hline$(\%\urcorner \cdot, \wedge \vee) q \wedge$ & $(\% \neg, \wedge r) \backslash 1$ & $(\% r \cdot, \theta) r r$ & $(\% 11, \wedge) 19$ & من · r إلى أقل من هr عامLا \\
\hline$(\% \Delta 1, Y Y) \leq Y$ & $(\% 9, \vee \curlyvee) \wedge$ & $(\% \wedge \theta, \wedge \theta) \backslash \mu$ & $(\% r r, I V) 19$ & من ه r إلى أقل من ه ؛ عامـا \\
\hline$(\% r \wedge, \diamond \vee) \backslash r$ & $\left(\% 1 \varepsilon, r^{q}\right)^{7}$ & $(\% 19, .0)^{\wedge}$ & $(\% \leftrightarrow \wedge, 1) 17$ & من ه ؛ إلى أقل من · ؟ عاماً \\
\hline$(\% \leq 4,11) 17$ & $(\%, \wedge q)^{r}$ & $(\%, r, r) 1$ & $(\% \varepsilon V, r V) \backslash \wedge$ & . . ا عاما فأكثر \\
\hline
\end{tabular}

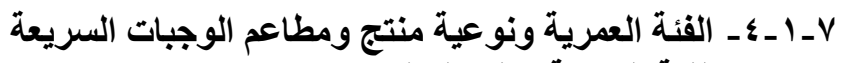

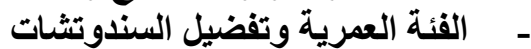

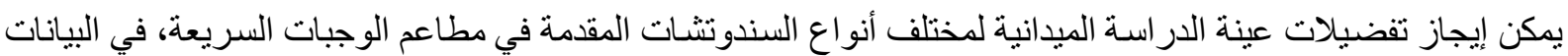

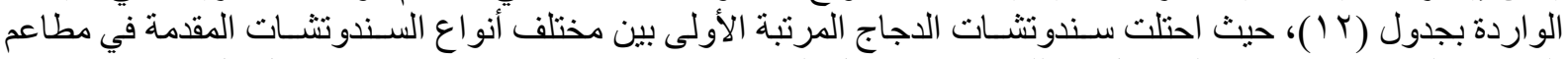

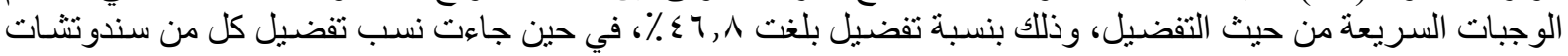




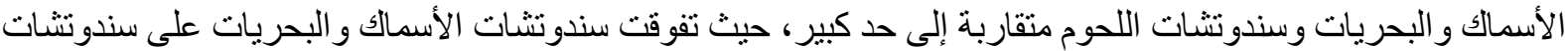

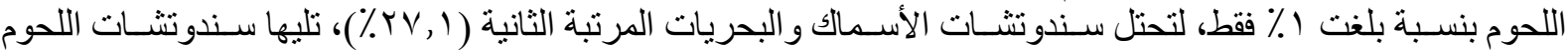

جدول (r Y ) تفضيل مختلف أنواع السندوتثات المقدمة في مطاعم الوجبات السريعة.

\begin{tabular}{|c|c|c|c|c|}
\hline المعياري الاف & الحسابي & $\%$ & ك] & 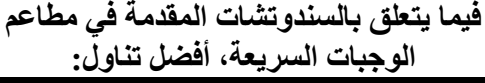 \\
\hline \multirow{4}{*}{$\cdot, V r \cdot$} & \multirow{4}{*}{$r, \cdot 1$} & $r q, 1$ & $1 \cdot 1$ & سندوتشات اللحوم \\
\hline & & $\leq 7,1$ & $1 \wedge 1$ & سندوتشات الاجاج \\
\hline & & $r v, 1$ & 1.0 & سندوتثـات الأسماك و البحريات \\
\hline & & $1 \cdots$ & $\mathrm{r} \wedge \mathrm{V}$ & الإجمالي \\
\hline
\end{tabular}

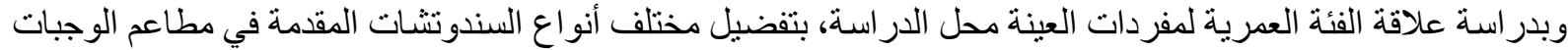

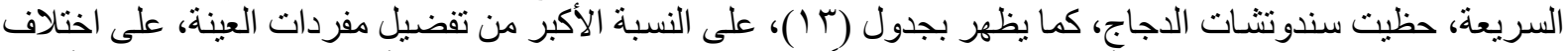

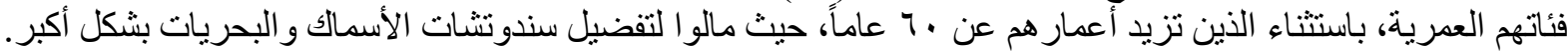

جدول (r ا ) علاقة الفئة العمرية للعينة بتفضيل أنواع السندوتثثات المقدمة في مطاعم الوجبات السريعة.

\begin{tabular}{|c|c|c|c|}
\hline \multicolumn{3}{|c|}{ تفضيل السندوتثشات } & \multirow[b]{2}{*}{ الفئة العمرية } \\
\hline 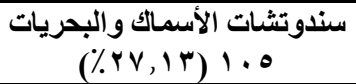 & 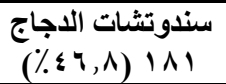 & 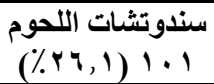 & \\
\hline$(\%$ Y $) 17$ & $(\% \leq \neg, \wedge \wedge) \mu$. & $(\% \curlyvee \wedge, 1 \%) \backslash \wedge$ & أقل من · Y عاماً \\
\hline$(\% 17, V V) Y V$ & $(\% r q, \cdot r) \bullet \wedge$ & $(\% r \cdot, \varepsilon r) \leq q$ & من · r إلى أقل من ه ب عاما \\
\hline$(\% r \Delta, r v) r q$ & $(\% r q, \cdot r) r r$ & $(\%, r 0, Y I) Y I$ & من ه广 إلى أقل من ه ؛ عاما \\
\hline$(\% \varepsilon \cdot, \leqslant \Lambda) \backslash \vee$ & $(\% \varepsilon V, T r) Y$. & $(\% 11,9)^{\circ}$ & من 0 ؛ إلى أقل من 7 عاماً \\
\hline$(\% \leqslant 4,11) 17$ & $(\% \sim Y, \wedge \varepsilon) \backslash \leq$ & $(\%, 1, .0)^{\wedge}$ & ، ، عاما فأكثر \\
\hline
\end{tabular}

-

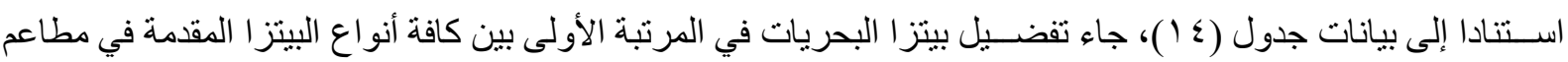

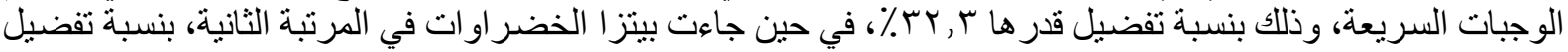

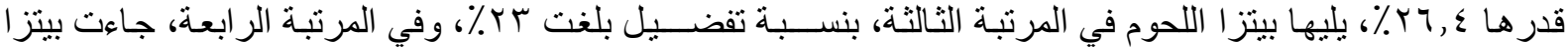

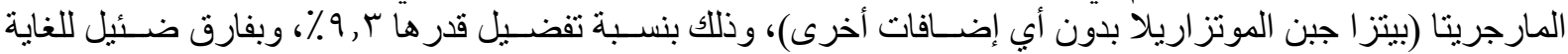

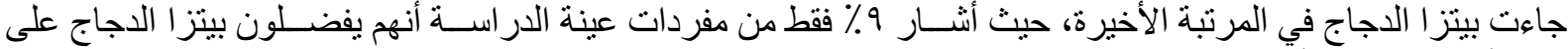
سائر أنواع البيتزا الأخرى المقدمة في مطاعم الوجبات السريعة.

جدول (ء 1) تفضيل مختلف أنواع البيتزا المقدمة في مطاعم الوجبات السريعة.

\begin{tabular}{|c|c|c|c|c|}
\hline الاتحر اف المعياري & الوسط الحسابي & $\%$ & ك & في مطاعم الوجبات السريعة، أفضل تناول بيتزا: \\
\hline \multirow{6}{*}{$1, \varepsilon \cdot v$} & \multirow{6}{*}{$r, \diamond V$} & $r r, r$ & 140 & البحريات \\
\hline & & $r r$ & $\wedge 9$ & 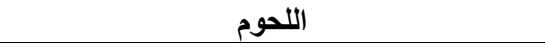 \\
\hline & & 9 & ro & الاجاج \\
\hline & & r४, \& & $1 \cdot r$ & الخضروات \\
\hline & & $q, r$ & r & 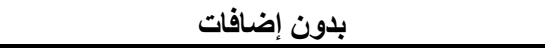 \\
\hline & & $1 \ldots$ & rAv & الإجمالي \\
\hline
\end{tabular}

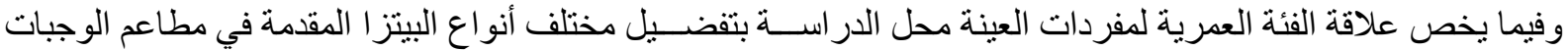

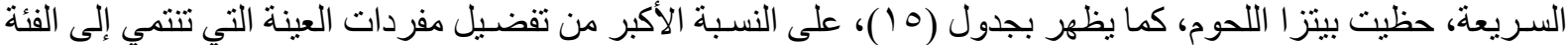

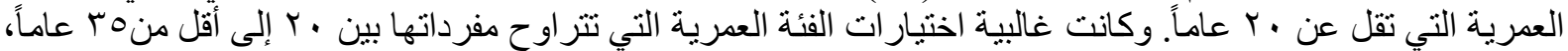

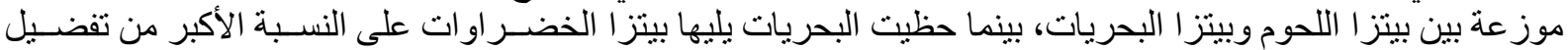

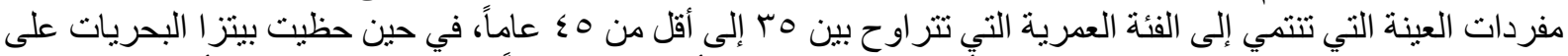

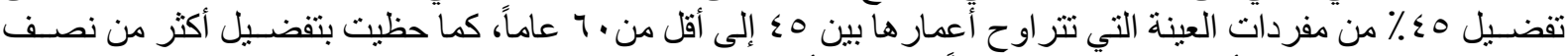

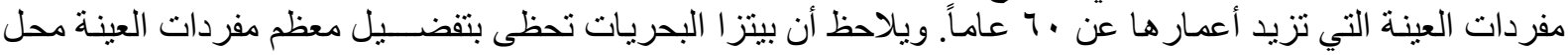
الدر اسة، على اختلاف فئاتها العمرية.

جدول (0 1 ) علاقة الفئة العمرية لعينة الدراسة بتفضيل أنواع البيتزا المقدمة في مطاعم الوجبات السريعة. 


\begin{tabular}{|c|c|c|c|c|c|}
\hline \multicolumn{5}{|c|}{ تفضيل البيتزا } & \multirow[b]{2}{*}{ الفئة العمرية } \\
\hline 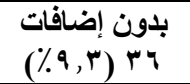 & 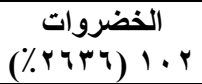 & هـ (ع •, الاجاج ٪) & 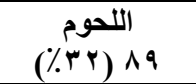 & 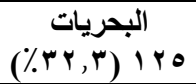 & \\
\hline$(\%, Y 0) \varepsilon$ & $(\% \wedge \wedge, 1 r) \backslash \wedge$ & $(\% \varepsilon, 79)^{\mu}$ & $(\% r \Delta, q \varepsilon) r r$ & $(\%$ Y $) 17$ & أقلّ من · r عامـاً \\
\hline$(\% 1,, 07) \backslash V$ & $(\% 1 \wedge, \cdot 1) \times q$ & $(\% \mid r, \cdot \varepsilon) Y 1$ & $(\% r q, 19) \leq V$ & $(\% \vee q, 19) \leq V$ & 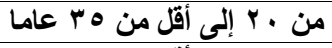 \\
\hline$(\% 7,1)^{0}$ & $(\% r \cdot, \leqslant 9)$ Yo & $(\% Y, \varepsilon \leq) Y$ & $(\% \wedge \theta, \wedge \theta) \backslash \mu$ & $(\% \leqslant 0,1 Y) r v$ & من ه r إلى أقل من ه ؛ عامـا \\
\hline$\left(\% Y^{\prime}, \leq \Psi\right)^{9}$ & $(\% 19, .0)^{\wedge}$ & $(\% 18,19) 7$ & $(\% r, r \wedge) 1$ & $(\% \leqslant Y, \wedge q) \backslash \wedge$ & من 0 ؛ إلى أقلّل من ، ج عاماً \\
\hline$(\%, Y r) 1$ & $(\% \diamond \vee, \wedge q) Y r$ & $(\%, \wedge q)^{r}$ & $(\% 1 r, 17)^{\circ}$ & $(\% \wedge, \varepsilon r) \vee$ & 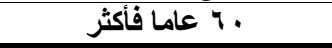 \\
\hline
\end{tabular}

\section{- الفئة العمرية وتفضيل مطاعم الوجبات السريعة على إختلاف تصنيفاتها}

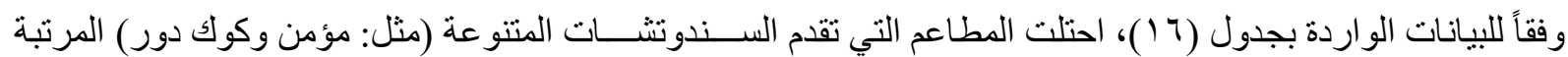

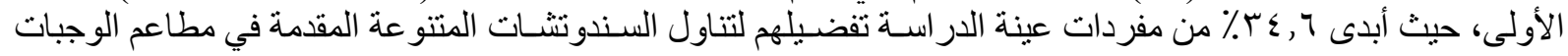

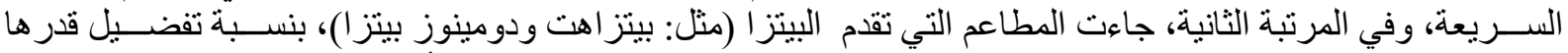

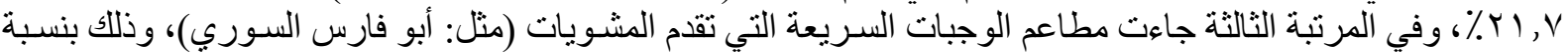

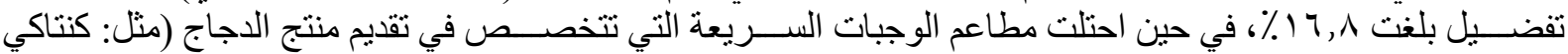

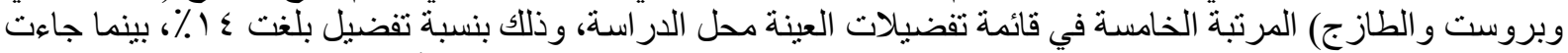

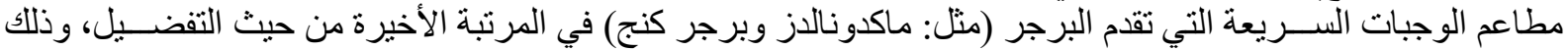

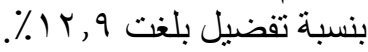

جلول (7 1 ) تفضيل مطاعم الوجبات السريعة على إختلاف تصنيفاتها.

\begin{tabular}{|c|c|c|c|c|}
\hline الاتحراف المعياري & الوسط الحسابي & $\%$ & ك & 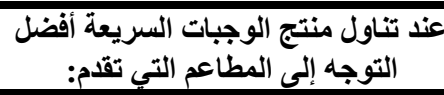 \\
\hline \multirow{6}{*}{$1, r \cdot q$} & \multirow{6}{*}{$r, Y$} & $1 r, 9$ & 0. & البرجز \\
\hline & & $r i, v$ & $\Lambda \leq$ & البيتزا \\
\hline & & $1 \leq$ & $0 \leq$ & الاجاج \\
\hline & & $r \leqslant, 7$ & ITs & السندوتثـات المتتوعة \\
\hline & & 17,1 & 70 & المشويات \\
\hline & & $1 \cdots$ & $r \wedge V$ & الإجمالي \\
\hline
\end{tabular}

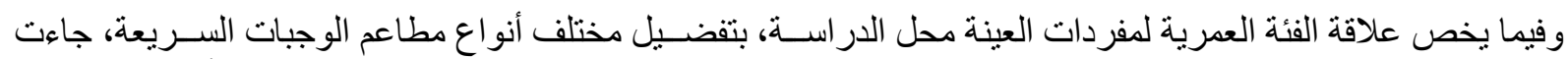

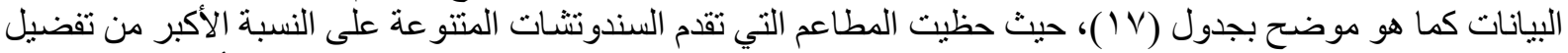

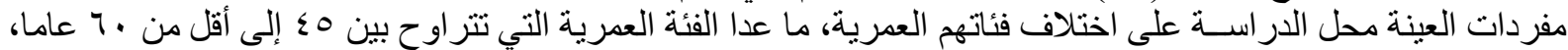

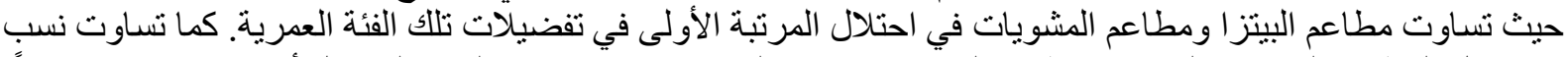

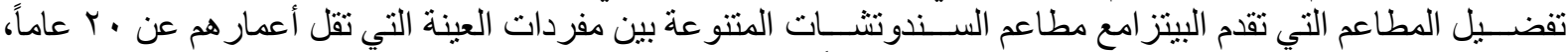

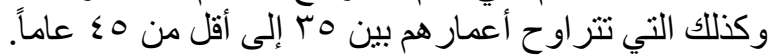

جدول (V ا ) علاقة الفئة العمرية لعينة الدراسة بتفضيل مطاعم الوجبات السريعة على إختلاف تصنيفاتها.

\begin{tabular}{|c|c|c|c|c|c|}
\hline \multicolumn{5}{|c|}{ تصنيف مطاعم الوجبات السريعة } & \multirow{2}{*}{ الفئة العمرية } \\
\hline 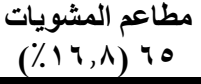 & 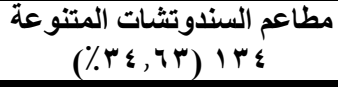 & 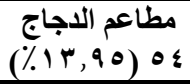 & 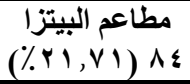 & 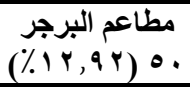 & \\
\hline$(\%, 79)^{r}$ & $(\% r l, r \theta) r$. & $(\% 10,7 \pi) 1$. & $\left(\% r_{1}, r_{\theta}\right) r$. & $(\% 1 \vee, 19) 11$ & أقلّ من · r عاماً \\
\hline$(\% 10,0 \%) Y 0$ & $(\% \varepsilon Y, Y \varepsilon) \sqcap \wedge$ & $(\% 11, \wedge) 19$ & $(\% 10,0 \%) Y 0$ & $(\% 1 \leq, 91) r \leq$ & من · r إلى أقل من هب عاما \\
\hline$(\%, 1,90) 11$ & $(\% r \checkmark, \wedge r) r r$ & $(\% 1 V, \cdot v) \backslash \leq$ & $(\% Y \neg, \wedge r) Y r$ & $(\%, r Y) Y$ & من ه r إلى أقل من ه ؛ عاما \\
\hline$(\% r \cdot, 90) 1 r$ & $(\% 17,7 \vee) \vee$ & $(\%, 9,0 Y) \leq$ & $(\% r \cdot, 90) 1 r$ & $(\% 11,9)^{\circ}$ & من ه ؛ إلى أقل من · ج عاماً \\
\hline$(\% 10,1 \vee 9) 7$ & $(\% \leq \varepsilon, V \leq) \backslash V$ & $(\% \backslash \wedge, \leq r) \vee$ & $(\% 1 \cdot, \Delta r) \varepsilon$ & $(\%, 1 \cdot, 0 r) \leq$ & 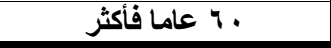 \\
\hline
\end{tabular}

- الفئة العمرية وتفضيل طابع منتج الوجبات السريعة

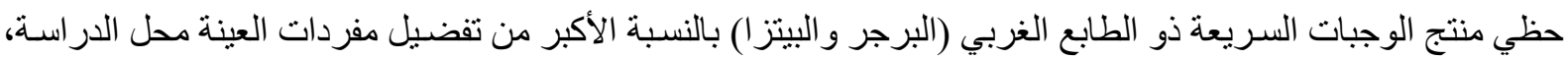

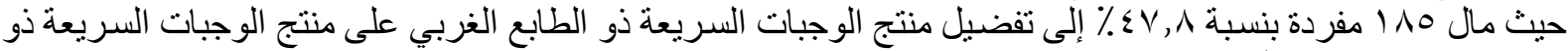

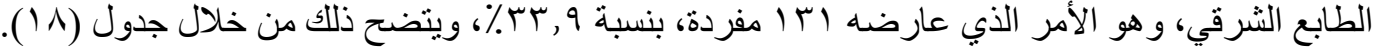
جدول (1 1 ) تفضيل منتج الوجبات السريعة ذو الطابع الغربي مقابل المنتج ذو الطابع الشرقي. 


\begin{tabular}{|c|c|c|c|c|}
\hline الانحراف & الحسابي & $\%$ & ك5 & الغربي، على مطاعة، أفضل مطاعم الوجبات الوبرة ذاتريعة ذات الطابع الثرقيع: \\
\hline \multirow{6}{*}{$1, r v 1$} & \multirow{6}{*}{$r, r_{1}$} & $r v, q$ & 1.1 & أوافق بشدة \\
\hline & & 19,9 & $v V$ & أوافق \\
\hline & & $1 \wedge, r$ & $v_{1}$ & لا أوافث ولا أعترض \\
\hline & & $r \mu, r$ & 9. & أعترض \\
\hline & & $1 \cdot, 7$ & $\varepsilon 1$ & أعترض بثدة \\
\hline & & $1 \cdots$ & $r \wedge V$ & الإجمالي \\
\hline
\end{tabular}

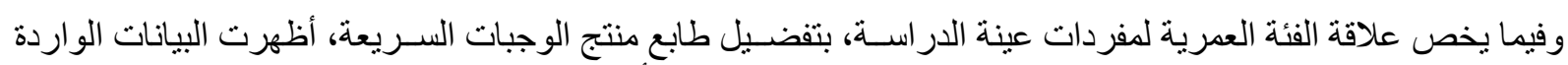

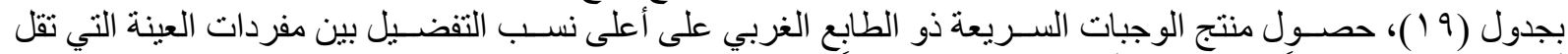

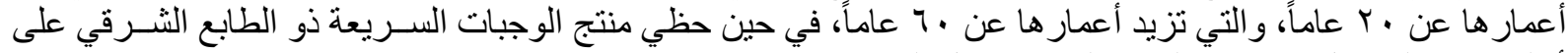

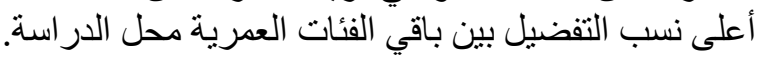

جدول (9 1) علاقة الخصائص الايموجرافية لمفردات عينة الدراسة بتفضيل طابع منتج الوجبات السريعة.

\begin{tabular}{|c|c|c|c|}
\hline \multicolumn{3}{|c|}{ مدى تفضيل منتج الوجبات السريعة ذو الطابع الغربي على المنتج ذو الطابع الثرقي } & \multirow[b]{2}{*}{ الفئة العمرية } \\
\hline 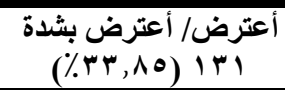 & 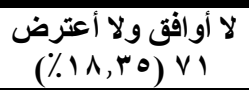 & 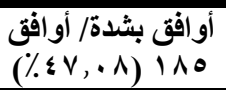 & \\
\hline 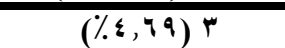 & $(\%, \wedge 1)^{\bullet}$ & $(\% \wedge \vee, 0) \otimes \curlyvee$ & أقلّ من · r عاماً \\
\hline$(\% \varepsilon \cdot, r v) 70$ & $(\% 19, \wedge \wedge) r r$ & $(\% \vee q, \vee \bullet) ~ \curlyvee \leq$ & من · r إلى أقلّل من هب عامـا \\
\hline$(\% \cdot 0 \cdot) \leqslant 1$ & $(\%, 1,90) 11$ & $(\% r \wedge, \cdot \theta) r r$ & من هب إلى أقلّ من 0؛ عاما \\
\hline$(\% r r, r r) 1 \leq$ & $(\% \wedge, 1) 17$ & $(\% r \wedge, \otimes \vee) I r$ & من هـ إلى أقلّ من ، ¥ عاماً \\
\hline$(\%, 1, .0) \wedge$ & ------- & $(\% \vee \wedge, q 0) \mu$. & . عاما فأكثر \\
\hline
\end{tabular}

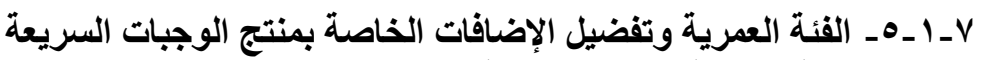

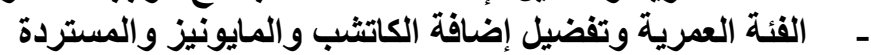

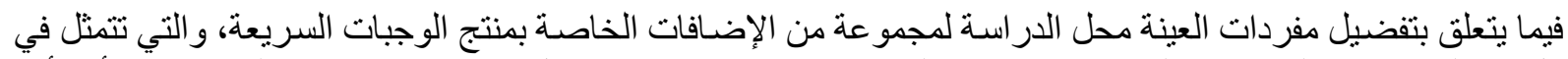

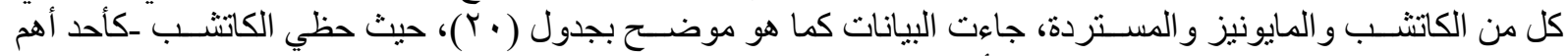

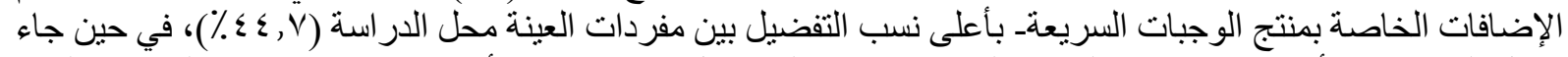

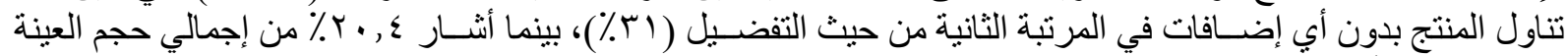

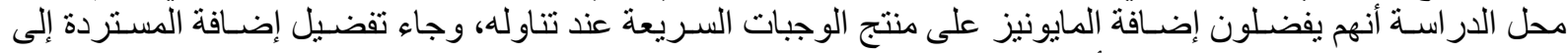

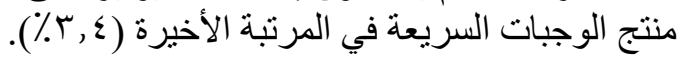

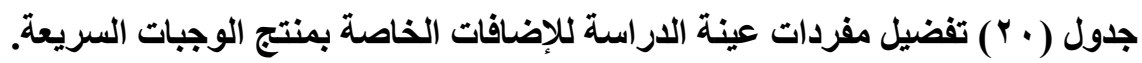

\begin{tabular}{|c|c|c|c|c|}
\hline الاتحراف المعياري & الوسط الحسابي & $\%$ & ك & عند تناول منتج الوجبات السريعة أفضل: \\
\hline \multirow{5}{*}{$1, r q \vee$} & \multirow{5}{*}{ r,, 1} & $\varepsilon \leqslant, V$ & IVT & الكاتشب \\
\hline & & $r \cdot, q$ & $\wedge 1$ & المايونيز \\
\hline & & $r, \varepsilon$ & 14 & المستردة \\
\hline & & $\mu$ & Ir. & لا أفضل وجود إضافات \\
\hline & & $1 \ldots$ & $r \wedge v$ & الإجمالي \\
\hline
\end{tabular}

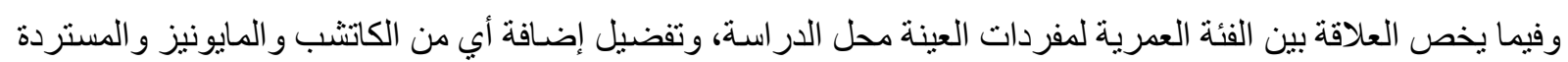

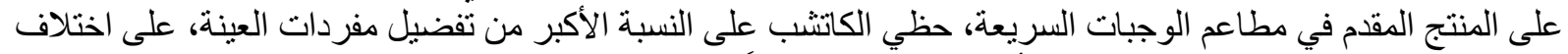

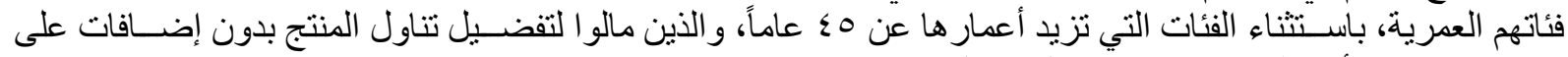

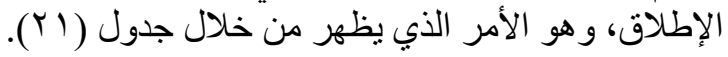


جدول ( ا Y) علاقة الفئة العمرية لمفردات عينة الدراسة بتفضيل الإضافات الخاصة بمنتج الوجبات السريعة.

\begin{tabular}{|c|c|c|c|c|}
\hline \multicolumn{4}{|c|}{ الإضافات المفضلة } & \multirow[b]{2}{*}{ الفئة العمرية } \\
\hline 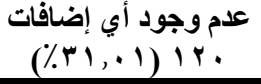 & سا المستردة" & 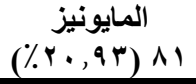 & 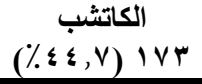 & \\
\hline$(\% 10,7 \pi) 1$ & $(\% 1,07) 1$ & $\left(\% r_{1}, r_{0}\right) r \cdot$ & $(\% 01,07) r r$ & أققل من · r عاماً \\
\hline$(\% r r, q \wedge) r V$ & $(\%, 7 r) 1$ & $(\% r r, \tau) r \wedge$ & $(\% \Delta r, \wedge) \wedge \bullet$ & من · r إلى أقل من هب عاما \\
\hline$(\%, r \leq, r q) Y$. & $(\%, r Y)^{\top}$ & $(\%, r \leq, r q) Y$. & $(\% \leqslant r, q) r q$ & من ه r إلى أقل من ه ؛ عاما \\
\hline$(\% \bullet V, 1 \leq) r \varepsilon$ & $(\% \varepsilon, \vee\urcorner) r$ & $(\%, 1 \varepsilon)^{\mu}$ & $(\% r \cdot, 90) 1 r$ & من ه ؛ إلى أقلّل من • ، عاماً \\
\hline$(\% \vee \neg, r Y) r q$ & $(\%, \wedge q)^{r}$ & --.--- & $(\% 10, \vee 9)^{7}$ & ، 7 عاما فأكثر \\
\hline
\end{tabular}

- الفئة العمرية وتفضيل إضافة الجبن بمختلف أنواعه

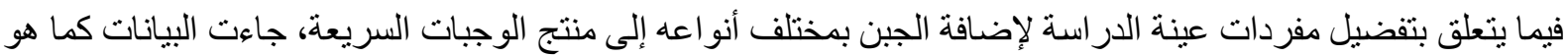

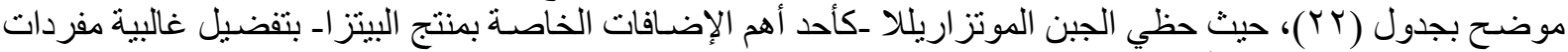

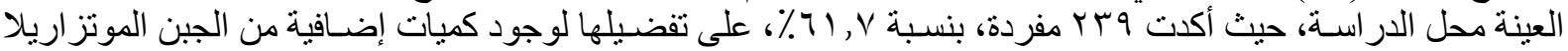

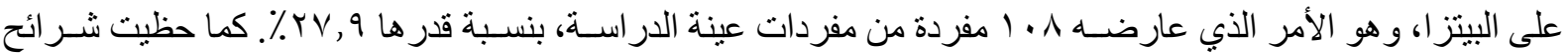

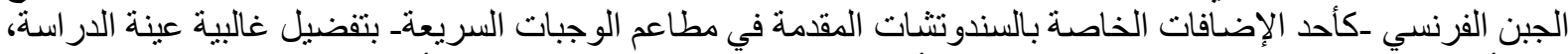

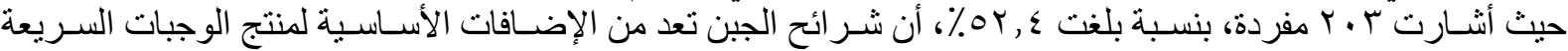

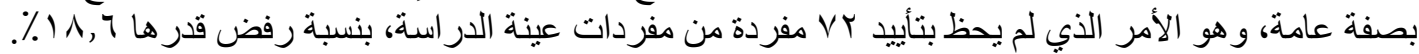
جدول (Y Y ) تفضيل عينة الاراسة للجبن كأحد الإضافات الخاصة بمنتج الوجبات السريعة.

\begin{tabular}{|c|c|c|c|c|}
\hline الانحراف المعياري & الوسط الحسابي & $\%$ & ك & عند تناول البيتزا، أفضل إضافة كميات إضافية من الجبن الموتزاريلا \\
\hline \multirow{6}{*}{1, rVo } & \multirow{6}{*}{$r, 07$} & $r r, \Lambda$ & IrV & أوافق بشدة \\
\hline & & $r \wedge, q$ & $11 \mathrm{r}$ & 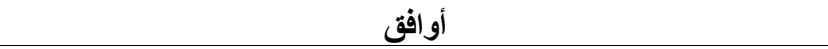 \\
\hline & & $1 \cdot r$ & $\varepsilon$. & لا أوافق ولا أعترض \\
\hline & & IV,r & $7 \mathrm{~V}$ & 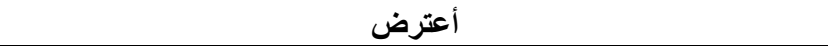 \\
\hline & & $1 \cdot, 7$ & \& & أعترض بشدة أعتد \\
\hline & & $1 \cdots$ & $r \wedge v$ & الإجمالي \\
\hline الانحراف المعياري & الوسط الحسابي & $\%$ & ك5 & أعتقد أن شرائح الجبن تعد من الإضافات الأساسية لمنتج الوجبات السريعة \\
\hline \multirow{6}{*}{$1,1 \times \wedge$} & \multirow{6}{*}{$\boldsymbol{r}, 0$} & 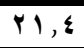 & $\Lambda r$ & أوافق بشدة \\
\hline & & $r_{1}$ & ir. & أوافق \\
\hline & & $r \wedge, q$ & $11 r$ & لا أوافق ولا أعترض \\
\hline & & $I T, Y$ & 01 & أعترض \\
\hline & & $0, \varepsilon$ & YI & أعترض بشدة \\
\hline & & $1 \ldots$ & $r \wedge v$ & الإجمالي \\
\hline
\end{tabular}

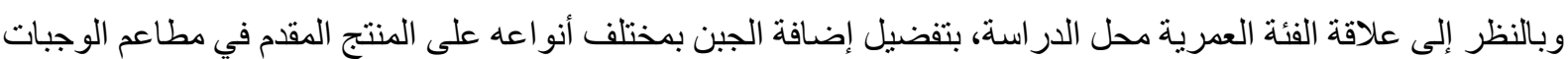

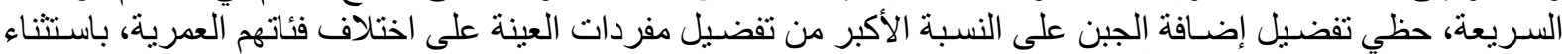

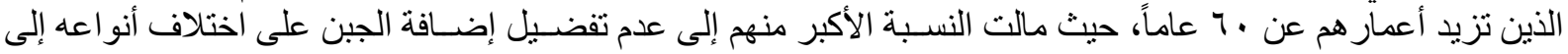

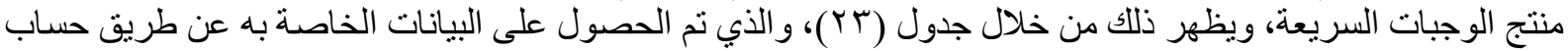
الوسيط للإستجابات الخاصة بمفردات العينة

جدول (Tr) علاقة الفئة العمرية لعينة الدراسة بتفضيل الجبن بمختلف أنواعه على منتج الوجبات السريعة.

\begin{tabular}{|c|c|c|c|}
\hline \multicolumn{3}{|c|}{ تفضيل إضافة الجبن بمختلف أنواعه } & \multirow[b]{2}{*}{ الفئة العمرية } \\
\hline 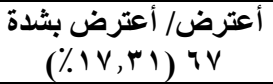 & 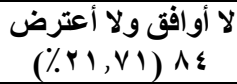 & 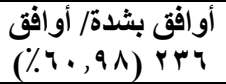 & \\
\hline$(\% 10,7 \%) 1$. & $(\% 1 \cdot, 9 \varepsilon) \vee$ & $(\% V r, \varepsilon \varepsilon) \leq V$ & أقلّ من · r عاماً \\
\hline$(\%, q, r r) 10$ & $(\%, r \varepsilon, Y r) r q$ & $(\% 74, \leqslant 7) 1 \cdot V$ & من · r إلى أقل من هr عامـا \\
\hline$(\% 19,01) 17$ & $(\% 1 V, \cdot v) 1 \leq$ & $(\% \pi r, \leqslant 1) \bullet r$ & من ه ب إلى أقل من ه ؛ عامـا \\
\hline$(\% 11,9)^{\circ}$ & $(\% \times 7,19) 11$ & $(\% 71,9) \times q$ & من ه ؛ إلى أقل من • ، عاماً \\
\hline$(\% \Delta 0, Y \bar{Y}) Y_{1}$ & $(\% r \varepsilon, Y I) \backslash r$ & $(\% 1 \cdot, 0 r) \leq$ & . 7 عامـا فأكثر \\
\hline
\end{tabular}

V - ا ـ - الفئة العمرية وتفضيل المصاحبات الخاصة بمنتج الوجبات السريعة 
- الفئة العمرية وتفضيل تناول المشروبات الغازية بمصاحبة منتج الوجبات السريعة

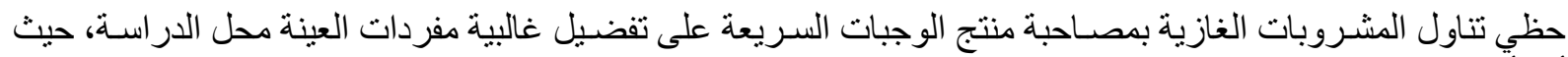

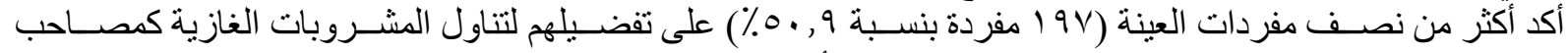

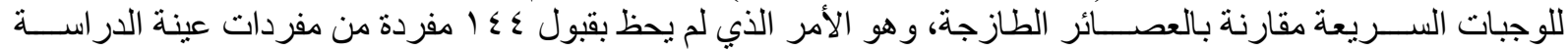

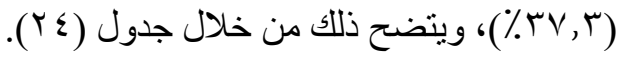

جدول ( \& Y) تفضيل تناول المشرويات الغازية بمصاحبة منتج الوجبات السريعة.

\begin{tabular}{|c|c|c|c|c|}
\hline المعياري & الحسابي & $\%$ & 5 & 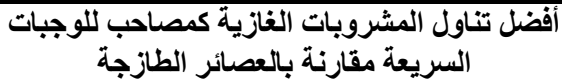 \\
\hline \multirow{6}{*}{1,079} & \multirow{6}{*}{ r, Y I } & $r \cdot, v$ & 119 & أوافت بشدة \\
\hline & & $r \cdot, r$ & $\vee \wedge$ & أوافق \\
\hline & & 11,9 & $\varepsilon 7$ & لا أوافق ولا أعترض \\
\hline & & $1 \leqslant$ & $0 \leqslant$ & أعترض \\
\hline & & $r r, r$ & 9. & أعترض بثدة \\
\hline & & $1 \ldots$ & $r \wedge V$ & الإجمالي \\
\hline
\end{tabular}

- الفئة العمرية وتفضيل تناول البطاطس المقلية بمصاحبة منتج الوجبات السريعة

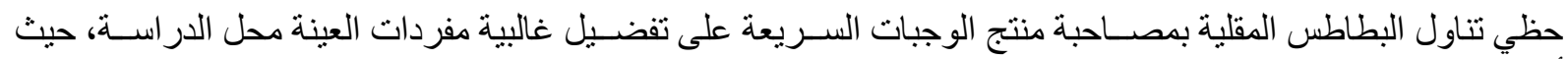

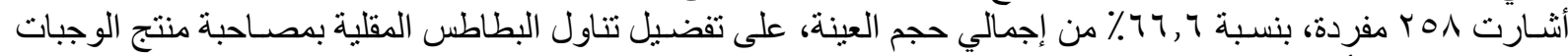

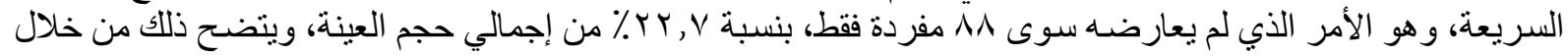

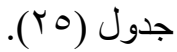

جدول (Y Y ) تفضيل تناول البطاطس المقلية بمصاحبة منتج الوجبات السريعة.

\begin{tabular}{|c|c|c|c|c|}
\hline الانحراف المعياري & الوسط الحسابي & $\%$ & ك5 & أفضل تناول البطاطس المقلية كمصاحب للوجبات السريعة \\
\hline \multirow{6}{*}{$1, \leqslant \Psi$} & \multirow{6}{*}{$r, 74$} & $r v, v$ & $1 \leq 7$ & أوافق بشدة \\
\hline & & $r \wedge, q$ & $11 Y$ & 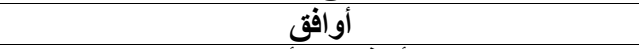 \\
\hline & & $1 \cdot, 7$ & $\leqslant 1$ & لا أوافق ولا أعترض \\
\hline & & $\mathrm{V}, \boldsymbol{0}$ & rq & أعترض \\
\hline & & $10, Y$ & 09 & 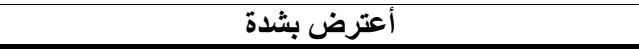 \\
\hline & & $1 \cdots$ & $r \wedge V$ & الإجمالي \\
\hline
\end{tabular}

- الفئة العمرية وتفضيل تناول السلاطات بمصاحبة منتج الوجبات السريعة

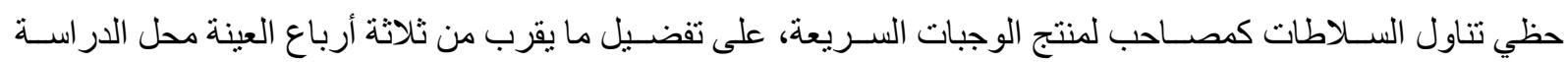

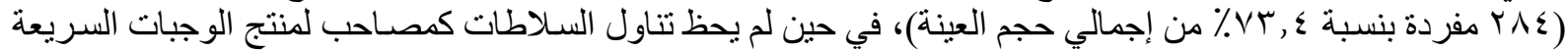

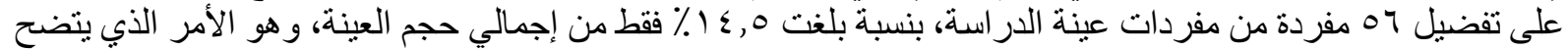

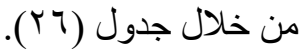

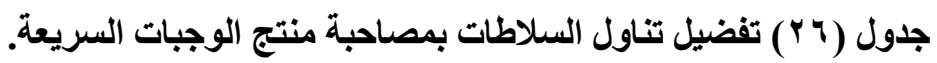

\begin{tabular}{|c|c|c|c|c|}
\hline الانحراف المعياري & الوسط الحسابي & $\%$ & ك & أفضل تناول السلاطات عند تناول منتج الوجبات السريعة \\
\hline \multirow{6}{*}{$1, Y \cdot T$} & \multirow{6}{*}{ r, qV } & $\varepsilon \leqslant, Y$ & $1 V 1$ & أوافق بشدة \\
\hline & & Yq, r & $11 \%$ & أوافق \\
\hline & & $\mid r, 1$ & $\varepsilon V$ & لا أوافق ولا أعترض \\
\hline & & $\Lambda, r$ & rr & 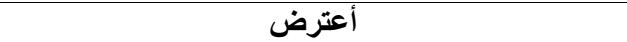 \\
\hline & & $7, Y$ & Y $\varepsilon$ & 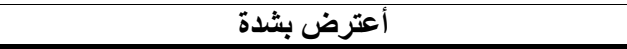 \\
\hline & & $1 \cdots$ & rᄉV & الإجمالي \\
\hline
\end{tabular}

- الفئة العمرية وتفضيل تناول المخلات بمصاحبة مع منتج الوجبات السريعة

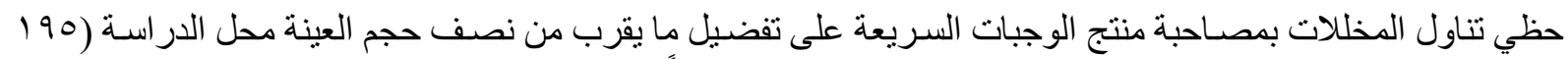

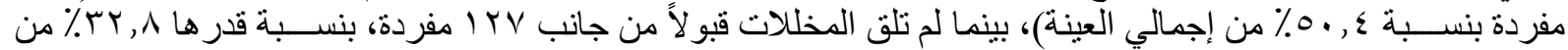

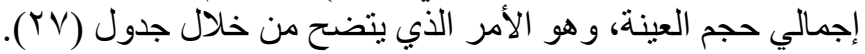
جدول (rV) تفضيل تناول المخلات بمصاحبة مع منتج الوجبات السريعة. 


\begin{tabular}{|c|c|c|c|c|}
\hline الانحراف المعياري & الوسط الحسابي & $\%$ & ك & أفضل تناول المخلات عند تناول منتج الوجبات السريعة \\
\hline \multirow{6}{*}{$1, r q \cdot$} & \multirow{6}{*}{$r, r_{1}$} & $r \cdot, V$ & $\Lambda$. & أوافق بشدة \\
\hline & & rq, V & 110 & أوافق \\
\hline & & 17,1 & 70 & لا أوافق ولا أعترض \\
\hline & & 10,0 & 7. & أعترض أعت \\
\hline & & IV,r & $7 \mathrm{~V}$ & أعترض بشدة \\
\hline & & $1 \cdots$ & r^V & الإجمالي \\
\hline
\end{tabular}

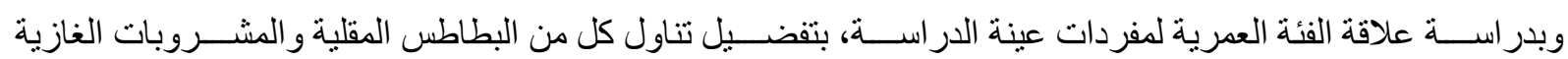

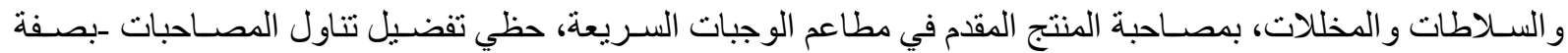

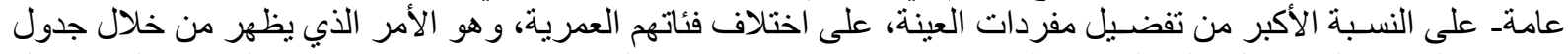

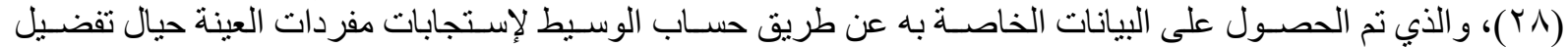
مختلف أنواع المصاحبات محل الدر استة الدان.

جدول (Y^) علاقة الفئة العمرية لعينة الاراسة بتفضيل تناول المصاحبات مع منتج الوجبات السريعة.

\begin{tabular}{|c|c|c|c|}
\hline \multicolumn{3}{|c|}{ تفضيل تناول المصاحبات } & \multirow[b]{2}{*}{ الفئة العمرية } \\
\hline 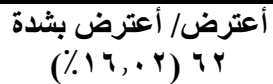 & 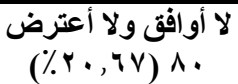 & 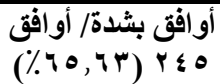 & \\
\hline$(\%, r, r \mid) \backslash r$ & $(\% 1 \varepsilon, .7)^{9}$ & $(\% \neg 0,7 r) \leq r$ & أققّل من · r عامـاً \\
\hline$(\% 1 \varepsilon, r q) r r$ & $(\% \wedge \wedge, 7 \mu)^{\mu}$ & $(\% \neg V, \cdot \Lambda) 1 \cdot \Lambda$ & 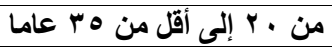 \\
\hline$(\% 1 \cdot, 9 \wedge)^{9}$ & $(\% r \checkmark, \wedge r) Y r$ & $(\% r r, r) \otimes 1$ & من ه T إلى أقل من ه ؛ عاما \\
\hline$(\% 17,7 \vee) \vee$ & $(\% r r, \wedge I) 1$. & $(\% \bullet q, \diamond r) r \diamond$ & من ه ؛ إلى أقّل من • צ عاماً \\
\hline$(\%, Y, r Y) 1$. & $(\% \curlyvee r, \neg \wedge)^{q}$ & $(\% 0 \cdot) 19$ & 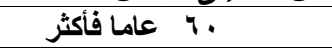 \\
\hline
\end{tabular}

لع_- - الفئة العمرية وتفضيل أساليب الخدمة المتبعة في مطاعم الوجبات السريعة

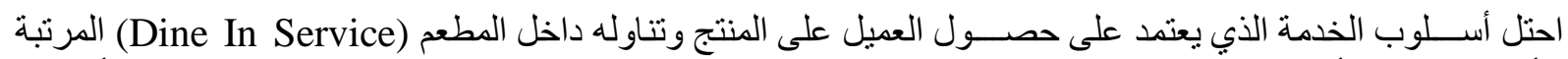

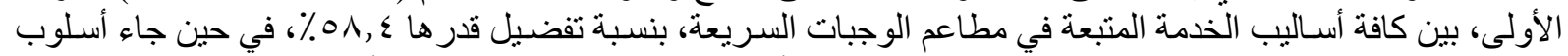

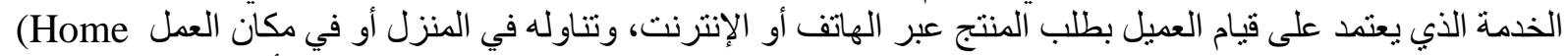
Delivery Service)

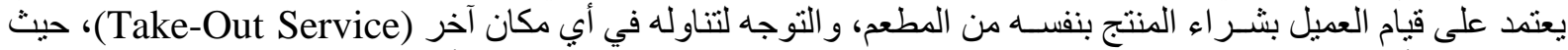

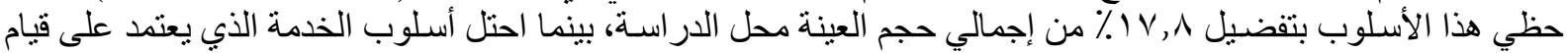

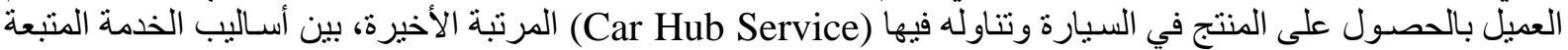

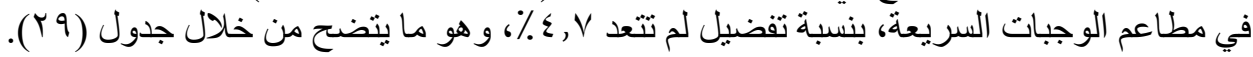

جدول (9 ץ ) تفضيل أساليب الخدمة المتبعة في مطاعم الوجبات السريعة.

\begin{tabular}{|c|c|c|c|c|}
\hline الانحر اف المعياري & الوسط الحسابي & $\%$ & ك & عند تناول منتج الوجبات السريعة أفضل \\
\hline \multirow{5}{*}{$1, Y Y_{1}$} & \multirow{5}{*}{1,97} & $0 \wedge, \xi$ & rry & الحصول على المنتج وتناوله داخل المطعم \\
\hline & & $\varepsilon, V$ & 11 & الحصول على المنتج في السيارة وتناوله فيها \\
\hline & & 19,1 & $V \varepsilon$ & طلب المنتج عبر الهاتف أو الإنترنت وتتاوله في المنزل أو في \\
\hline & & $i v, \Lambda$ & 99 & شراء المنتج من المطعم وتتاوله في أي مكان آخر \\
\hline & & $1 \cdots$ & $r \wedge V$ & الإجمالي \\
\hline
\end{tabular}

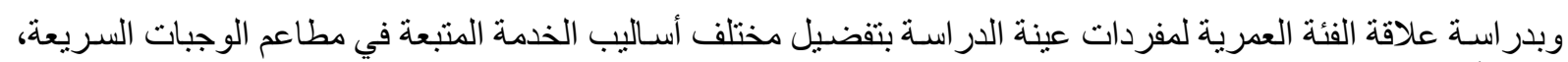

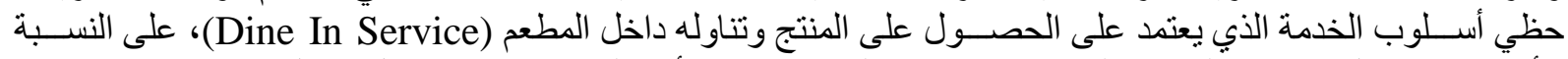

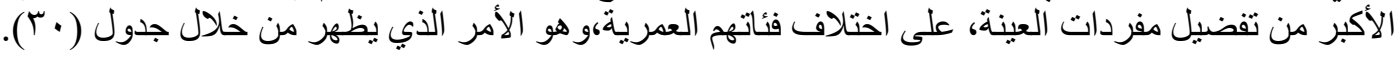


جدول ( • (r) علاقة الفئة العمرية لعينة الدراسة بتفضيل أساليب الخدمة المتبعة في مطاعم الوجبات السريعة.

\begin{tabular}{|c|c|c|c|c|}
\hline \multicolumn{4}{|c|}{ تفضيل أساليب الخدمة المتبعة في مطاعم الوجبات السريعة } & \multirow[b]{2}{*}{ الفئة العمرية } \\
\hline 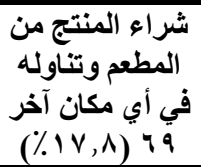 & 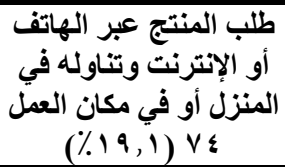 & المنتج في السيارة فئل & 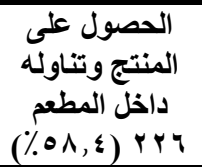 & \\
\hline$(\% 10,7 \pi) 1$ & $(\% \wedge \Lambda, \vee \theta) \backslash r$ & $(\%, 1 r) r$ & $(\% \neg r, 0) \leqslant \cdot$ & أقلّ من • r عامـاً \\
\hline$(\% 10,0 r) Y 0$ & $(\%, 1,1 Y) r \varepsilon$ & $(\%, 0,09)^{9}$ & $(\% \bullet V, V 7) 9 r$ & من · r إلى أقل من هب عاما \\
\hline$(\% r r, 1 V) 19$ & $(\% 1 \leq, 7 r) \backslash r$ & $(\% 1, Y Y) 1$ & $(\% 9 \cdot, 9 \wedge) \bullet$ & من هب إلى أقل من ه ؛ عاما \\
\hline$(\% 19, .0)^{\wedge}$ & $(\% r \cdot, 90) 1 r$ & ------ & $(\% \cdot 0 \cdot)$ & من 0 ؛ إلى أقلّ من · \\
\hline$(\% \backslash \wedge, \varepsilon Y) \vee$ & $(\%, \wedge ৭)^{r}$ & $(\% 10, \vee 9)^{7}$ & $(\% \bullet V, \wedge q) Y r$ & 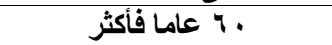 \\
\hline
\end{tabular}

_- Y_V

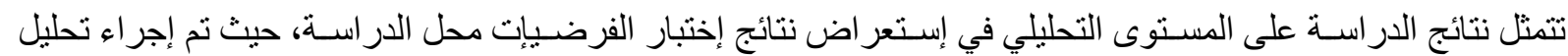

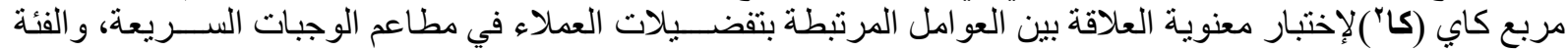

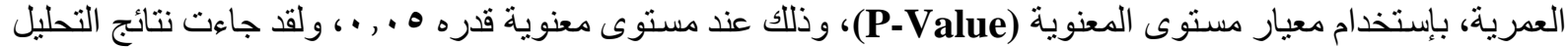

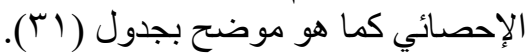

جدول ( آr) العلاقة بين الفئة العمرية وتفضيلات العملاء في مطاعم الوجبات السريعة بالإسكندرية.

\begin{tabular}{|c|c|c|c|c|}
\hline المعنوية مستوى & الحرية & 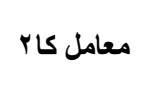 & \multicolumn{2}{|c|}{ العوامل المرتبطة بتفضيلات العملاء في مطاعم الوجبات السريعة } \\
\hline$\cdot, 19$ & r. & ro, 1rq & الخاصية الحسية الأكثر حفزاً & \multirow{4}{*}{ | ـ الخصائص الحسية } \\
\hline$\cdot, \cdots$ & $\wedge$ & $\Delta r, . \varepsilon \varepsilon$ & تفضيل المذاق & \\
\hline$\cdot, \cdots$ & $\wedge$ & VV, VY. & تفضيل القوام & \\
\hline$\cdot, \cdots$ & $\wedge$ & 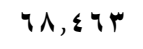 & 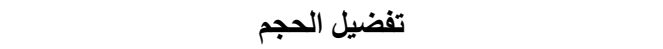 & \\
\hline$\cdot, \cdots$ & ir & $\bullet \leq, M \bullet V$ & أسلوب تكوين العميل للوجبة & 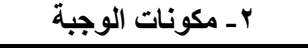 \\
\hline$\cdot, \cdot \varepsilon$ & $\wedge$ & $Y Y, \leqslant 1 \leqslant$ & تفضيل السندوتشات & \\
\hline$\cdot, \cdots$ & 17 & $\neg \vee, \vee ฯ 1$ & تفضيل البيتزا & rـ نوعية منتجات ومطاعم \\
\hline$\cdot, \cdot r$ & 17 & $r v, v \circ r$ & تفضيل مطاعم الوجبات السريعة وفقاً لتصنيفها & \\
\hline$\cdot, \cdots$ & 17 & $1 \leqslant Y, \Lambda 10$ & تفضيل طابع منتج الوجبات السريعة (غربي/ شرقي) & \\
\hline$\cdot, \cdots$ & ir & $\Lambda Y, r \vee \Lambda$ & تفضيل الكاتثب والمايونيز والمستردة & a \\
\hline$\cdot, \cdots$ & 17 & $1.9,971$ & تفضيل الجبن (الفرنسي والموتزاريلا) & 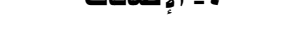 \\
\hline$\cdot$, & 17 & $\wedge 9, \wedge \leq 1$ & تفضيل المصاحبات (المشروبات الغازية/ البطاطس المقلية/ & هـ المصاحبات \\
\hline$\cdot, 11$ & ir & $r \leqslant, r \vee q$ & تفضيل أساليب الخدمة المتبعة في مطاعم الوجبات السريعة & جـ أسلوب الخدمة \\
\hline
\end{tabular}

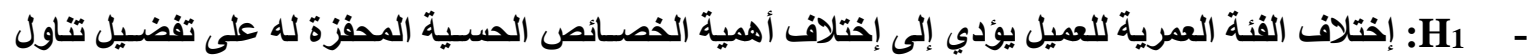
منتج الوجبات السريعة الفتلة

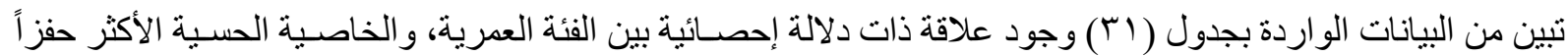

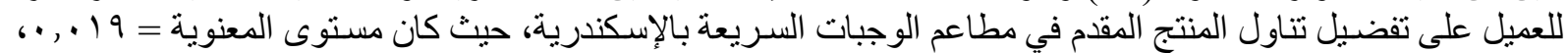

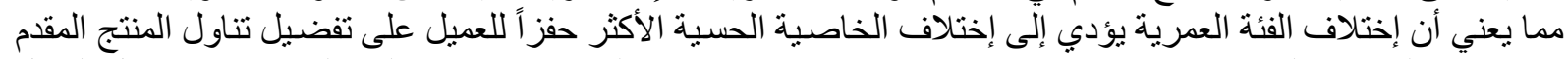

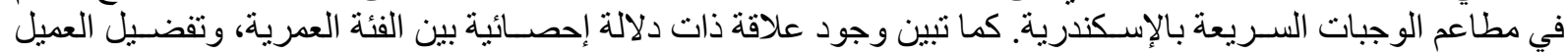

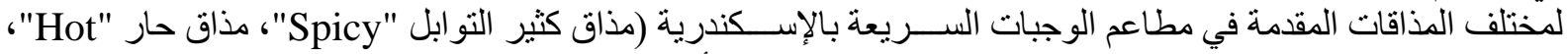

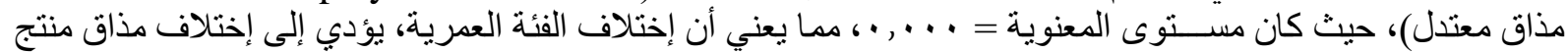
الوجبات السريعة الذي يفضله العميل.

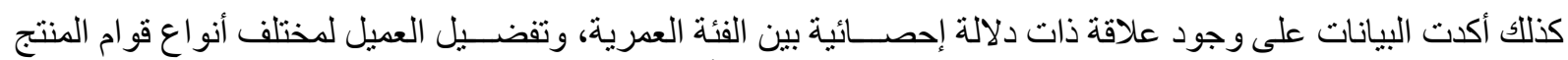

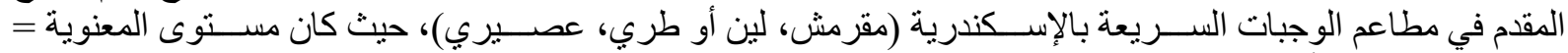

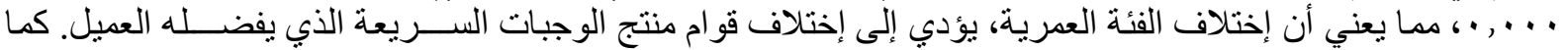

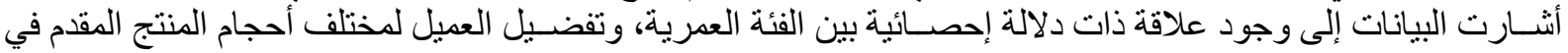




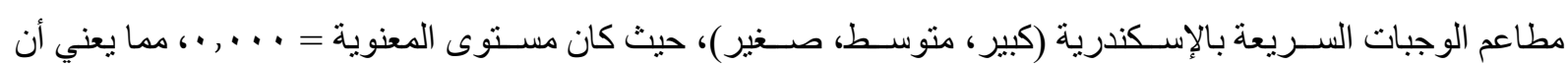
إختلاف الفئة العمرية، يؤدي إلى إختلاف حجم منتج الوجبات السريعة الذي يفضله العميل.

- - _H2: إختلاف الفئة العمرية للعميل يؤدي إلى إختلاف الأسلوب الذي يتبعه عند تكوين الوجبة التي يتناولها في

مطاعم الوجبات السريعة

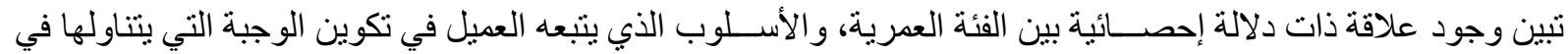

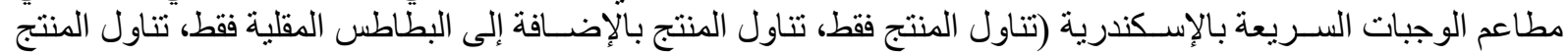

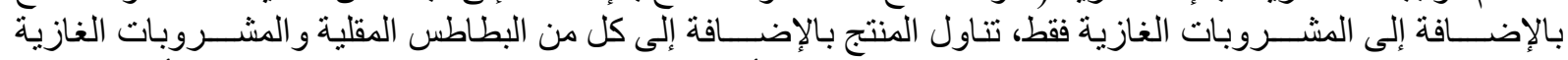

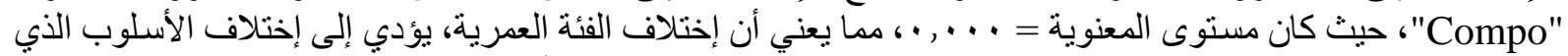

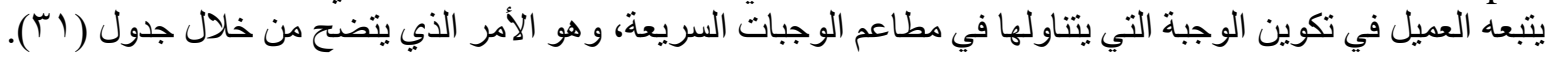

-

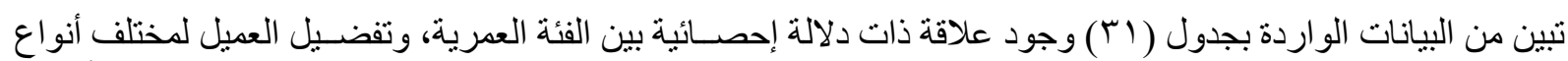

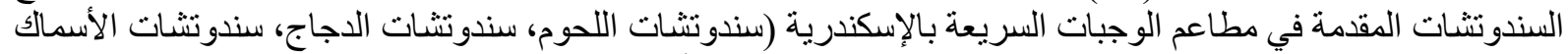

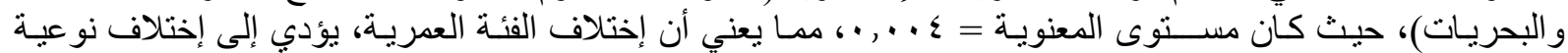

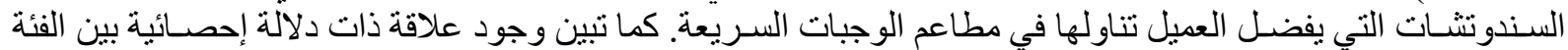

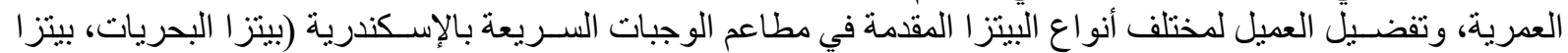

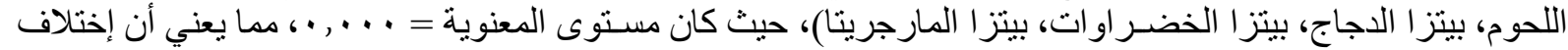

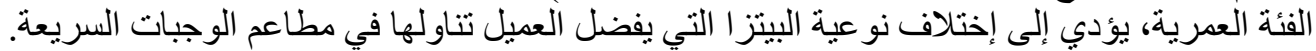

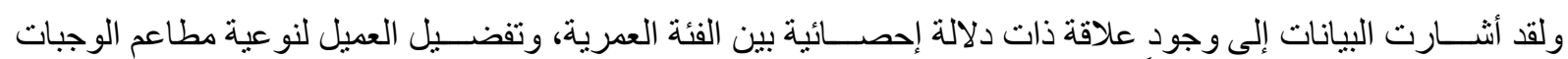

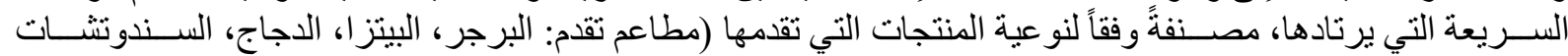

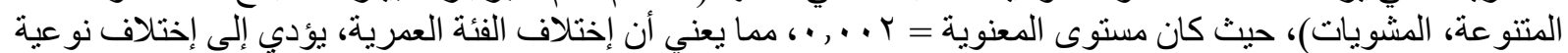

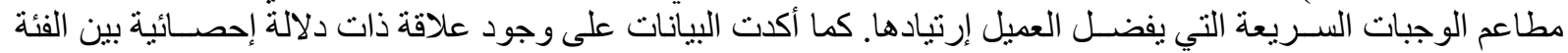

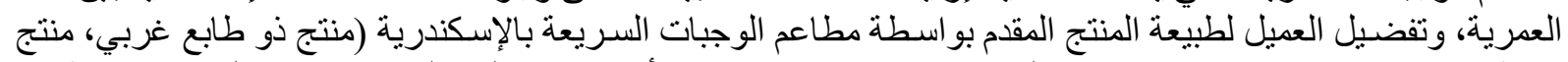

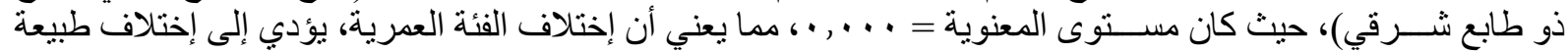
منتج الوجبات السريعة الذي يفضله العميل.

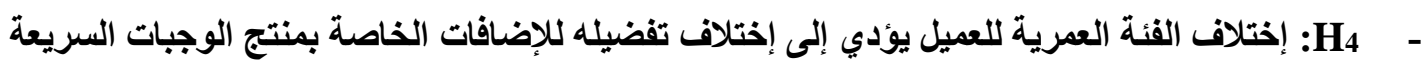

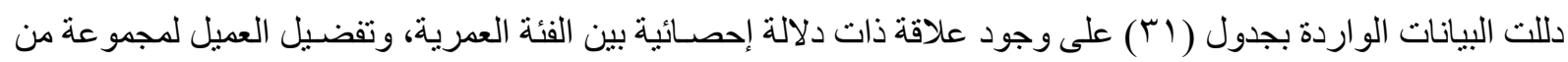

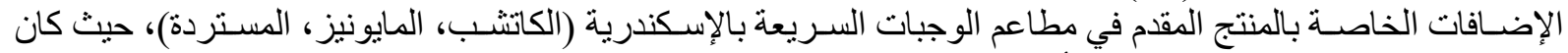

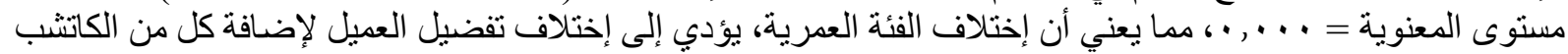

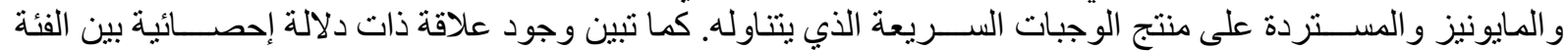

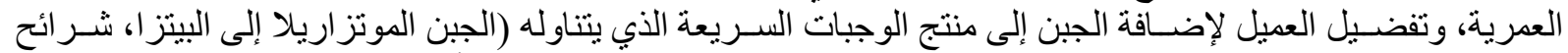

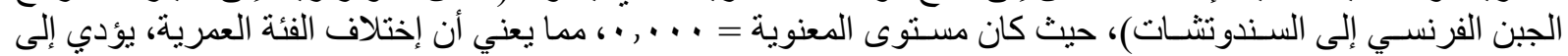

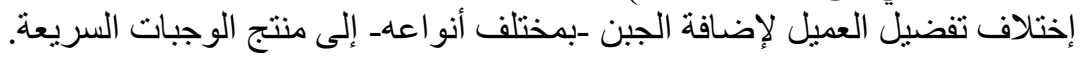

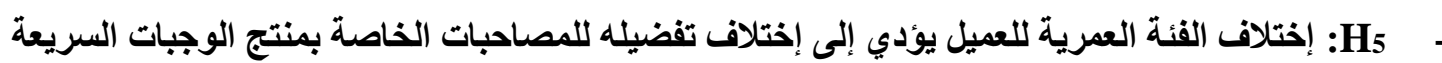

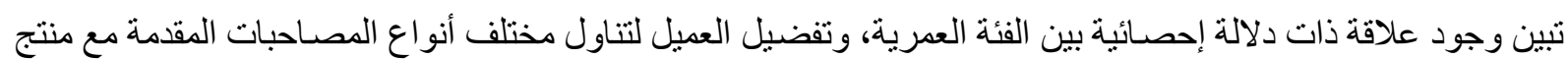

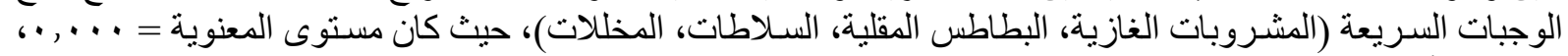

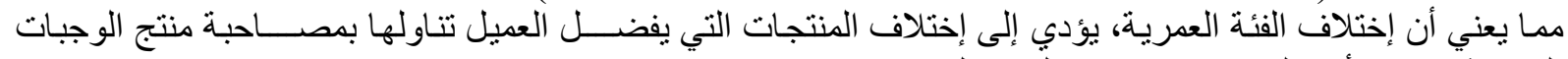

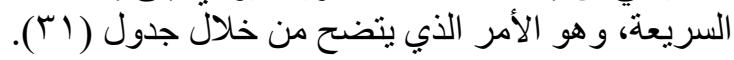

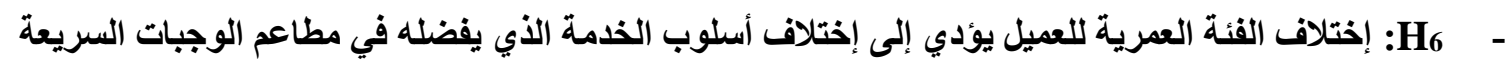

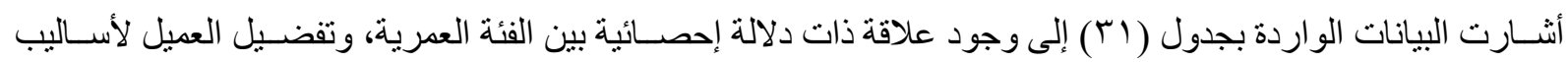

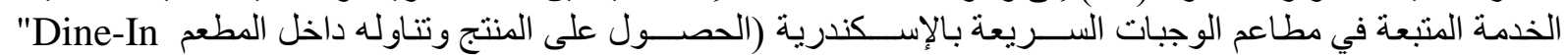

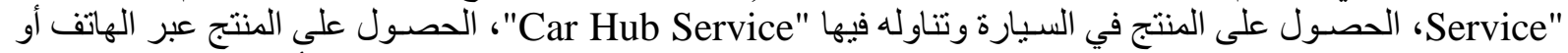

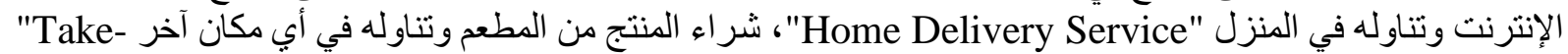
"Out Service" الخدمة الذي يفضله العميل، عند تناول منتج الوجبات السرئهة 


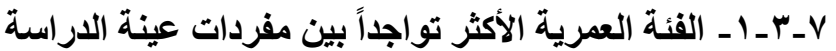

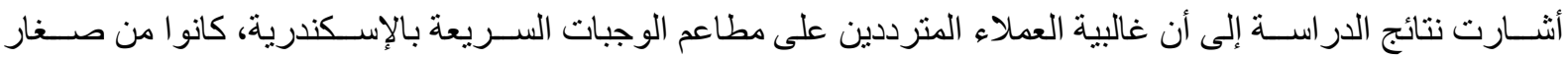

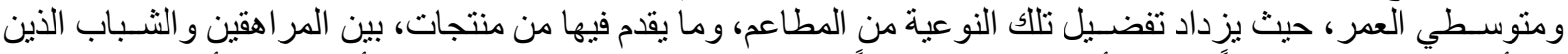

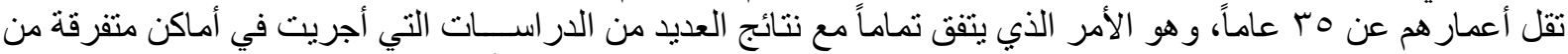

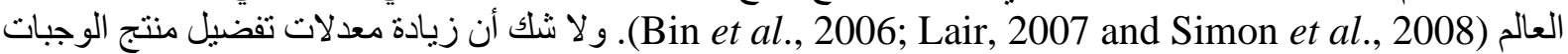

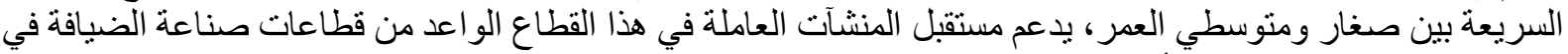

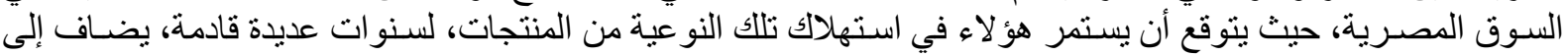

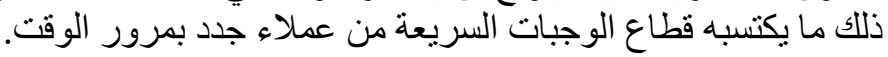

الخص_-r_V

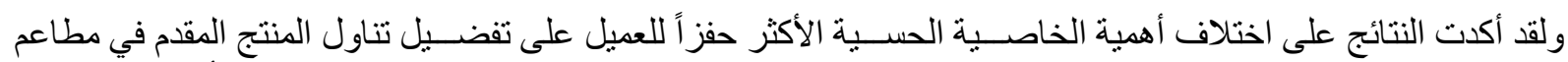

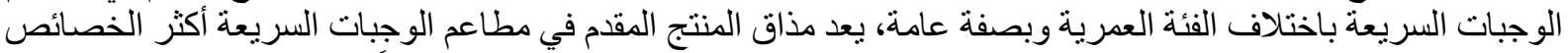

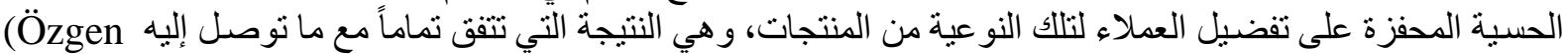
and ve Sanlier, 2002)

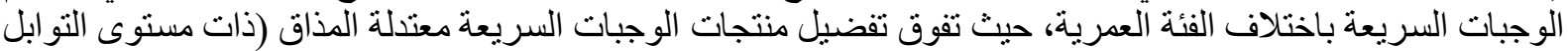

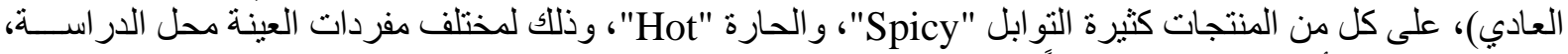

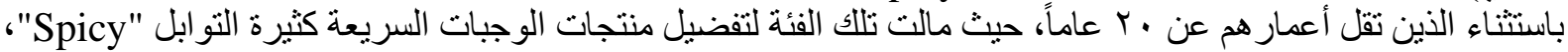

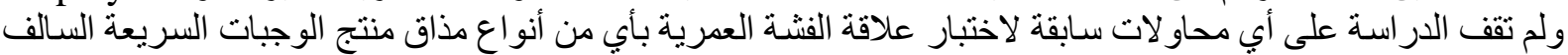

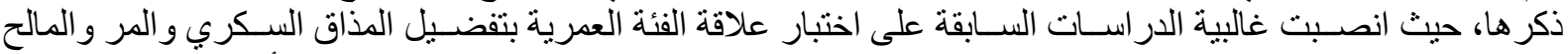

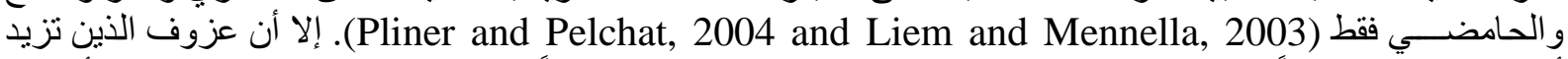

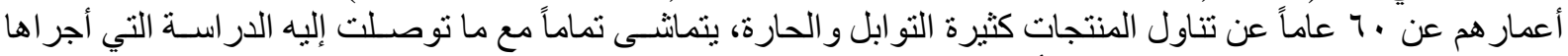

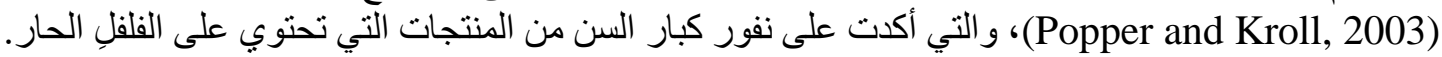

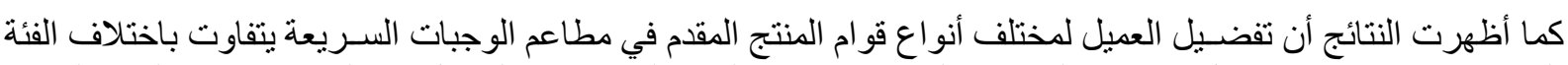

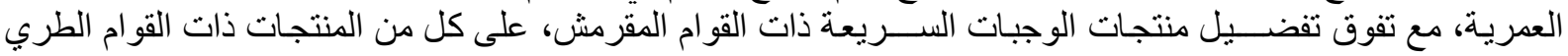

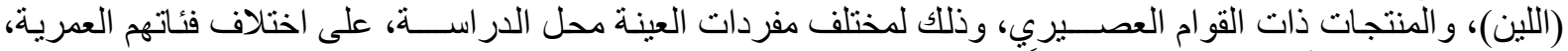

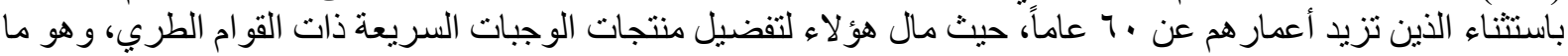
يتفق مع ما توصل إليه (Forde and Delahunty, 2002).

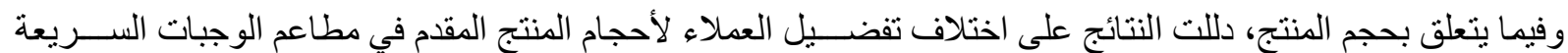

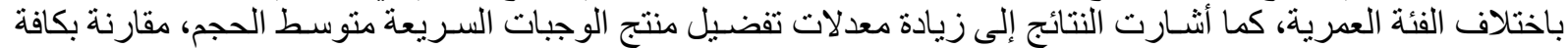

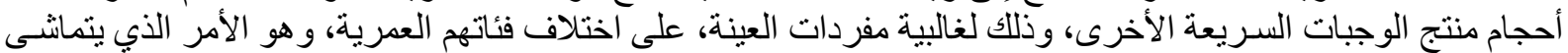

تماماً مع النتائج التي توصل التر إليها (Gomez-Ortigoza, 2006)

|r-r-V

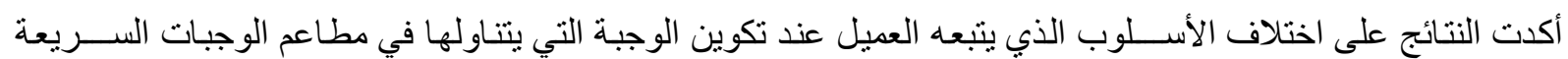

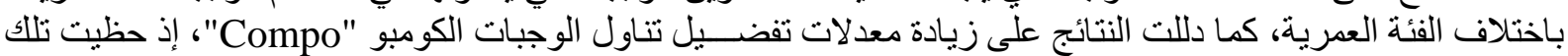

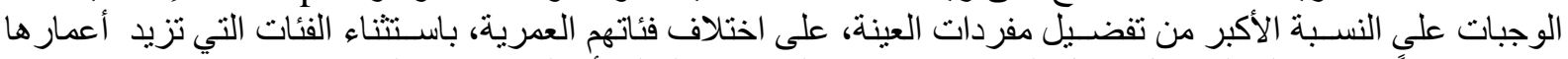

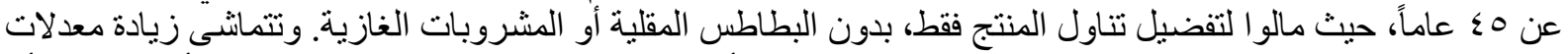

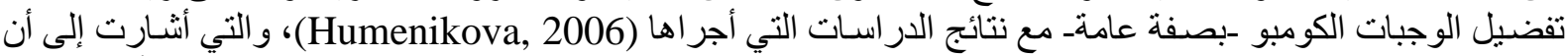

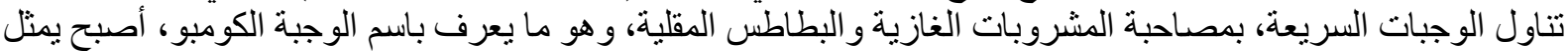

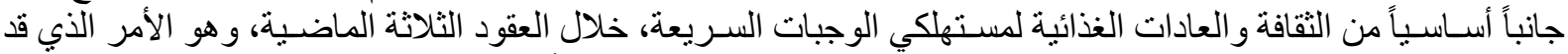

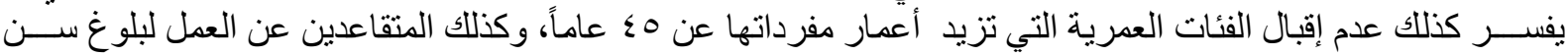
المعاش على تفضيل الوجبات الكومبو.

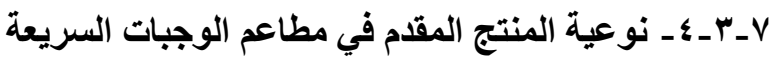

أكدت النتائج على اختلاف تفضيل العملاء لنو عية السندوتثـات المقدمة في مطاعم الوجبات السريعة باختلاف الفئة العمرية

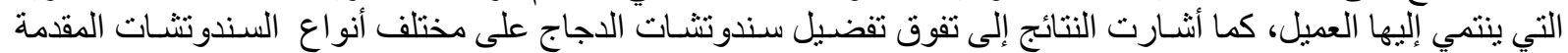

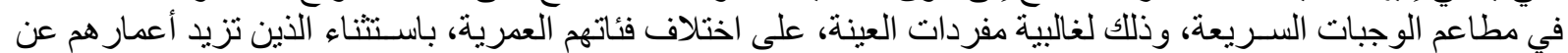

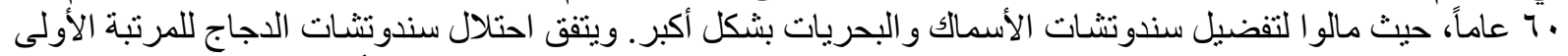

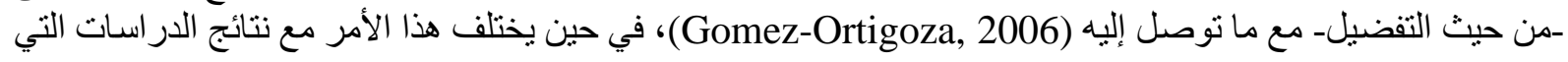




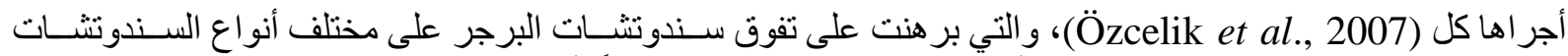

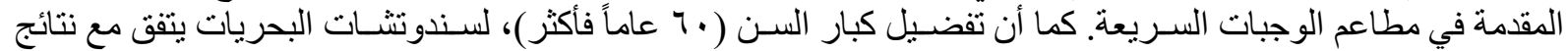

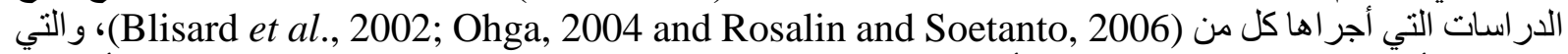
دللت على أن تقدم العمر يقترن بتفضــيل الأســاك و البحريات، مقارنة باللحوم و الاجاج، حيث ينظر كبار السـن للأسـماك

و البحريات على أنها منتجات غذائية صحية.

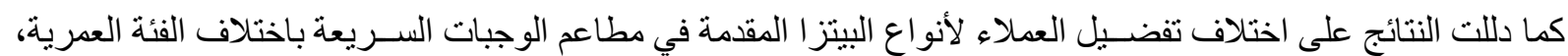

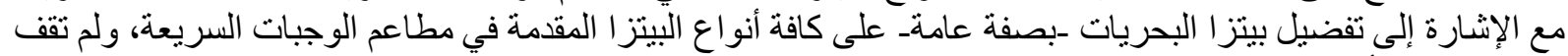

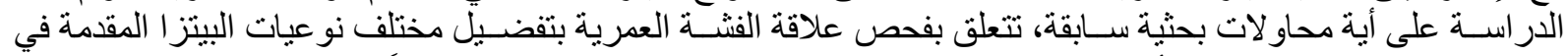

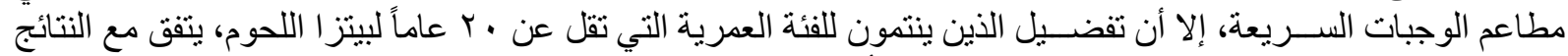

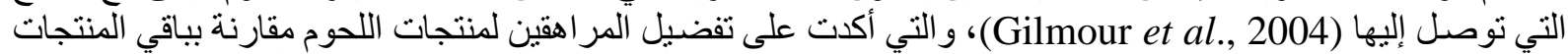

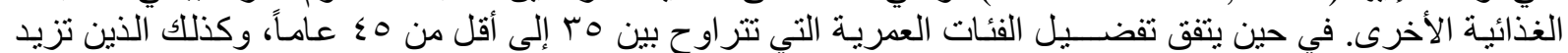

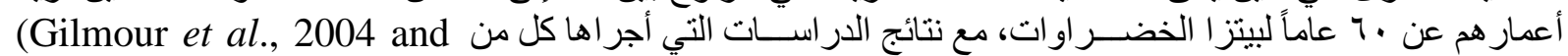

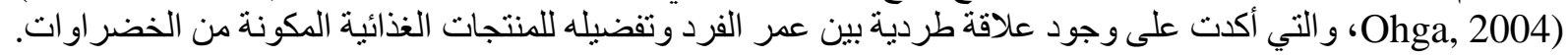

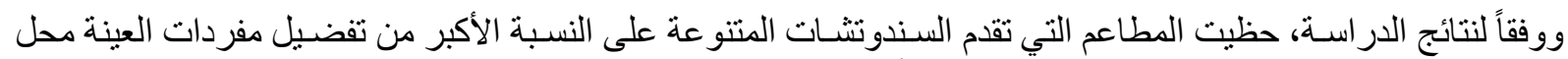

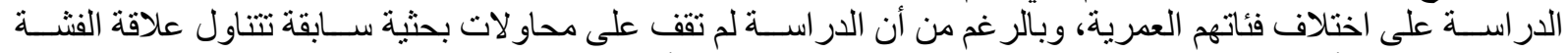

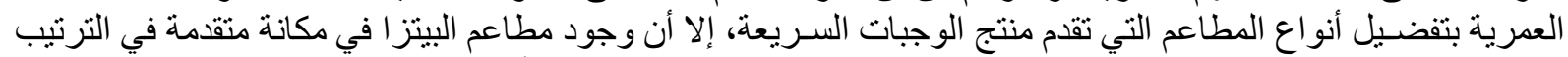

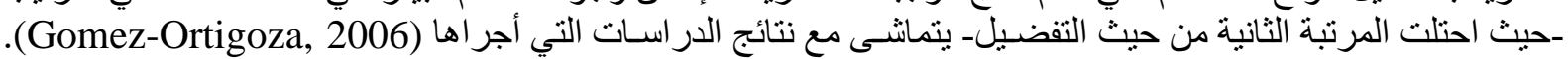

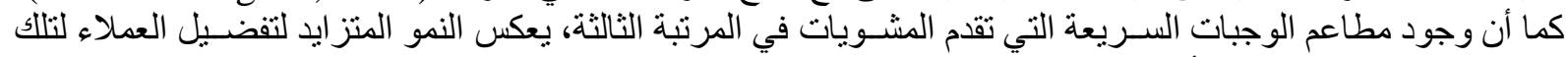

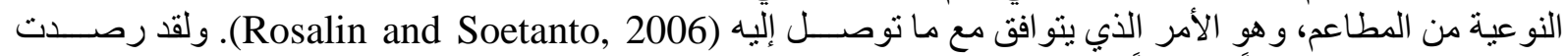

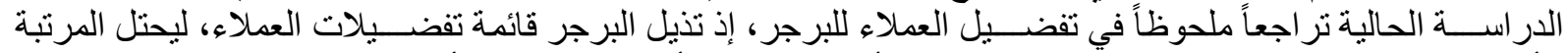

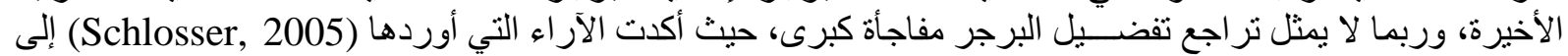

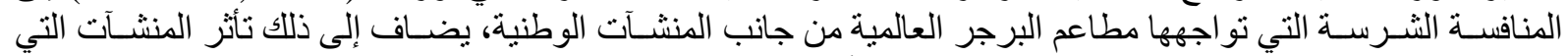

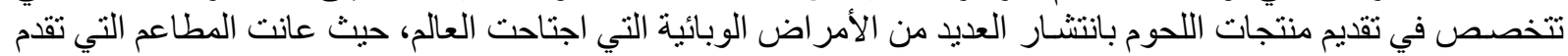

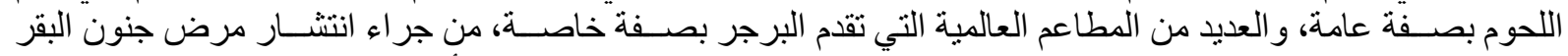

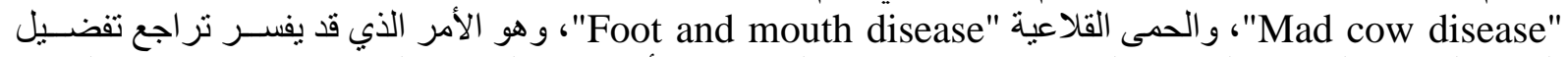

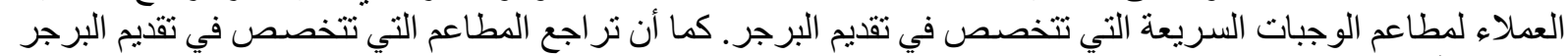

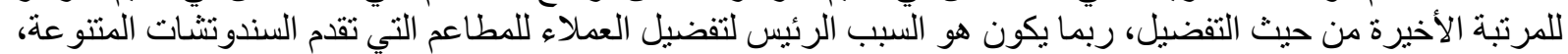
كبديل شديد الخصوصية بالسوق المصرية، حيث لا تحقق تلألك النوعية من المطاعم انتشار آ عالمياً ملحوظاً حتى الآن.

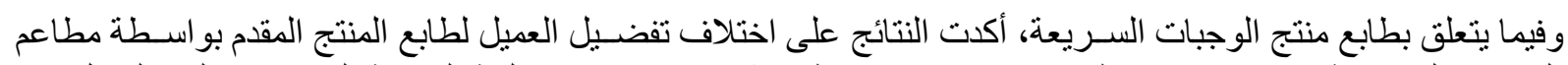

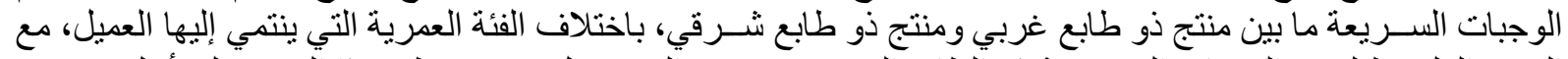

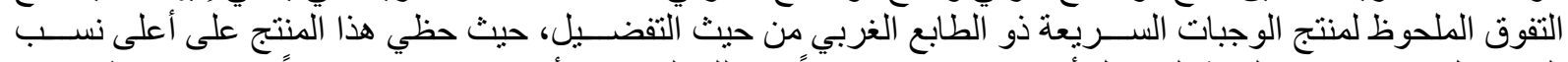

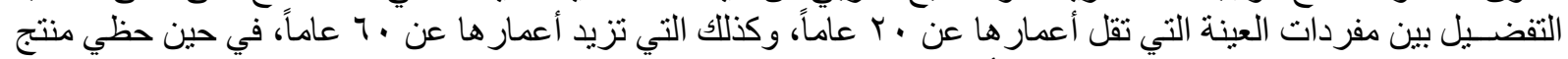

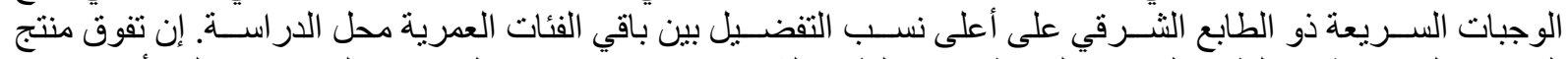

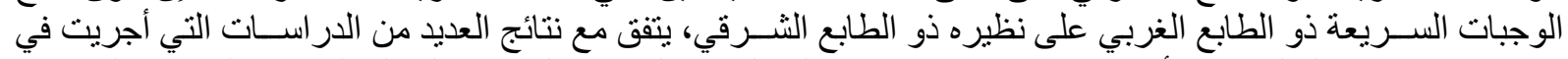

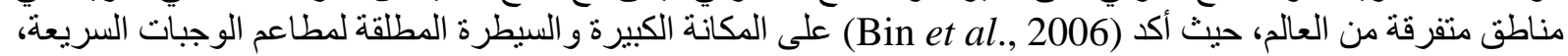

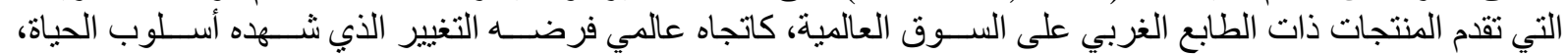

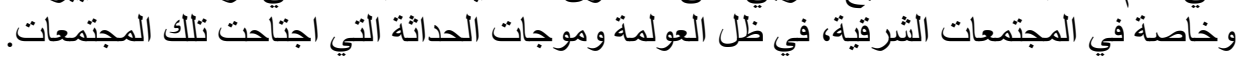

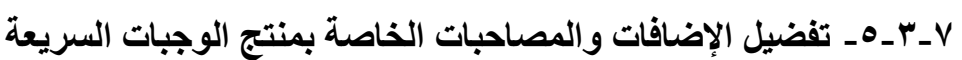

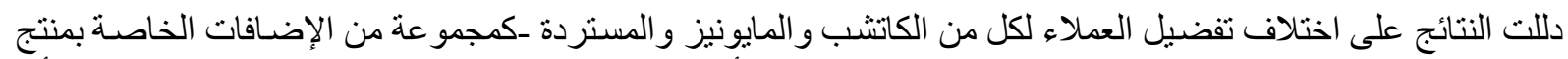

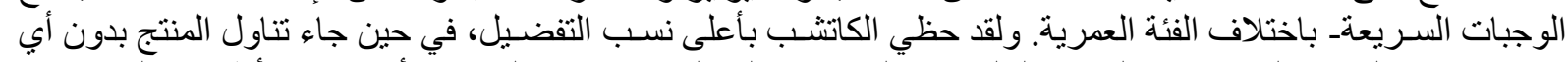

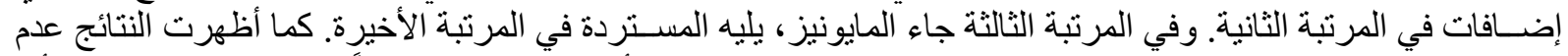

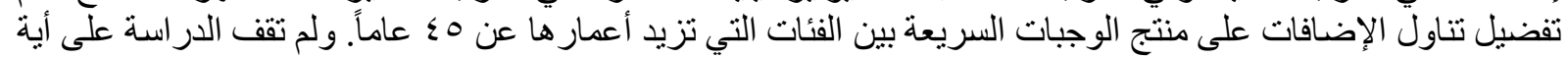

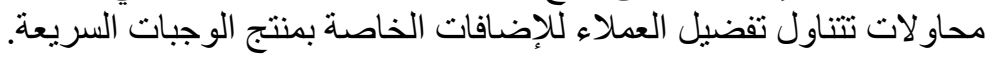

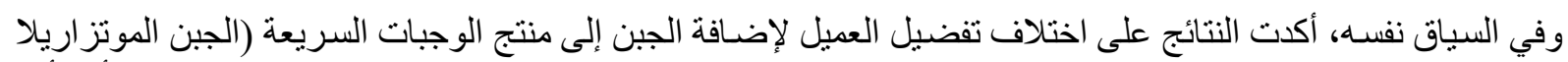

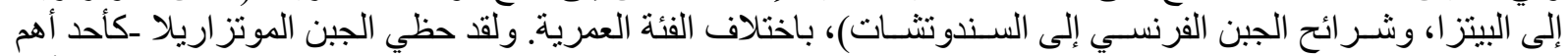

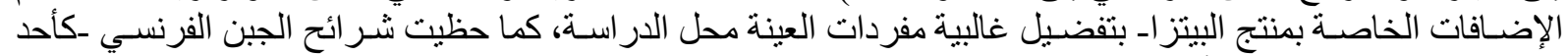

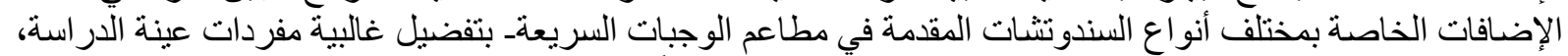

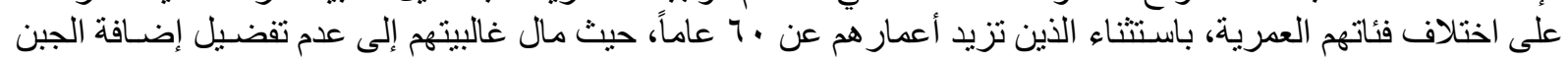




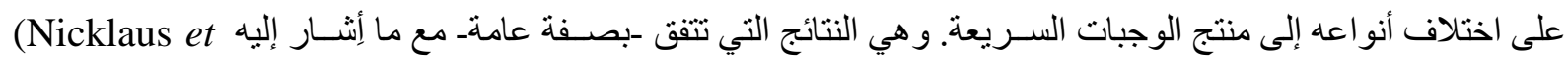
(al., 2004) من زيادة معدلات تفضيل تنتاول الجبن.

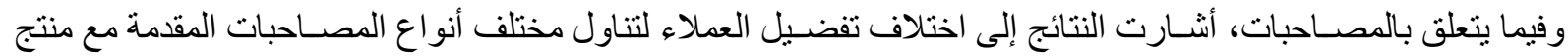

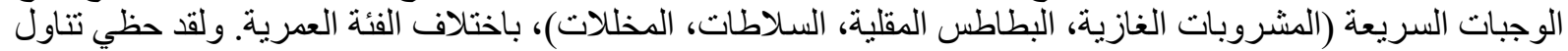

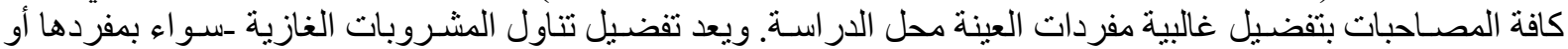

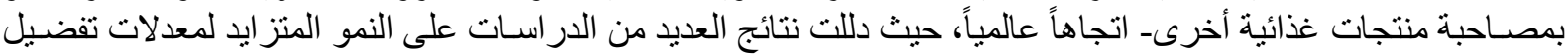

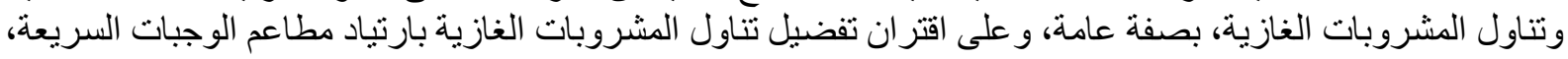

بصفة خاصة (Gomez-Ortigoza, 2006 and Humenikova, 2006)

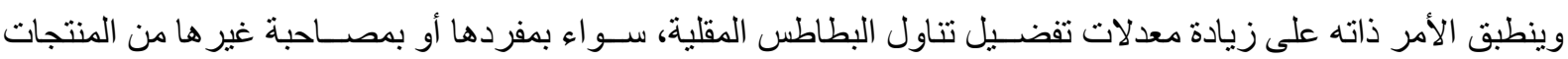

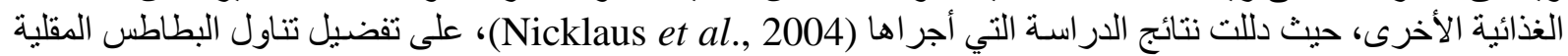

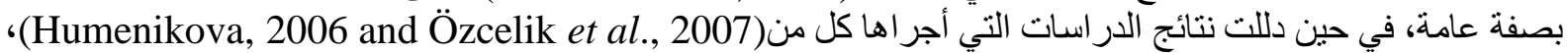
على افتران تفضيل تناول البطاطس المقلية بتفضيل تتاول منتج الوجبات السريعة.

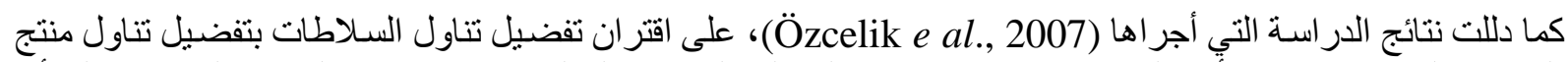

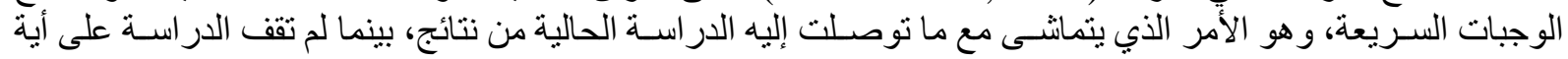

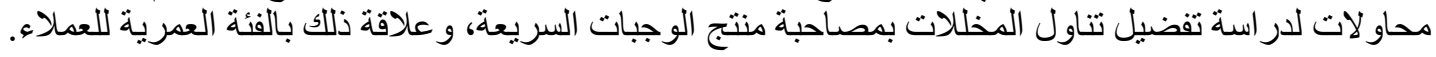

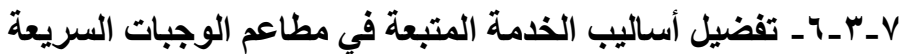

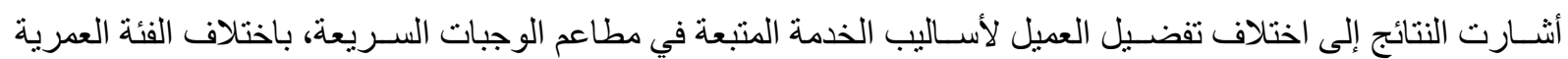

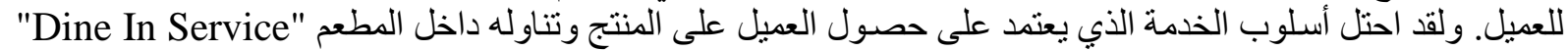

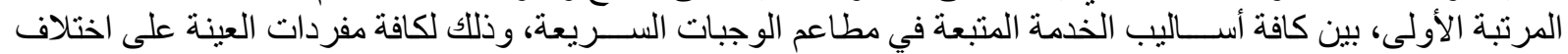

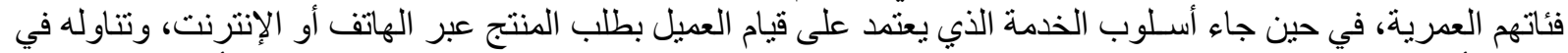

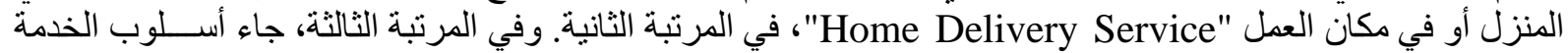

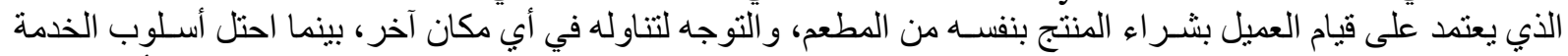

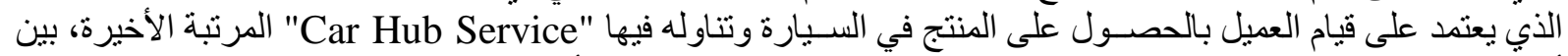

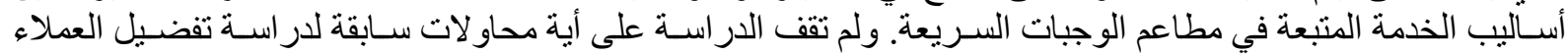
لمختلف أساليب الخذمة المتبعة في مطاعم الوجبات السريعة، و علاقة ذللك بالفئة العمرية.

^- حدود الاراسة وتوصياتها

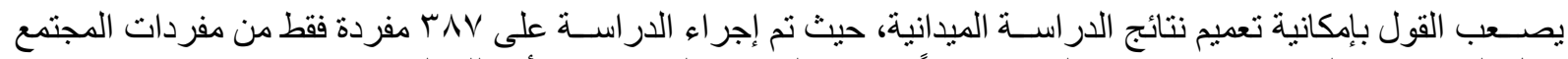

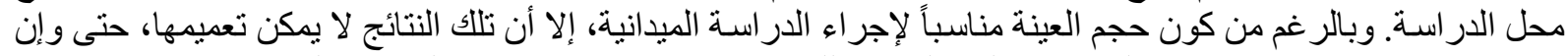

كانت تقدم مؤشر ات هامة وقوية على على علاقة الفئة العمرية للعملاء بتفضيلاتهم في مطاعم الوجبات الأنة السريعة بالإسكندرية.

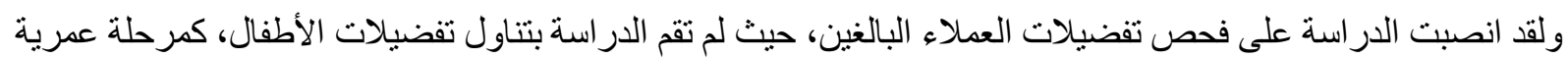

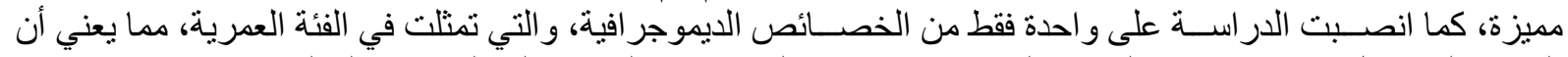

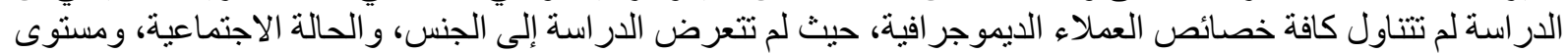

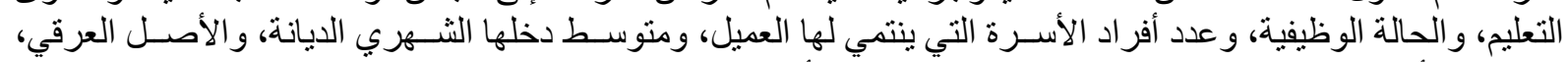

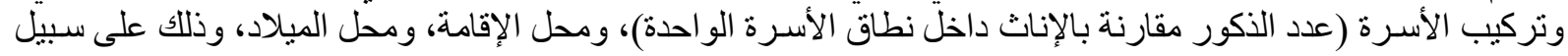

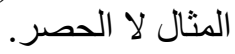

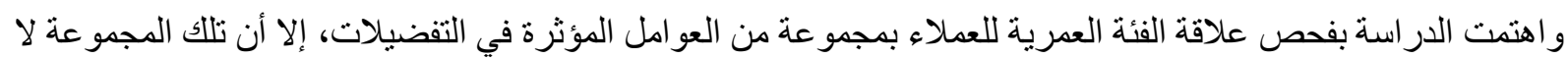

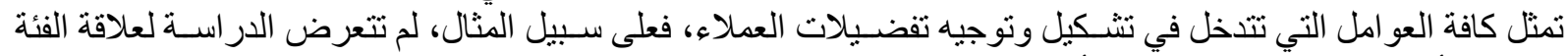

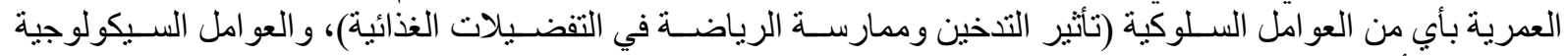

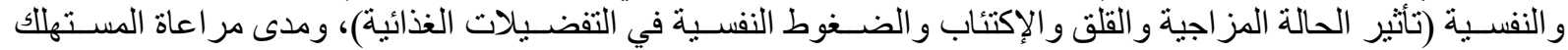

للاعتبار ات البيئية و الأخلاقية كعامل مؤثر في توجيه التفضيلات، وأسعار المنتجات، و البيئة الثقافية، وأسلوب حياة الفئل الفرد.

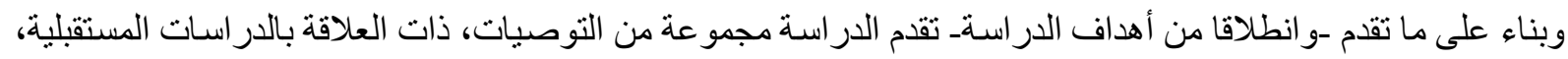

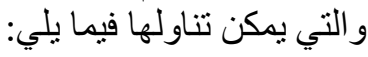

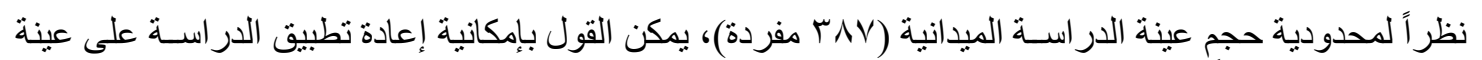

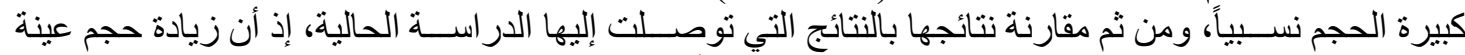

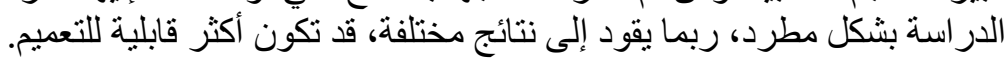


تقتر ح الدر اسة قيام الباحثين بفحص وتحليل تفضيلات الأطفال، المترددين على مطاعم الوجبات السريعة، إذ تنتأثر

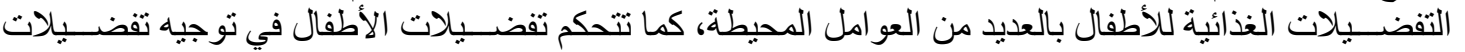

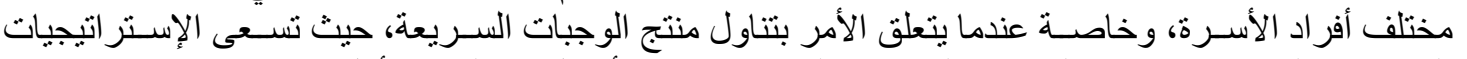

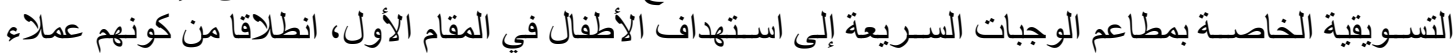

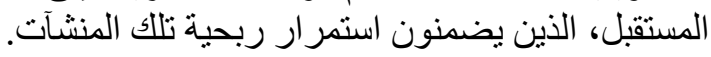

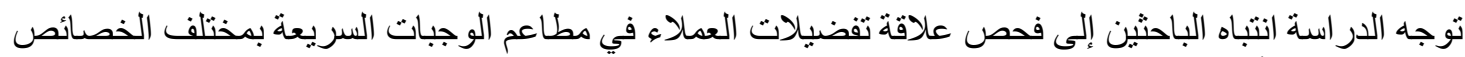

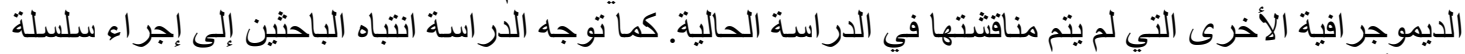

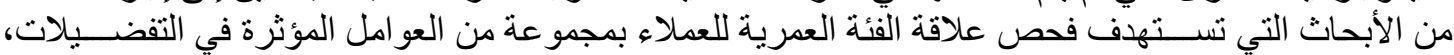

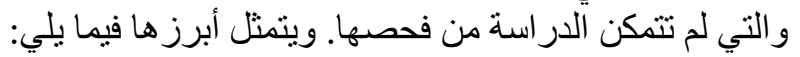

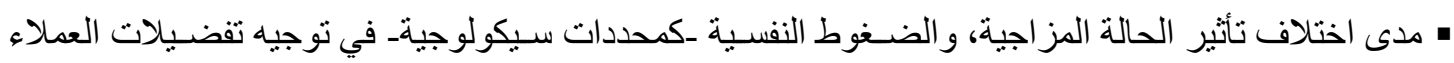
نحو المنتج المقدم في مطاعم الوجبات السريعة، و علاقة ذللك باختلاف الفئة العمرية للععيل.

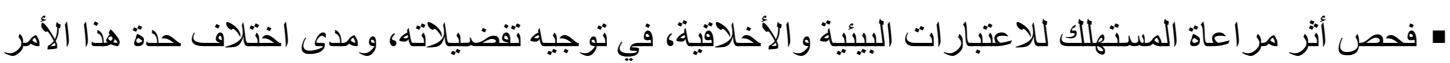
باختلاف الفئة العمرية للعميل.

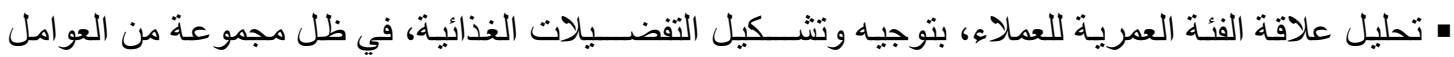

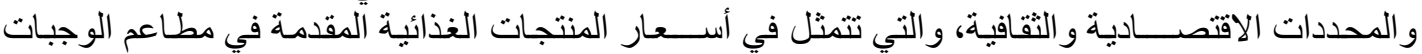
السريعة، والبيئة الثقافية التي ينتمي إلبها التعيل، وأسلوب حياة الفرد.

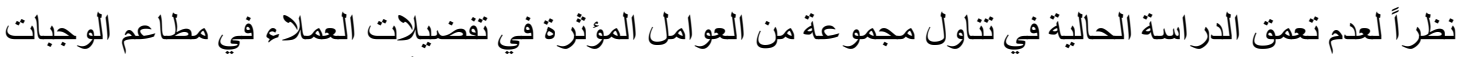

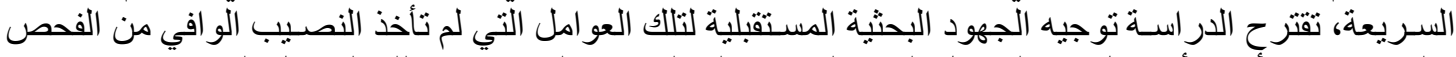

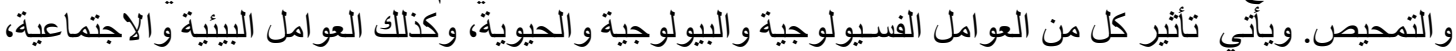

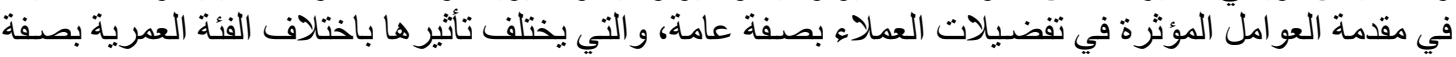

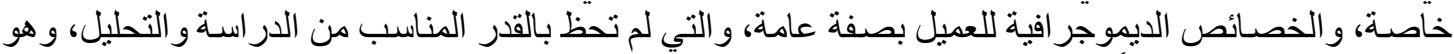

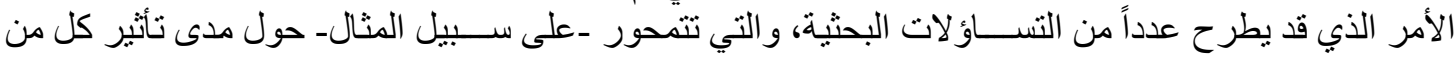

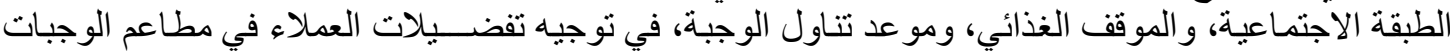

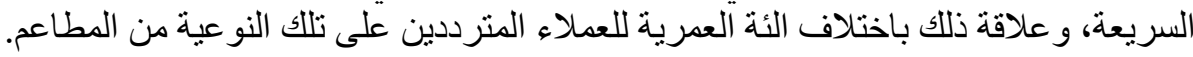

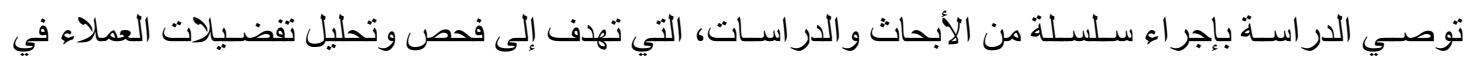

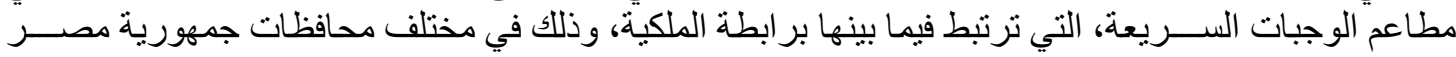

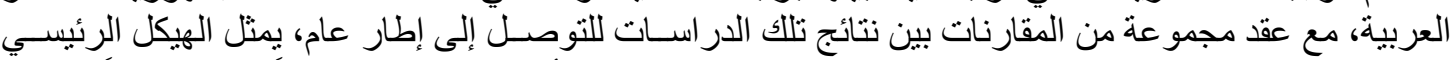

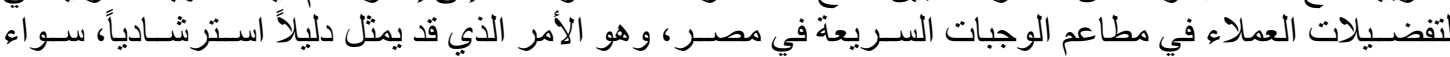

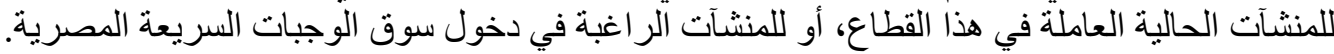

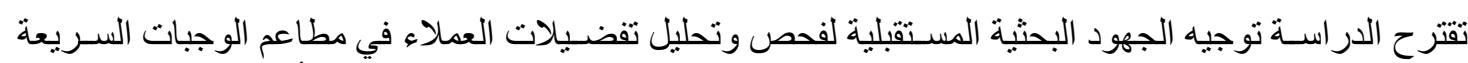

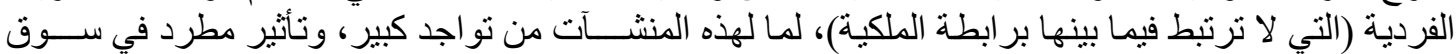
الوجبات السريعة المصرية.

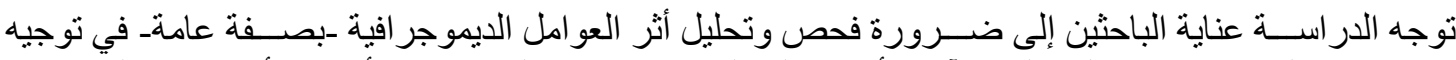

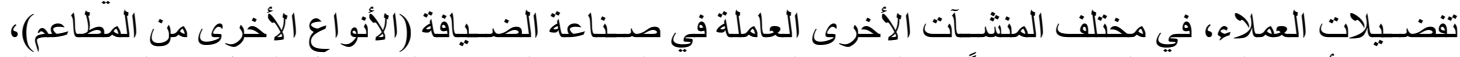

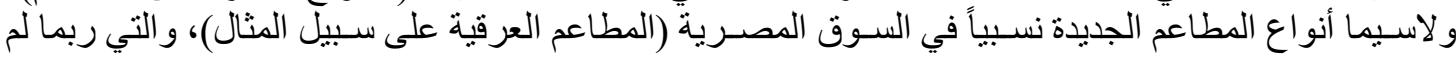
يتحدد الهيكل الرئيسي للعملاء المترددين عليها بعد. 
American Institute of Food Distribution. (2006). "Baby Boomers, A \$43 Billion Retail Opportunity". The Food Institute Report, August 28, Fair lawn, NJ. American Institute of Food Distribution, Inc.

Ballco, P., de-Magistris, T. and Caputo, V. (2019). "Consumer preferences for nutritional claims: An exploration of attention and choice based on an eye-tracking choice experiment". Food Research International, Vol. 116, pp: 37-48.

Bech-Larsen, T. and Grunert, K. G. (2003). "The perceived healthiness of functional foods. A conjoint study of Danish, Finnish and American consumers' perception of functional foods". Appetite, Vol. 40, No. 1, pp. 9-14.

Bellisle, F. (2005). "The Determinants of Food Choice". Food Today. The European Food Information Council (EUFIC), April.

Bin, Y., Ni, X., Wentao, T., Linqing, H., Peng, D., Liaoyuan, L. and Jihong Y. (2006). "Chinese Food Industry and Market Report". LIFS, Zhongnan University of Economics and Law, China, July $1^{\text {st }}$, Part 3, pp. 61-137.

Blisard, N., Lin, B-H., Cromartie, J. and Ballenger, N. (2002). "America's Changing Appetite: Food Consumption and Spending to 2020". Food Review, Vol. 25, No. 1, pp. 2-9.

Bogue, J., and Ryan, M. (2000). "Market-oriented new product development: Functional foods and the Irish consumer". Agribusiness Discussion Paper No. 27. Department of Food Economics, National University of Ireland, Cork.

Dagevos, H. (2005). "Consumers as four-faced creatures. Looking at food consumption from the perspective of contemporary consumers". Appetite, Vol. 45, No. 1, pp. 32-39.

Damen, F. W. M., Luning, P. A., Fogliano, V. and Steenbekkers, B. L.P.A. (2019). "What influences mothers' snack choices for their children aged 2-7?". Food Quality and Preference, Vol. 74, pp: 10-20.

Forde, C. G. and Delahunty, C. M. (2002). "Examination of chemical irritation and textural influences on food preferences in two age cohorts using complex food systems". Food Quality and Preference, Vol. 13, No. 7-8, pp. 571-581.

Gilmour, B., Zafiriou, M. and Quiroga, J. (2004). "Canada". Pacific Food System Outlook 2003-2004, pp. 9-16.

Gomez-Ortigoza, L. J. (2006). "The Impact of Nutrition Education on College Students' Eating Behaviors and Health Risks". M.Sc. Thesis of Arts, Department of Family and Consumer Sciences, California State University, Long Beach, UMI No., 1442148.

Hannon, P. A., Bowen, D. J., Moinpour, C. M. and McLerran, D. F. (2003). "Correlations in perceived food use between the family food preparer and their spouses and children". Appetite, Vol. 40, No. 1, pp. 77-83.

Haynes, A., Hardman, C. A., Makin, A. D. J., Halford, G. C. G., Jebb, S. A. and Robinson, E. (2019). "Visual perceptions of portion size normality and intended food consumption: A norm range model". Food Quality and Preference, Vol. 72, pp: 77-85.

Honkanen, P. and Voldnes, G. (2006). "Russian Consumers' Food Habits: Results from qualitative study in Moscow". Fiskeriforskning, Report No. 27, November. 
Humenikova, L. (2006). "Cross-Cultural Comparison of Factors Influencing Body Mass Index in Czech and American School-Aged Children". M.Sc. Thesis, Faculty of the Graduate College, the Oklahoma State University.

Iglesias-Gutiérrez, E. I., García-Rovés, P. M., García, Á. And Patterson, Á. M. (2008). "Food preferences do not influence adolescent high-level athletes' dietary intake". Appetite, Vol. 50, No. 2-3, pp. 536-543.

Jaeger, S. R. and MacFie, H. J. H. (2001). "The effect of advertising format and means end information on consumer expectations for apples". Food Quality and Preference, Vol. 12, No. 3, pp. 189-205.

Jekanowski, M., Binkley, J. K. and Eales, J. (2001). "Convenience, accessibility, and the demand for fast food". Journal of Agricultural and Resource Economics, Vol. 26, No. 1, pp. 58-74.

Klopčič, M., Slokan, P. and Erjave, K. (2020). "Consumer preference for nutrition and health claims: A multimethodological approach". Food Quality and Preference, Vol. 82, pp: 110.

Laing, D. G. and Clark, P. J. (1983). "Puberty and olfactory preferences of males". Physiology and Behavior, Vol. 30, No. 4, pp. 591-597.

Laureati, M., Sandvik, P., Almli, V. L., Sandell, M., Zeinstra, G. G., Methven, L., Wallner, M., Jilani, H., Alfaro, P. and Proserpioa, C. (2020). "Individual differences in texture preferences among European children: Development and validation of the Child Food Texture Preference Questionnaire (CFTPQ)". Food Quality and Preference, Vol, 80, pp: $1-9$.

Lair, C. D. (2007). "The Outsourcing of Intimate Affairs". Ph.D Thesis, Faculty of the Graduate School, University of Maryland.

Liem, D. G. and Mennella, J. A. (2003). "Heightened sour preferences during childhood". Chemical senses, Vol. 28, No. 2, pp. 173-180.

Luu, L., Manero, J., Lee, S-Y., Nickols-Richardson, S. and Chapman-Novakofski, K. (2020). "Role of seasoning vegetables on consumer behavior: Purchase, intake, liking, and intention to pay for larger servings". Food Quality and Preference, Vol. 82, pp: 1-7.

Mennella, J. A., Nicklaus, S., Jagolino, A. L. and Yourshaw, L. M. (2008). "Variety is the spice of life: Strategies for promoting fruit and vegetable acceptance during infancy". Physiology and Behavior, Vol. 94, No. 1, pp. 29-38.

Mennella, J. A., Pepino, M. Y. and Reed, D. R. (2005). "Genetic and Environmental Determinants of Bitter Perception and Sweet Preferences". Pediatrics, Vol. 115, No. 2, pp. e216-e222.

Mihalpoulos, V. G. and Demoussis, M. (2001). "Greek household consumption of food away from home (FAFH): A microeconometric approach". European Review of Agricultural Economics, Vol. 28, No. 4, pp. 421-432.

Muñoz-Vilches, N. C., van Trijp, H. C. M. and Piqueras-Fiszman, B. (2020). "Tell me what you imagine and I will tell you what you want: The effects of mental simulation on desire and food choice". Food Quality and Preference, Vol. 83, pp: 1-8.

National Policy and Resource Center on Nutrition and Aging. (1999). "Better Eating for Better Aging". National Policy and Resource Center on Nutrition and Aging, Florida International University, Miami, November. 
Nicklaus, S., Boggio, V., Chabanet, C. and Issanchou, S. (2004). "A prospective study of food preferences in childhood". Fifth Rose Marie Pangborn Sensory Science Symposium. Food Quality and Preference,, Vol. 15, No., 7-8, pp. 805-818.

Nystrand, B. T. and Olsen, S. O. (2020). "Consumers' attitudes and intentions toward consuming functional foods in Norway". Food Quality and Preference, Vol. 80, pp: 111.

Ohga, K. (2004). "Japan". Pacific Food System Outlook 2003-2004, pp. 24-29.

Özcelik, A. Ö., Akan, L. S. and Sürücüoglu, M. S. (2007). "An Evaluation of Fast-Food Preferences According to Gender". Humanity and Social Sciences Journal, Vol. 2, No. 1, pp. 43-50.

Özgen, L. and Ve Sanlier, N. (2002). "Farkli Egitim Düzeyindeki Ögrencilerin Hizli Hazir Yiyecek (fast food) Tüketim Durumlarinin Saptanmasi". Turizm Akademik, Vol. 2, pp. 31-38.

Pelchat, M. L. (2000). "You can teach an old dog new tricks: Olfaction and responses to novel foods by the elderly". Appetite, Vol. 35, No. 2, pp. 153-160.

Pliner, P. and Mann, N. (2004). "Influence of social norms and palatability on amount consumed and food choice".Appetite, Vol. 42, No. 2, pp. 227-237.

Plomin, R., DeFries J., McClearn, G. and McGuffin, P. (2001). "Behavioral Genetics". New York: Worth Publishers.

Popper, R. and Kroll, B. J. (2003). "Food Preference and Consumption among the Elderly", Food Technology, Vol. 57, No. 7, pp. 32- 40.

Raynor, H. A., Polley, B. A., Wing, R. R. and Jeffery, R. W. (2004). "Is dietary fat intake related to liking or household availability of high- and low- fat food?" Obesity Research, Vol. 12, No. 5, pp. 816-823.

Reid, C. (2005). "A risk model for obesity: Reward sensitivity, food preferences, and being eating". M.Sc. Thesis, Faculty of Graduate Studies, York University, Toronto, Ontario.

Robert, P.G. Goedegebure, R. P. G., van Herpen, E. and van Trijp, H. C. M. (2020). "Using product popularity to stimulate choice for light products in supermarkets: An examination in virtual reality". Food Quality and Preference, Vol. 79, pp: 1-11.

Rosalin, G. and Soetanto, T. I. (2006). "Analysis of the customers' preferences in determining a suitable menu: A case study of river side oriental cuisine restaurant". Jurnal Manajemen Perhotelan, Vol. 2, No. 2, pp. 57-67.

Rozin, P., Riklis, J. and Margolis, L. (2004). "Mutual exposure or close peer relationships do not seem to foster increased similarity in food, music or television program preferences". Appetite, Vol. 42, No. 1, pp. 41-48

Santagiuliana, M., Bhaskaran, V., Scholten, E. and Piqueras-Fiszman, B. (2019). "Don't judge new foods by their appearance! How visual and oral sensory cues affect sensory perception and liking of novel, heterogeneous foods". Food Quality and Preference, Vol. 77, pp: 64-77.

Schlosser, E. (2005). "Fast Food Nation: The Dark Side of the American Meal". New York. Harper Perennial. 
Shepherd, R., (1989). "Factors influencing food preferences and choice". In: Sheperd, R. (Eds.), "Handbook of the Psychophysiology of Human Eating". Chichester, UK: Wiley. pp. 324.

Simon, P. A., Kwan, D., Angelescu, A., Shih, M. and Fielding, J. E. (2008). "Proximity of fast food restaurants to schools: Do neighborhood income and type of school matter?" American Journal of Preventive Medicine, Vol. 47, No. 3, pp. 284-288.

Skinner, J. D., Carruth, B. R., Bounds, W. and Ziegler, P. J. (2002). "Children's food preferences: A longitudinal analysis". Journal of the American Dietetic Association, Vol. 102, No 11, pp. 1638-1647.

Stewart, H., Blisard, N., Bhuyan, S., Rodolfo M. and Nayga, R. M. (2004). "The Demand for Food Away From Home: Full-Service or Fast Food?" Economic Research Service, United States Department of Agriculture (USDA), Agricultural Economic Report No. 829 , January.

Szczesniak, A. S. (2002). "Texture is a sensory property". Food Quality and Preferences, Vol. 13, No. 4, pp. 215-225.

USDA. (2006). "U.S food supply nutrients and other food components, 1909-2004; Competitive foods: soft drinks versus milk; in the long run; Soft Drinks and School-Age Children: Trends, Effects, Solutions Paper". U.S. Department of Agriculture.

van Kleef, E., van Trijp, H. C. M. and Luning, P. (2005). "Functional foods: health claim-food product compatibility and the impact of health claim framing on consumer evaluation". Appetite, Vol. 44, No. 3, pp. 299-308.

Van Loo, E. J., Grebitus, C. and Roosen, J. (2019). "Explaining attention and choice for origin labeled cheese by means of consumer ethnocentrism". Food Quality and Preference, Vol. 78, No. 103716, pp: 1-10.

Vélez, L. F. and Beatriz, B. (2003). "La selección de los alimentos: una práctica compleja". Colombia Médica, Vol. 34, No. 2, pp. 92-96.

Von Post-Skagegärd, M., Samuelson, G., Karlström, B., Mohsen, R., Berglund, L. and Bratteby, L-E. (2002). "Changes in food habits in healthy Swedish adolescents during the transition from adolescence to adulthood". European Journal of Clinical Nutrition, Vol. 56, No. 6, pp. 532-538.

Wang, M., Crawford, P. and Bachrach, L. (1997). "Intakes of nutrients and foods relevant to bone health in ethnically diverse youths". Journal of the American Dietetic Association, Vol. 97, No. 9, pp. 1010-1013.

. August (2014). 